Portland State University

PDXScholar

Fall 12-12-2014

\title{
Applications of Remote Sensing to the Study of Estuarine Physics: Suspended Sediment Dynamics in the Columbia River Estuary
}

Austin Scott Hudson

Portland State University

Follow this and additional works at: https://pdxscholar.library.pdx.edu/open_access_etds

Part of the Civil and Environmental Engineering Commons, and the Sedimentology Commons Let us know how access to this document benefits you.

Recommended Citation

Hudson, Austin Scott, "Applications of Remote Sensing to the Study of Estuarine Physics: Suspended Sediment Dynamics in the Columbia River Estuary" (2014). Dissertations and Theses. Paper 2093. https://doi.org/10.15760/etd.2091

This Thesis is brought to you for free and open access. It has been accepted for inclusion in Dissertations and Theses by an authorized administrator of PDXScholar. Please contact us if we can make this document more accessible: pdxscholar@pdx.edu. 
Applications of Remote Sensing to the Study of Estuarine Physics:

Suspended Sediment Dynamics in the Columbia River Estuary

by

Austin Scott Hudson

A thesis submitted in partial fulfillment of the requirements for the degree of

Master of Science

in

Civil and Environmental Engineering

Thesis Committee:

Stefan Talke, Chair

Chris Mooers

David Jay

Portland State University

2014 
(C) 2014 Austin Scott Hudson 


\section{ABSTRACT}

Estuarine circulation and its associated transport processes drive the environmental integrity of many near-shore habitats (the coastal ocean, rivers, estuaries and emergent wetlands). A thorough understanding and consideration of this circulation is, therefore, vital in the proper management of these habitats. The aim of this study is to bring together theory and new satellite observations in the Columbia River Estuary to increase our understanding of estuarine circulation and transport. Surface reflectance measurements gathered by the Moderate Imaging Spectroradiometer (MODIS) are first compared to in situ observations to develop an empirical model for remotely derived surface turbidity. Results indicate that MODIS data significantly correlate with in situ measurements of turbidity throughout the CRE $\left(R^{2}=0.96\right)$. Remote estimates of turbidity are then used to explore the physical processes that drive their spatial distribution. Although the response to different hydrodynamic conditions varies throughout the system, global levels of turbidity are most sensitive to fluvial and tidal inputs and increase during spring tides and high river flow. As a result, the turbidity field has temporal cycles that are consistent with the frequency of these processes. The location of the estuarine turbidity maximum (ETM) is highly dynamic and typically migrates downstream as the tidal velocity or river flow increases. The ETM becomes trapped near the Megler Bridge (river kilometer 20), however, and the presence of strong topography in this region suggests there exists an interaction between bottom topography and sediment transport. 
A 2-D semi-analytical model, developed herein from the simplified NavierStokes equations, confirms that topographic features exhibit substantial influence on longitudinal turbidity distributions. The model considers the coupled, tidallyaveraged velocity (composed of gravitational circulation, internal tidal asymmetry, and river flow) and salinity fields and assumes a condition of morphodynamic equilibrium to estimate the distribution of sediment for arbitrary channel configurations. Model simulations demonstrate that topographic highs tend to increase local seaward sediment fluxes, and that topographic lows increase local landward sediment fluxes. Sediment flux convergence near topographic highs compresses the local turbidity distribution, whereas flux divergence near topographic lows dilates the distribution and, under appropriate conditions, produces multiple ETMs.

In summary a combination of the model and satellite data has given valuable new insights into the sediment dynamics of estuarine environments; in particular, both show that turbidity distribution and ETM location vary considerably with tidal and river flow conditions, fluctuating on a variety of timescales, and are heavily influenced by bottom topography. 


\section{DEDICATION}

This work is dedicated to Kari. 


\section{ACKNOWLEDGEMENTS}

I would like to acknowledge the outstanding achievements made by those who established the foundation upon which we can continue to advance our understanding of nature; my advisor, Stefan Talke, and committee members for their patience and invaluable guidance during this project; and my family and friends for their adamant support of my desire to pursue a life of scientific discovery. 


\section{TABLE OF CONTENTS}

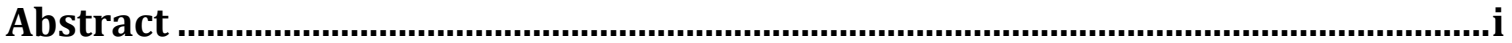

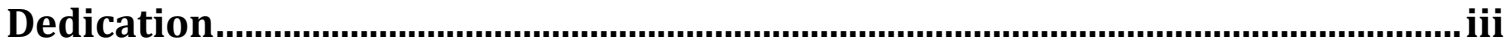

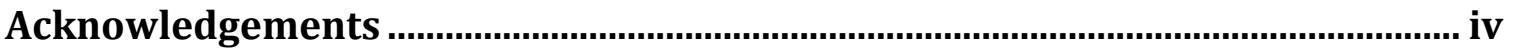

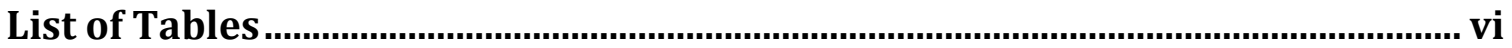

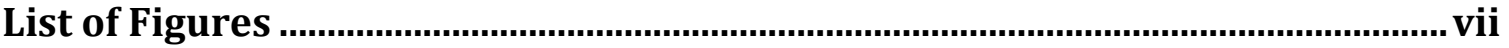

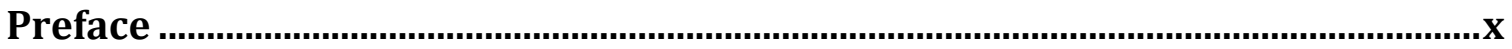

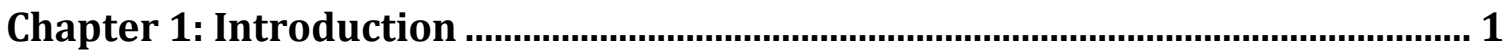

Chapter 2: Observational Study ........................................................................... 13

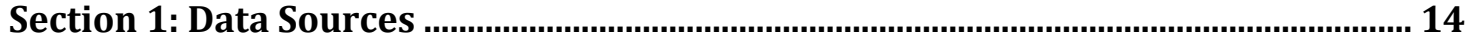

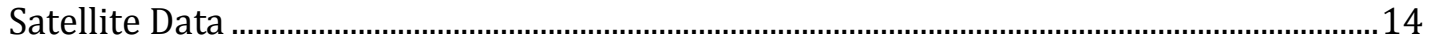

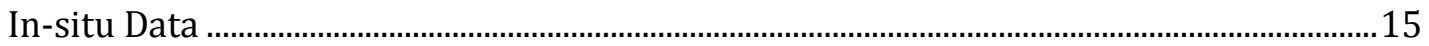

Section 2: Remote sensing of turbidity ................................................................. 18

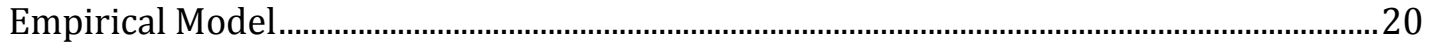

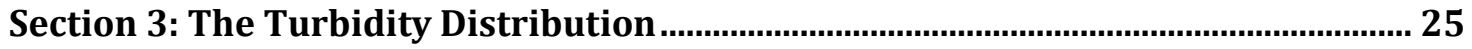

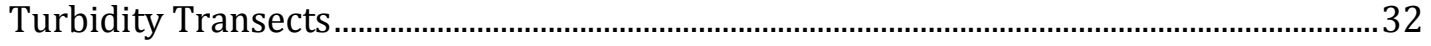

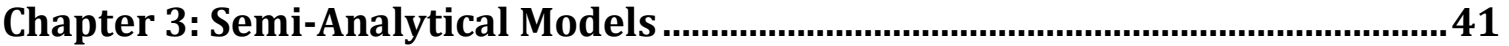

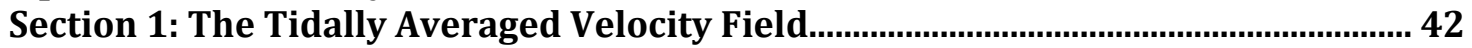

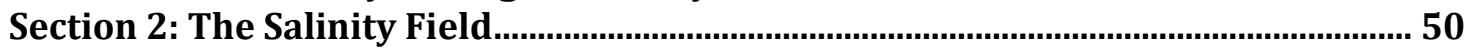

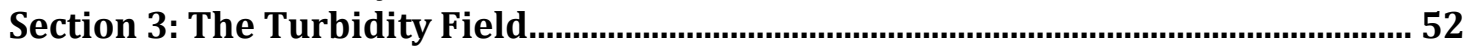

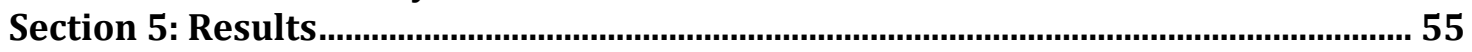

The Coupled Velocity and Salinity Fields ................................................................................ 55

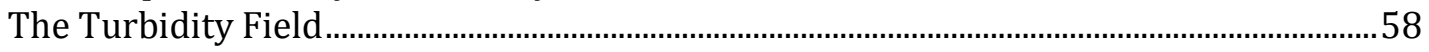

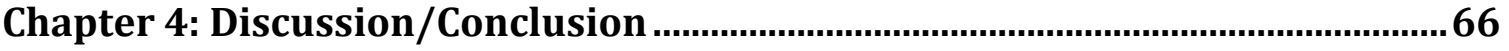

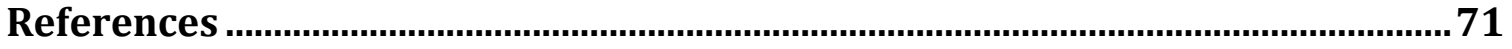

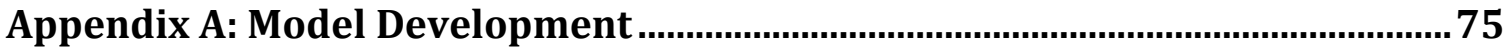

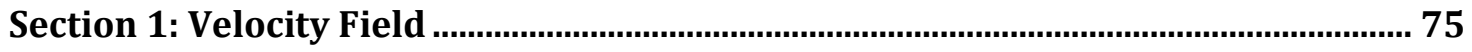

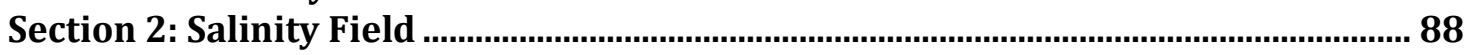




\section{LIST OF TABLES}

Table 2.1.1. Locations of in situ turbidity measurements used in OLS 15

Table2.1.2. Locations of in situ measurements used to derive salinity profiles. ........ 16

Table 2.1.3. Measurement details of forcing parameters used in the analysis.

Table 2.2.1. Model statistics for OLS between Band1 and in situ turbidity and coefficient estimates. Confidence intervals ( $\alpha=0.05$ ) for coefficients are provided in brackets.

Table 3.5.1 Scaling magnitudes used in model simulations. 


\section{LIST OF FIGURES}

Figure 1.1.1 The Columbia River Estuary, as it is defined in this paper. The lowerestuary extends from the mouth (rkm 0) to Youngs Bay ( rkm 15), midestuary continues up to Tongue Point ( $\sim$ rkm 30$)$, and the upper-estuary to the landward limits of salinity intrusion ( $\sim$ rkm 50$)$. Transects denote the two main channels (North and South) in the system

\section{2}

Figure 1.1.2 Tidal elevation (measured at Astoria) during October 2000, a period of low river flow and consequently appreciable tidal variability.................................. 4

Figure 1.1.3 Annual hydrograph measured at Beaver Army Terminal ( rkm 85) averaged during the study period (2000-2013). Maximum river flows are observed May-June during the spring freshet; minimum flows occur during late summer.

Figure 1.1.4 Example turbidity distributions in the CRE derived from MODIS-based surface reflectance (See Ch. 2). The turbidity is a function of both river flow and tidal range. The left panels are measured at a time of moderate tidal ranges $(\sim 2.6 \mathrm{~m})$ during low (top) and high (bottom) flow rates. Right panels illustrate neap $(1.7 \mathrm{~m}) /$ spring $(3.5 \mathrm{~m})$ (top and bottom, respectively) conditions at a time of low river flow.

Figure 1.1.5 Conceptual view of barotropic and baroclinic pressure gradients that form the residual circulation. In this example density gradients force water landward and the surface slope of the river forces water seaward.

Figure 1.1.6 Conceptual view of the estuarine circulation modes considered in this study. Note that the exchange flow and ITAC change sign with depth, with landward (positive) velocities near the bed.

Figure 1.1.6 Approximate depths along the South Channel of the CRE. The channel is maintained at a minimum depth of $13+m$ and has several topographic lows... 10

Figure 2.1.1. Example of 10x10, 250m grid at the mouth of the CRE............................ 14 Figure 2.1.2. Buoy sites for stations used in ordinary least squares to derive MODIS-

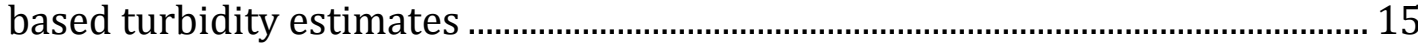

Figure 2.1.3. Buoy sites for stations used to derive salinity transects and

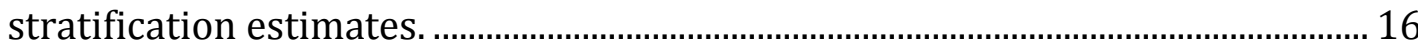

Figure 2.2.1. Conceptual diagram of absorption spectra for various OACs and the

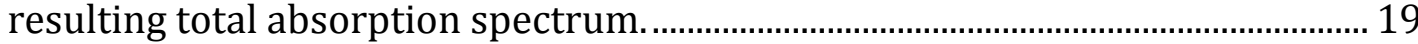

Figure 2.2.2 Averaging of in-situ measurements. The filter reduces fluctuations in turbidity caused by changes in vertical height of the sensor at SAT1 that do not accurately represent the state of the pixel during the time of MODIS measurement. Data here is recorded at SAT1 on February 26, 2010.................... 21

Figure 2.2.3 Scatter plots of remotely estimated, and in situ turbidity. Results for the low (left) and high (right) aerosol cases are statistically similar........................... 22

Figure 2.3.1 Monthly averaged turbidity distributions. Elevated concentrations begin during the winter months and persist throughout the spring while high river flows are maintained. Minimum concentrations occur in late summer at

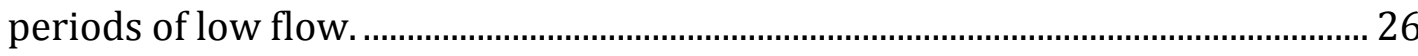


Figure 2.3.2 Correlation map between surface turbidity and wind-related forcing. Wind speed has a minimal effect on turbidity and is confined to shallow regions in the system. Wind direction is of greater importance when measured at either location. 29

Figure 2.3.2. Correlation map between MODIS derived turbidity and tidal range. Tidal range is positively correlated with surface turbidity. 30

Figure 2.3.3. Correlation map between MODIS derived turbidity and river flow measured at Beaver Army Terminal, The Dalles, Willamette River, and Cowlitz River 31

Figure 2.3.3 Hydrograph measured at Beaver and mean turbidity measurements. MODIS estimates are averaged along the North Channel. SAT1 data are daily averaged.

Figure 2.3.4 Transect positions for the North and South Channels. Data were sampled along each transect and median filtered across the five most adjacent pixels.

Figure 2.3.5 Data smoothing for measured turbidity transects. Measured data (grey circles) match reasonably with analytical model (black lines).

Figure 2.3.6 Longitudinal transects of turbidity in the North (left) and South (right) Channels. Transects are averaged in bins according to greater diurnal tidal ranges $(0.5 \mathrm{~m}$ window $)$ and river flow $\left(1000 \mathrm{~m}^{3} \mathrm{~s}^{-1}\right.$ window). River flow transects are those measured during spring tides. Note: transects are plotted on different horizontal scales.

Figure 2.3.7. The location (Xmax) and magnitude (Cmax) of the ETM in the North (left) and South (right) Channel plotted in the forcing parameter space. Increasing river flow and tidal range promote seaward advection and greater intensity of the ETM.

Figure 2.3.8 Daily averaged stratification in the North Channel measured at SAT1 (2008-2012). Its relationship to freshwater discharge (left) is unclear. Increased tidal range (right) serves to decrease stratification.

Figure 2.3.9. Monthly averaged turbidity at SAT5 (from 2010 to 2013), representing seasonal fluctuations in the fluvial source of turbidity to the CRE. Sediment loads brought into the system are largest during the spring and winter freshets.

Figure 2.3.10. Daily averaged stratification (bottom - top salinity) behavior in the South Channel of the CRE. Fresh water discharge (left) serves to increase stratification in the lower-estuary but decreases stratification at mid-estuary. Increasing tidal range decreases stratification in the lower reaches of the system.

Figure 2.3.11 Turbidity (black) and salinity (blue) transects in the North and South Channels. $X_{2}$ is marked by an ' $\mathrm{x}$ ' along the turbidity transects for reference. .... 40

Figure 3.1.1 Residual Flow modes that constitute the model developed herein........ 42 Figure 3.1.2. Model structure for the velocity field. Three components are considered to describe the residual flow: ITAC, Gravitational Circulation, and River Flow. Each component is driven by distinct forcing mechanisms. 
Figure 3.5.1. Example vertical profiles of the three residual circulation modes (left) and the resulting salinity defect (right).Profile taken $20 \mathrm{~km}$ from the mouth for constant depth channel, tidal velocity is $1 \mathrm{~ms}^{-1}, \mathrm{U}_{\mathrm{RO}}=0.05 \mathrm{~ms}^{-1}, \mathrm{H}=15 \mathrm{~m}$.

Figure 3.5.2 Ratio of the gravitational circulation scaling to that of ITAC as a function of vertical and horizontal salinity differences. ITAC dominates the gravitational circulation for most estuarine conditions, except in systems with weak horizontal density gradients and considerable stratification. 57

Figure 3.5.3. Surface turbidity transects during various river flow conditions (left) and stages of the neap/spring cycle (right) for domains with constant depth (top), topographic elevation (middle), and topographic depression (bottom). 59

Figure 3.5.4 Sediment fluxes $\left[\mathrm{gm}^{-2} \mathrm{~s}^{-1}\right]$ and $\mathrm{X}_{\max }$ location (grey line) for the three cases during $U_{\text {river }}=-0.075 \mathrm{~ms}^{-1}$ and $U_{\text {tide }}=1 \mathrm{~ms}^{-1}$ (see Figure 3.5.4). Disparities between advective and internal mode fluxes lead to the interesting differences observed in the turbidity distribution.

Figure 3.5.5. Surface turbidity transects during various stages of the spring/neap cycle (top) and river flow conditions (bottom). More complicated bottom topography mimicking that found in the CRE produces distributions that approach those of the observed transects.

Figure 3.5.7. Location of turbidity maximum (measured as the distance in kilometers from the estuary mouth) as a function of river flow and tidal velocity for each experiment. Topographic highs reduce sensitivity to each forcing variable, the lows drive turbidity maxima upstream as a result of increased landward flux. 


\section{Preface}

This study was inspired by recent work that investigated the applications of satellite data in coastal environments; here an attempt is made to advance these efforts by exploring the spatial and temporal character of turbidity in the Columbia River Estuary (CRE). The purpose of this study is: 1) develop a method to remotely estimate turbidity to understand the global behavior of turbidity distributions in the CRE; and 2) investigate the effect of local bottom topographic features on global turbidity structure. A primary advantage of satellite data is that measurements are synoptic, thereby revealing spatially resolved features of the turbidity distribution that cannot be measured by either ship-based experiments or existing moored observations. These spatial snapshots can be compared to theoretical descriptions of the turbidity distribution to reveal which physical mechanisms are responsible. Although monitoring estuaries with satellites is a young and developing science, this work shows its potential for improving understanding of physical estuarine processes, which can improve our ability to find solutions to coastal problems such as the destruction of wildlife habitat or degradation of infrastructure.

This document is structured as follows. Following an introduction, Chapter 2 describes the investigation of satellite data in which I examine the spatial and temporal distribution of turbidity in the CRE. A semi-analytical, 2-D model is then developed in Chapter 3 to explore processes driving this distribution. Chapter 4 concludes the document with a statement regarding the implications of the study and possible directions for future work. 


\section{ChAPTER 1: INTRODUCTION}

Estuaries and their surrounding coastal environment are largely defined by the behavior of sediment transport in the system. Variations in particle settling velocity and vertical mixing control transport, deposition, and erosion patterns that shape the bottom topography of these regions, for example (Jay et al. 1990; Sherwood et al. 1990). Similar mechanisms also influence the supply of nutrients, organic matter, and contaminants and thereby regulate ecological activity. Estuarine circulation, characterized by seaward advection of river water interacting with a collection of flow modes induced by the density gradients between seawater and riverwater (Hansen \& Rattray 1965), greatly affects sediment transport-both through horizontal transport and vertical turbulent mixing driven by the tides-and is therefore crucial to understand when assessing and diagnosing system behavior. In this study we work towards understanding this circulation and the underlying physical processes that drive sediment transport using satellite-based estimates of turbidity (which is directly proportional to suspended sediment in the Columbia River Estuary; Fain et al. 2001) in the Columbia River Estuary (CRE) and processbased analytical models. 
Running the border between Oregon and Washington, the CRE is a drowned river valley composed of two primary channels interspersed with sand flats and bordered by large shallow water bays. It has a shallow aspect ratio with depths rarely exceeding $15 \mathrm{~m}$. In this study the system is divided into three regions (Figure 1.1.1), the lower-estuary, river kilometer (rkm) 0-20, where saltwater is nearly always present throughout the tidal cycle and mechanical energy is dominated by tide and wave processes; mid-estuary, rkm 20-35, which typically exhibits the largest salinity gradients observed in the system; and the upper-estuary, rkm 35-50, where salinity is usually absent but the associated density gradients still occasionally affect the velocity field.

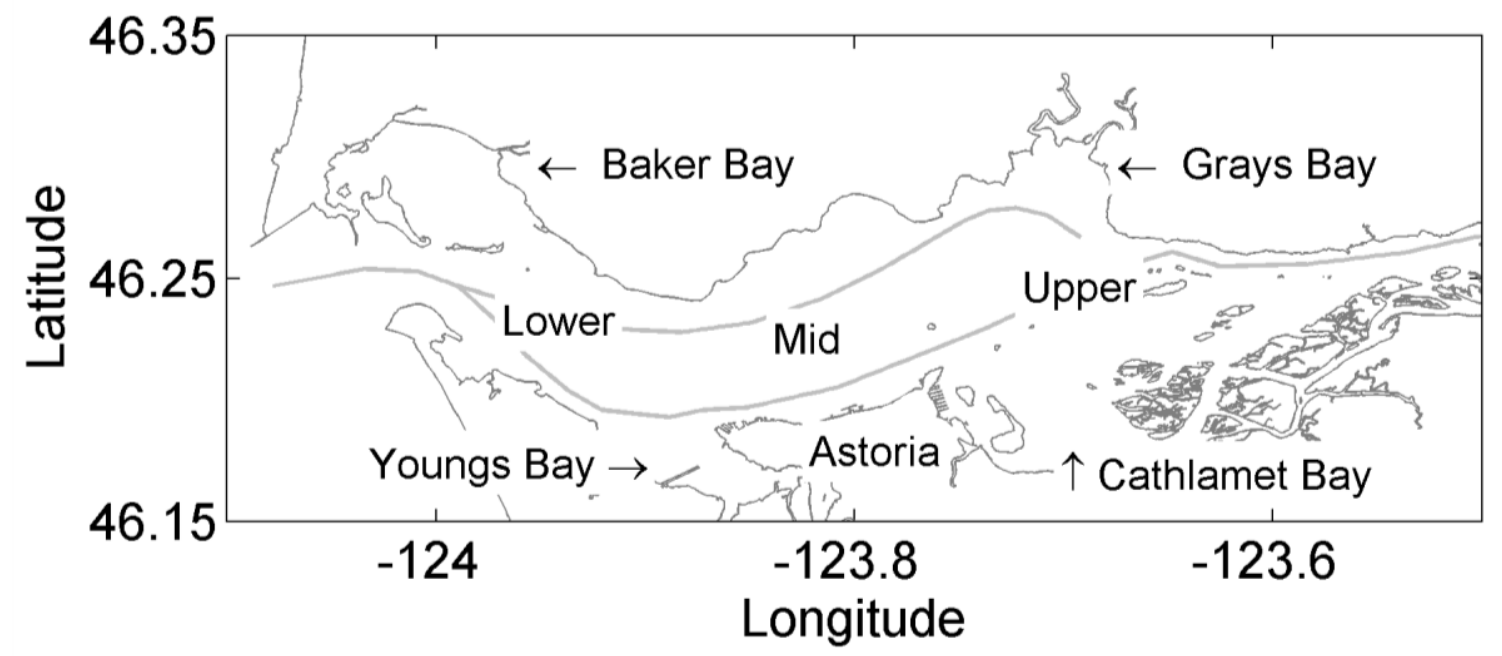

Figure 1.1.1 The Columbia River Estuary, as it is defined in this paper. The lower-estuary extends from the mouth (rkm 0) to Youngs Bay ( rkm 15), mid-estuary continues up to Tongue Point ( rkm 30), and the upper-estuary to the landward limits of salinity intrusion ( rkm 50). Transects denote the two main channels (North and South) in the system. 
Suspended sediment in the CRE is primarily of fluvial origin, composed mostly of fines (silt and clay) except during large tides and river flows when boundary shear stress is sufficient to suspended sands at the bed (Jay et al. 1990). Fines are supply limited; the capacity for transport is nearly always present and fine sediments will move whenever they are available. Coarse sediment, in contrast, consisting of sands and gravel are transport capacity limited, and there is an abundant supply in the bed that becomes mobile only under appropriate flow conditions (Naik and Jay 2011). Suspended sediment concentration (SSC) is typically less than $100 \mathrm{gm}^{-3}$ throughout the CRE (Fain et. al 2001), a level dwarfed by those found in other estuarine systems (Talke et al. 2009, Doxoran et al. 2009), though ETM sediment concentration at the bed may reach $1 \mathrm{kgm}^{-3}$.

Tidal, river, and-to a much lesser degree-atmospheric forces drive sedimentary processes in the CRE (Jay et al. 1990). Transport is spatially dynamic and has a strong seasonal signature primarily tied to river flow; supply to the CRE during the spring freshet can account for up to $\sim 70 \%$ of the total sediment load during the year (Fain et al. 2001). Sediment is trapped in an estuary turbidity maximum (ETM) in the lower/mid-estuary, where SSC can reach four to ten times greater than elsewhere in the system (Jay et al. 1990). ETM processes are differ in the North and South Channels due to the distinct circulation patterns of each location; the North Channel is tied more directly to the ocean whereas the South Channel is more so to the river. As a result, tidally-averaged salt flux is landward in the North Channel and seaward in the South Channel (Hughes and Rattray 1980; Jay and Smith 1990a). 
Since similar physics control sediment fluxes, the ETM in each channel should respond differently to fluvial and tidal input.

Tides are mixed (predominately semidiurnal), and comparatively large with an $\mathrm{M}_{2}$ amplitude of $0.95 \mathrm{~m}$ at mid-estuary. Most of the tidal energy is focused in the lower and mid-estuary, quickly decaying upstream due to friction, cross-section convergence, and river flow (Jay et al. 1990; Jay 1991). The neap/spring cycle has a clear signal throughout the year, it has a greater diurnal tidal range spanning anywhere from 1.6 to more than 3.6 meters (Figure 1.1.2) and is strongest at the end of summer when the effect of river flow on wave propagation is minimal.

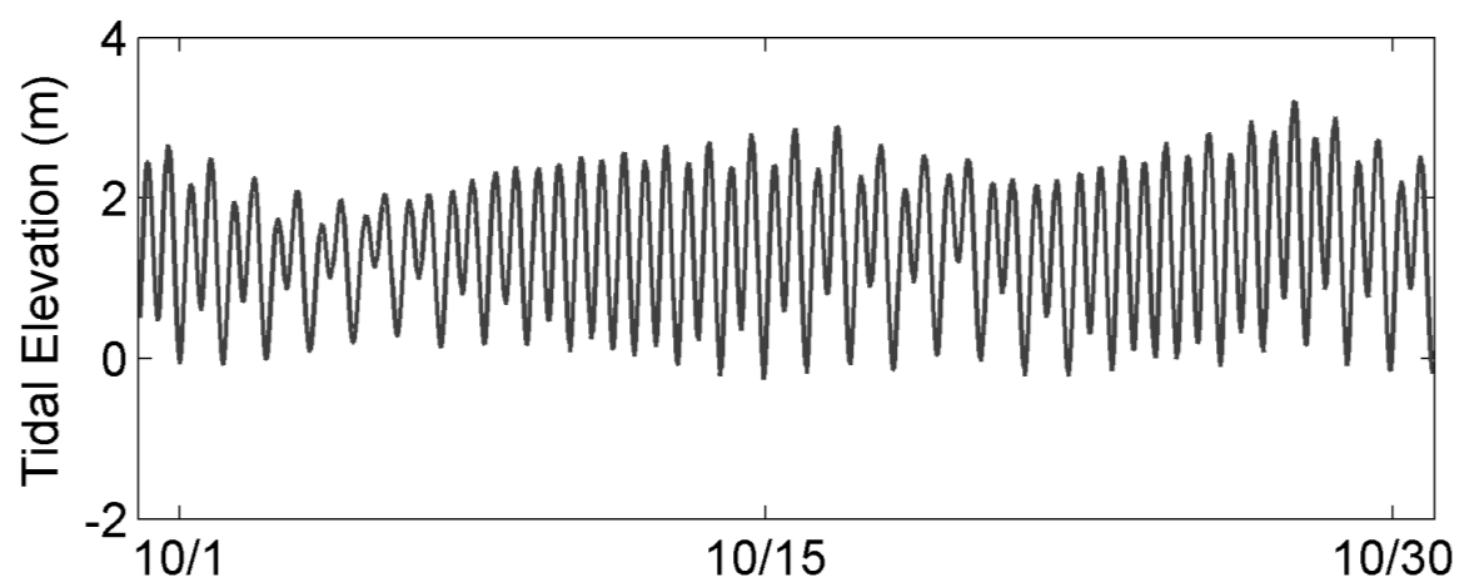

Figure 1.1.2 Tidal elevation (measured at Astoria) during October 2000, a period of low river flow and consequently appreciable tidal variability.

The CRE supports the largest river system on the west coast of North America; $60 \%$ to $90 \%$ of the freshwater input to the coastal ocean of Oregon and Washington stems from the CRE (Simenstad et al. 1990). River flow exhibits strong seasonal variability, with largest flows historically occurring during the May/June freshet (Naik \& Jay 2005, 2011) and smaller flows during late summer when precipitation 
and snowmelt runoff are minimal (Figure 1.1.3). The annual regime of river flow has been dramatically altered by flow regulation, and to a lesser extent climate change, during the last century; for example current spring freshet flows have been reduced by almost $50 \%$ and occur one month earlier than early $20^{\text {th }}$ century counterparts (Naik and Jay 2011).

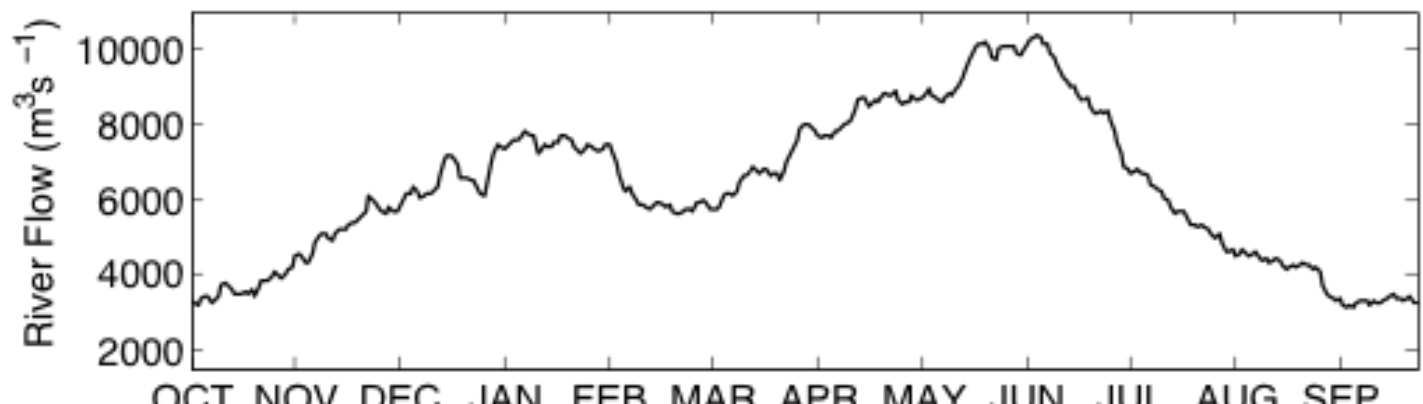

Figure 1.1.3 Annual hydrograph measured at Beaver Army Terminal ( rkm 85) averaged during the study period (2000-2013). Maximum river flows are observed May-June during the spring freshet; minimum flows occur during late summer.

Temporal patterns of tidal and river forcing result in a strongly variable turbidity field (Figure 1.1.4, which is derived from the empirical model developed in the next section using MODIS surface reflectance). As the source of most of the suspended sediment in the system (Jay et al. 1990), river flow has a direct relationship with surface concentrations throughout the estuary. Dependence on the neap/spring cycle is also apparent; greater concentrations are observed during spring tides when the larger tidal velocities that promote vertical mixing are able to stir up sediment from the bed to the surface. Figure 1.1.4 highlights the primary 
advantage of satellite measurements, that they are a synoptic observation of global estuarine processes that is otherwise intangible with traditional methods.
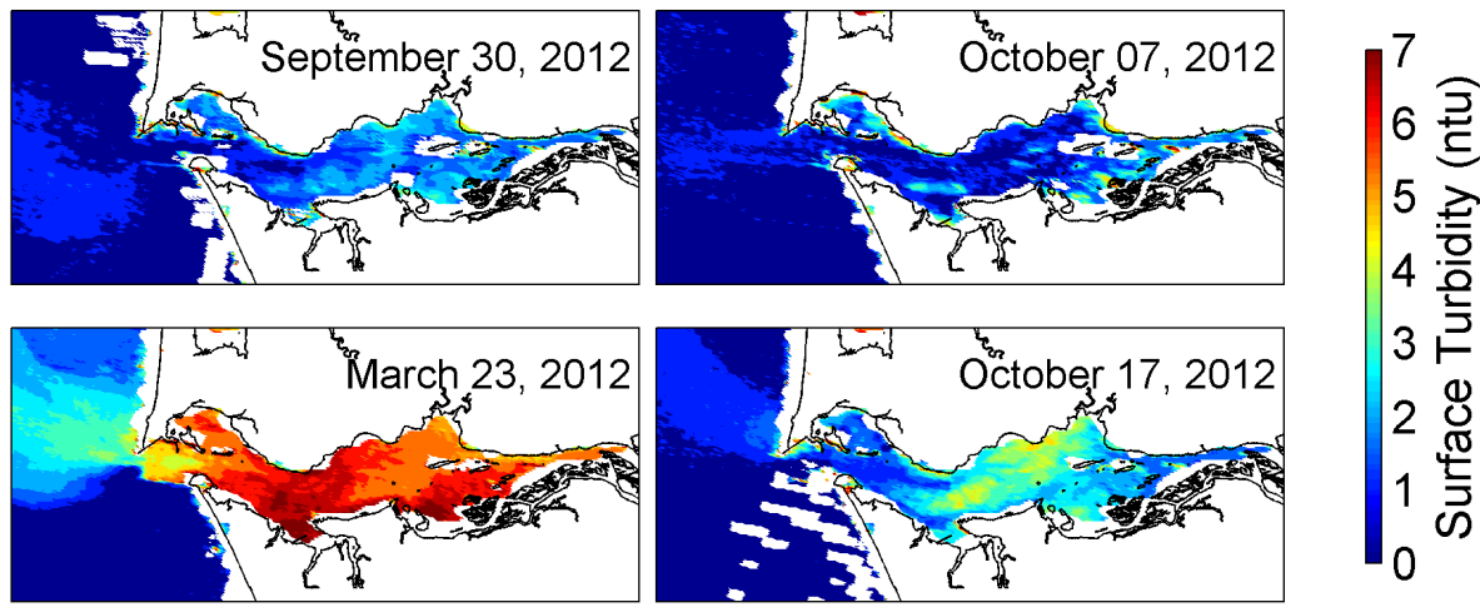

Figure 1.1.4 Example turbidity distributions in the CRE derived from MODIS-based surface reflectance (See Ch. 2). The turbidity is a function of both river flow and tidal range. The left panels are measured at a time of moderate tidal ranges ( $2.6 \mathrm{~m})$ during low (top) and high (bottom) flow rates. Right panels illustrate neap $(1.7 \mathrm{~m}) / \mathrm{spring}(3.5 \mathrm{~m})$ (top and bottom, respectively) conditions at a time of low river flow.

The relationship between turbidity and river flow and the tides is, however, more complicated than Figure 1.1.4 suggests; high discharge and strong tidal forcing does not necessarily cause high turbidity. In general, it is horizontal convergences in the residual and tidal flows that serve to trap particles in an estuary and form an ETM, the strength and location of which depends on the interaction between tides, river flow, and bottom topography (Jay and Musiak 1994; Talke et al. 2009; Geyer 1993). Since the turbidity distribution reflects these processes, characterizing its spatial variability provides insight into the underlying physical processes driving its development, and it is this link we will exploit to study circulation and transport processes with satellite measurements. 
Circulation in the CRE has been well documented (Hughes and Rattray 1980; Jay and Smith 1990a-c; Jay and Musiak 1996; Chawla et al. 2007 and others), and therefore serves as an ideal field laboratory by which to develop such methods of studying estuarine hydrodynamics. The residual (tidally-averaged) circulationdriven to first order by internal tidal asymmetry followed by river flow, and gravitational circulation (Jay 2010) —is highly variable. In general it transitions from weakly stratified throughout most of the tidal month, to strongly stratified conditions during and directly following neap tides (Jay and Smith 1990c). These patterns are nearly in phase with changes in the tidal and fluvial regimes (Jay and Smith 1990a), and as such remotely derived turbidity estimates are fairly representative of related transport processes. Despite the progress gained through previous studies, data analyzed herein still illuminates novel insights about the circulation and transport behavior in the CRE. Satellite measurements, therefore, should prove useful in studying estuarine hydrodynamics in other systems as well.

To review, estuarine circulation is the movement of water due to the influence and interaction of barotropic (surface slope due to tides and river) and baroclinic (density differences due to disparities in salinity or temperature) pressure gradients (Figure 1.1.5) ${ }^{1}$. Tidal and residual components constitute the estuarine circulation. Here we focus on the residual circulation composed of three modes: river flow, gravitational circulation (exchange flow), and circulation due to internal tidal asymmetry (ITAC) (Figure 1.1.6).

\footnotetext{
${ }^{1}$ [A more detailed description can be found in Fischer et al. 1979, Jay 2010, and others who provide a detailed account of estuarine circulation. Here the intent is simply to introduce the concept.]
} 


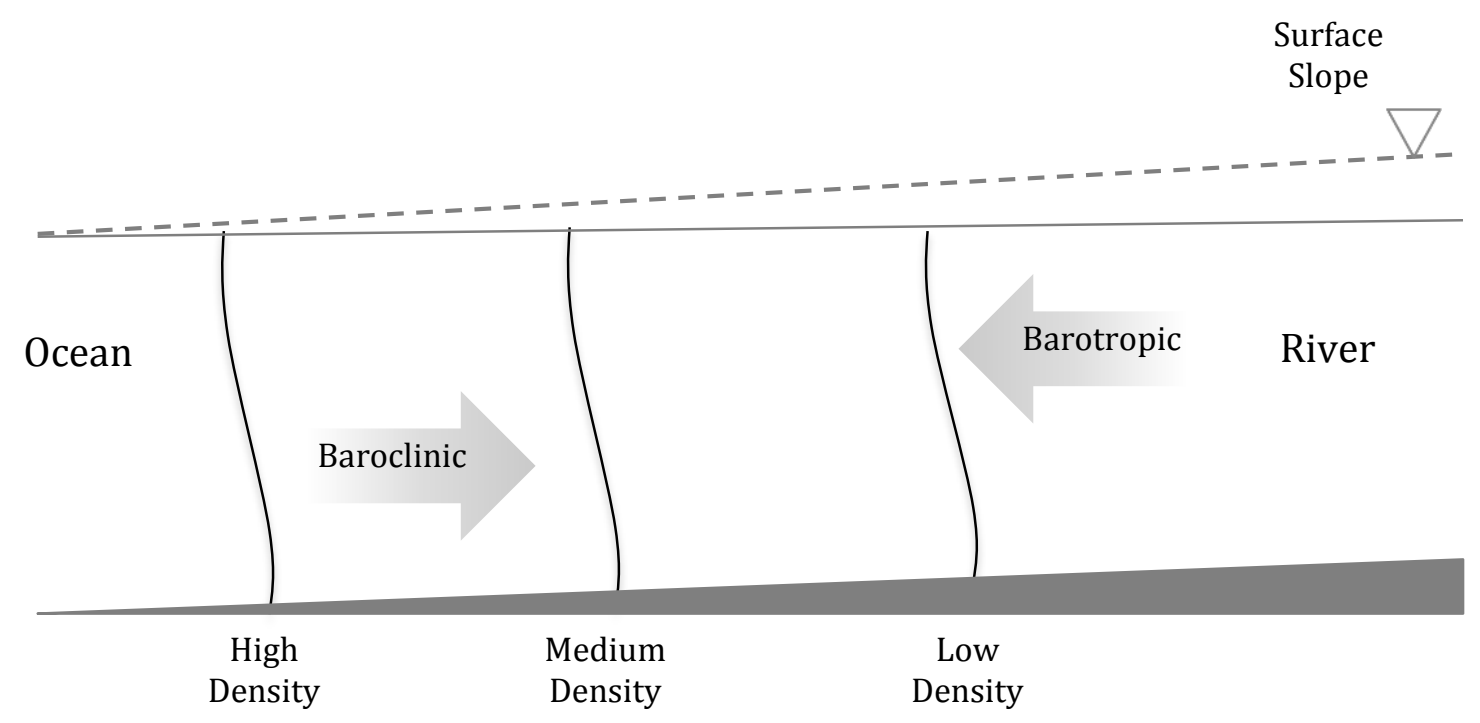

Figure 1.1.5 Conceptual view of barotropic and baroclinic pressure gradients that form the residual circulation. In this example density gradients force water landward and the surface slope of the river forces water seaward.

The origin of the river mode is readily understood as the advection of water seaward due to fluvial input at the head of the system, which creates a surface slope and barotropic pressure gradient directed towards the ocean. Gravitational circulation results from horizontal density gradients in the system, it is an internal mode (zero net transport) with landward fluxes near the bed and seaward fluxes near the surface. ITAC, also an internal mode, is the consequence of tidally variable horizontal density gradients, which vary in magnitude but not sign, and is particularly important in systems with strong river flow and tides (Jay and Musiak 1996). 


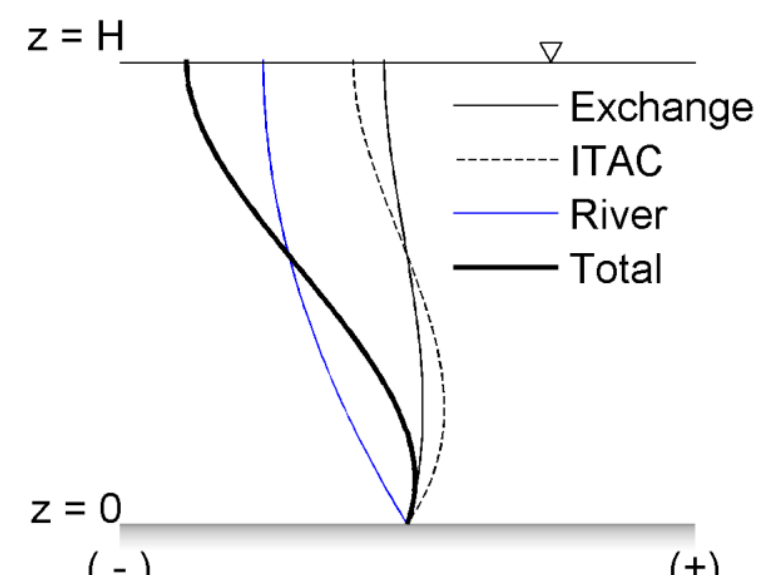

Figure 1.1.6 Conceptual view of the estuarine circulation modes considered in this study. Note that the exchange flow and ITAC change sign with depth, with landward (positive) velocities near the bed.

The origins of ITAC are more complex than the other two, so it is useful to summarize its development. Consider, for example, the movement of water in an estuary during the tidal cycle. During flood tide baroclinic and barotropic pressure gradients act together, while on ebb they are in opposition. Baroclinic currents are concentrated near the bed whereas barotropic velocity maxima are near the surface, resulting in a more uniform advance on flood and sheared retreat on ebb. Tidal modulations of the vertical salinity structure (tidal straining; Simpson et al. 1990) cause further asymmetry between ebb and flood velocity profiles, through changes in vertical momentum exchange (Jay and Musiak 1996). Differential displacement of freshwater over sea water increases stratification on ebb, thereby inhibiting vertical mixing and increasing shear. Flood tides, in contrast, tend to homogenize the water column. The asymmetry between flood and ebb velocity profiles results in a flow pattern with landward flux at depth and seaward flux near the surface. The circulation due to internal tidal asymmetry, therefore, can be viewed as the result of tidally variable shear, stratification, and vertical mixing, as will become clear when in the analytical model developed in Chapter 3. 
Bottom topographic and other physical properties of the system greatly affect the nature of estuarine circulation. Cross sectional convergences create local velocity maxima, frictional properties of the bed affect the balance of momentum in tidal and residual flows, and topographic lows enforce gravitational circulation and ITAC. The bottom topography of the CRE is complex (Figure 1.1.6), and therefore has strong spatial gradients in estuarine circulation patterns (Jay and Smith 1990a).

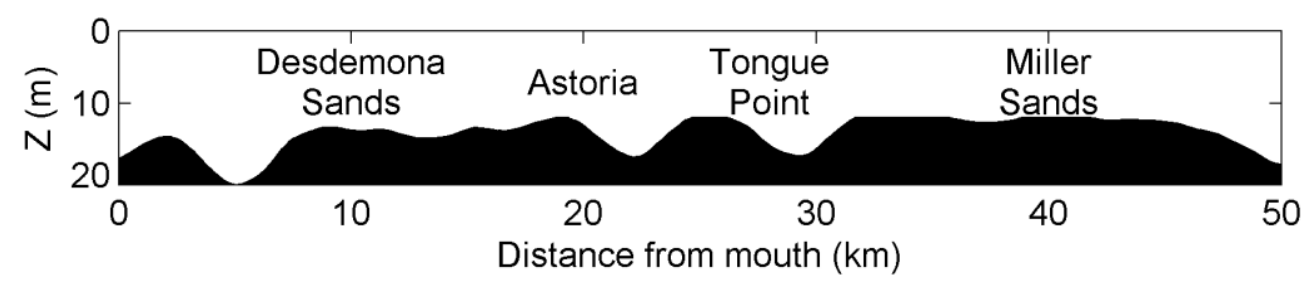

Figure 1.1.6 Approximate depths along the South Channel of the CRE. The channel is maintained at a minimum depth of $13+m$ and has several topographic lows.

CRE bottom topography has evolved over time due to natural morphological changes and anthropogenic activities. Climate patterns during the $20^{\text {th }}$ century reduced total annual sediment supply to the CRE by almost $20 \%$, though the biggest influence on sediment supply stemmed from freshet regulation related to the dam system; $>60 \%$ reduction (Naik and Jay 2010, 2011). In addition, the system is becoming deeper and narrower as a result of channel maintenance activities such as dredging, channelization, etc.; water volumes in the estuary below a depth of 12.8 meters increased by $\sim 8 \%$ during the transition from the $19^{\text {th }}$ to the $20^{\text {th }}$ century, while at the same time volumes above that depth decreased by 15\% (Sherwood et al. 1990). Similar trends have persisted throughout the $21^{\text {st }}$ century and continue to shape the physical character of the CRE at this very moment. 
How do these spatial and temporal patterns in circulation and bottom topography drive distributions of sediment, nutrients, and pollutants, which so greatly impact ecosystem function in the CRE and other estuarine environments? Satellites are particularly well suited to address this concern, in part because of their ability to measure system-wide behavior but also because of the legacy of data that has been created over the past few decades of their deployment. Even if direct measurements of a system's transformation were unavailable, studying sedimentcirculation interaction using satellites can still help develop intuition into how historical-and future-events affect sedimentary processes, because causal relationships that drive these processes can be examined under a variety of estuarine conditions.

Satellites capable of monitoring SSC typically house instruments that measure surface reflectance (a unitless ratio of the incident and reflected radiation at a point on the Earth's surface) within the visible light spectrum. Here we will use the MODIS (Moderate Imaging Spectroradiometer) instrument because of its relatively high sampling frequency and resolution ( $\sim 0.5$ days and $250 \mathrm{~m})$. Since particles in the water column generally have a unique optical signature, MODIS observations of the water's spectral intensity at different wavelengths can reveal what particulates are present. A number of studies have developed a foundation of methodologies for remotely measuring SSC in estuarine environments using MODIS and related instrumentation (e.g. Chen et al. 2006; Doxoran et al. 2003, 2006, 2009; Lehner et al. 2004; Palacios et al. 2009). Their progress confirms the ability of satellites to consistently measure SSC, 
monitor its spatial and temporal patterns, and explore qualitatively its relationship to tidal and fluvial processes. Such efforts, however, have not used satellite data to do more than a superficial process study of sediment dynamics.

This study advances remote measurement applications to monitor the physical mechanisms responsible for driving variability in the sediment field through careful interpretation of its distribution. By conditionally sampling the 15- year MODIS record and using insights from estuarine oceanography one can determine which variables (river flow, tides, etc.) dominate sedimentary processes in estuarine environments. This thesis addresses the following questions:

1. Can satellite-based surface reflectance measurements be calibrated to in-situ turbidity measurements in the CRE, and can they be used to monitor turbidity?

2. What spatial and temporal signals exist in the turbidity field and how do they relate to different estuarine conditions?

3. How does bottom topography affect the along-channel distribution of turbidity, and what physical mechanisms are responsible?

This investigation begins with an observational study of the satellite data followed by theoretical interpretations using a semi-analytical 2-D model of the estuarine circulation and resulting turbidity field. 


\section{Chapter 2: Observational Study}

Chapter 2 outlines results of the observational study. First, data sources used in the analysis are described. A brief summary of the underlying physical mechanisms that lead to a relationship between satellite measurements and in situ water quality variables (WQVs) follows. Using standard methods, (Siegel, 2005; Palacios et al., 2009; Doxaran et al., 2009; Hu et al., 2004) an ordinary least squares regression is used to develop a relationship between in situ turbidity and MODIS-based surface reflectance. Next, A climatology of turbidity in the CRE is constructed to gain insight into the seasonal variability of system turbidity. Spatial distributions of the turbidity field are then analyzed with regard to their response to river flow, tides, and wind. Finally, the along-channel structure of turbidity is compared to in situ salinity measurements and examined in the context of simple analytical expressions of the estuarine circulation. MODIS-based measurements are shown to reliably reproduce the turbidity and demonstrate that turbidity distributions are heavily dependent on river flow and the tides and that bottom topographic features are likely also to be linked to the transport of sediment in the system. 


\section{SECTION 1: DATA SOURCES}

\section{SATELLITE DATA}

Satellite data are derived from surface reflectance measurements made by MODIS. This instrument records observations at least twice daily aboard the AQUA and TERRA satellites (2000 to present), sampling the CRE approximately 2 hours apart near midday. Data are available at various processing levels, ranging from raw data (Level-0) to highly processed end-products (Level-3). A Level-2 swath product (MOD09), processed by NASA though the Level 1 and Atmosphere Archive and Distribution System (LAADS), was used in this study. MOD09 is atmospherically corrected; calibrated radiance data are adjusted for solar and sensor zenith angles to provide top-of-the-atmosphere measurements, which are then corrected for various atmospheric scattering and absorption properties yielding estimates of the surface reflectance (Vermote and Vermeulen 1999; Vermote et al. 2011). A detailed description of the algorithms used to derive surface reflectance from raw data is provided in (Vermote and Vermeulen, 1999). These algorithms also produce state and quality datasets that flag pixels as clouds, high or low aerosols, land, etc. and mark poor quality measurements. These flags were used to filter measurements that poorly represent the state of the water surface. Analyses developed in Chapter 2 use measurements from MOD09 Band $1(620-670 \mathrm{~nm})$ at a $250 \mathrm{~m}$ resolution (Figure 2.1).

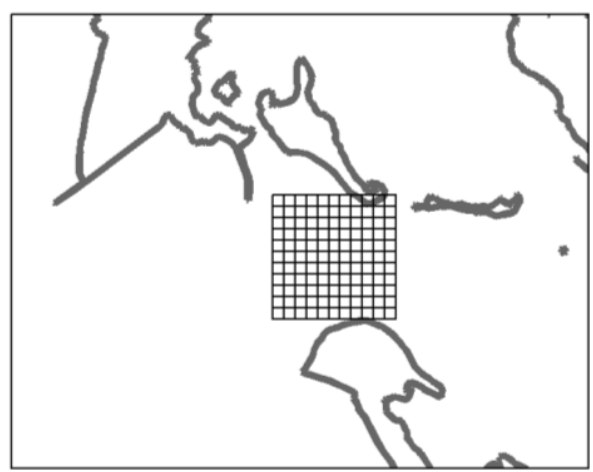

Figure 2.1.1. Example of 10x10, $250 \mathrm{~m}$ grid at the mouth of the CRE. 
IN-SITU DATA

In situ measurements of turbidity were derived from five stationary buoys (Table 2.1.1; Figure 2.1.2), which are managed by the Center for Coastal Margin Observation and Prediction (CMOP; http://www.stccmop.org/datamart/). Turbidity observations used in this study were recorded periodically from 2009 to 2012 at subminute intervals using WETLab's ECO FLNTU (measuring at 695nm) or Turner Designs' Cyclops 7 (620-715nm) fluorometers. At each location measurements are made within 2.5 meters of the water surface.

Table 2.1.1. Locations of in situ turbidity measurements used in OLS.

\begin{tabular}{|c|c|c|c|}
\hline Buoy & $\begin{array}{c}\text { Measurement Depth } \\
\text { (meters) }\end{array}$ & $\begin{array}{c}\text { Latitude } \\
\text { (degrees) }\end{array}$ & $\begin{array}{c}\text { Longitude } \\
\text { (degrees) }\end{array}$ \\
\hline SAT1 & 0 & 46.235 & -123.872 \\
\hline SAT2 & $0-1$ & 46.173 & -124.127 \\
\hline SAT3* & 2.5 & 46.200 & -123.940 \\
\hline SAT4 ${ }^{*}$ & 0.3 & 46.204 & -123.759 \\
\hline SAT5 & 2.5 & 46.184 & -123.188 \\
\hline
\end{tabular}

*Turbidity measured with Turner Designs Cyclops 7.

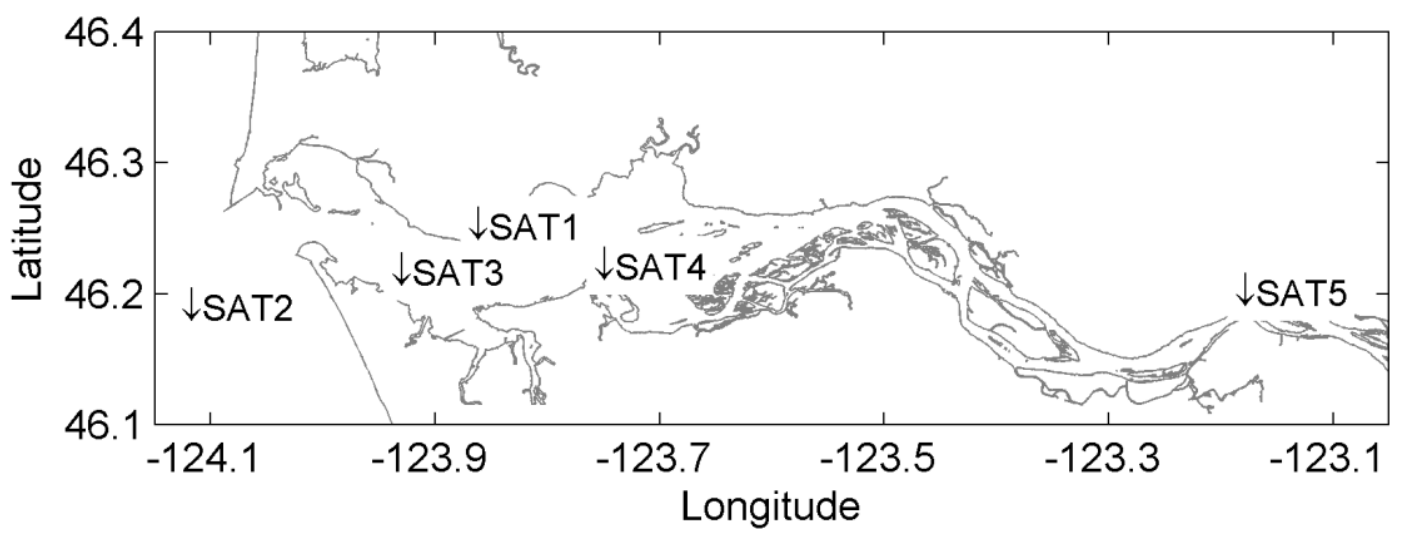

Figure 2.1.2. Buoy sites for stations used in ordinary least squares to derive MODIS-based turbidity estimates 
Salinity measurements were also used in the analysis to construct salinity intrusion and stratification estimates. Data were derived from six stationary buoys (Table 2.1.2; Figure 2.1.3), managed by CMOP, recording at sub-minute intervals from the years 2003 to 2010 . Near bed measurements at the six locations were used to construct salinity intrusion estimates (data recorded during fall of 2008 in the North Channel and from 2003 to 2010 in the South Channel). Surface and near bed measurements at SAT1, SAT3, MBS (the south end of Megler Bridge), and SAT4 were also used to calculate the stratification at each location (data from 2011 to 2013 in the North Channel, from 2001 and 2009 to 2013 in the South Channel).

Table2.1.2. Locations of in situ measurements used to derive salinity profiles.

\begin{tabular}{|c|c|c|c|c|}
\hline Buoy & $\begin{array}{c}\text { Measurement Depth } \\
\text { (meters) }\end{array}$ & $\begin{array}{c}\text { Latitude } \\
\text { (degrees) }\end{array}$ & $\begin{array}{c}\text { Longitude } \\
\text { (degrees) }\end{array}$ & $\begin{array}{c}\text { Distance from mouth } \\
(\mathrm{km})\end{array}$ \\
\hline SANDS & 7.9 & 46.256 & -123.982 & 7 \\
\hline DESD & 7.3 & 46.226 & -123.955 & 11 \\
\hline TANSY & 8.4 & 46.189 & -123.919 & 15 \\
\hline SAT1 & 7.4 & 46.235 & -123.872 & 16 \\
\hline SAT4 & 8.6 & 46.204 & -123.759 & 30 \\
\hline CBNC & 6.5 & 46.210 & -123.714 & 34 \\
\hline MBS & 14.3 & 46.196 & -123.251 & - \\
\hline
\end{tabular}

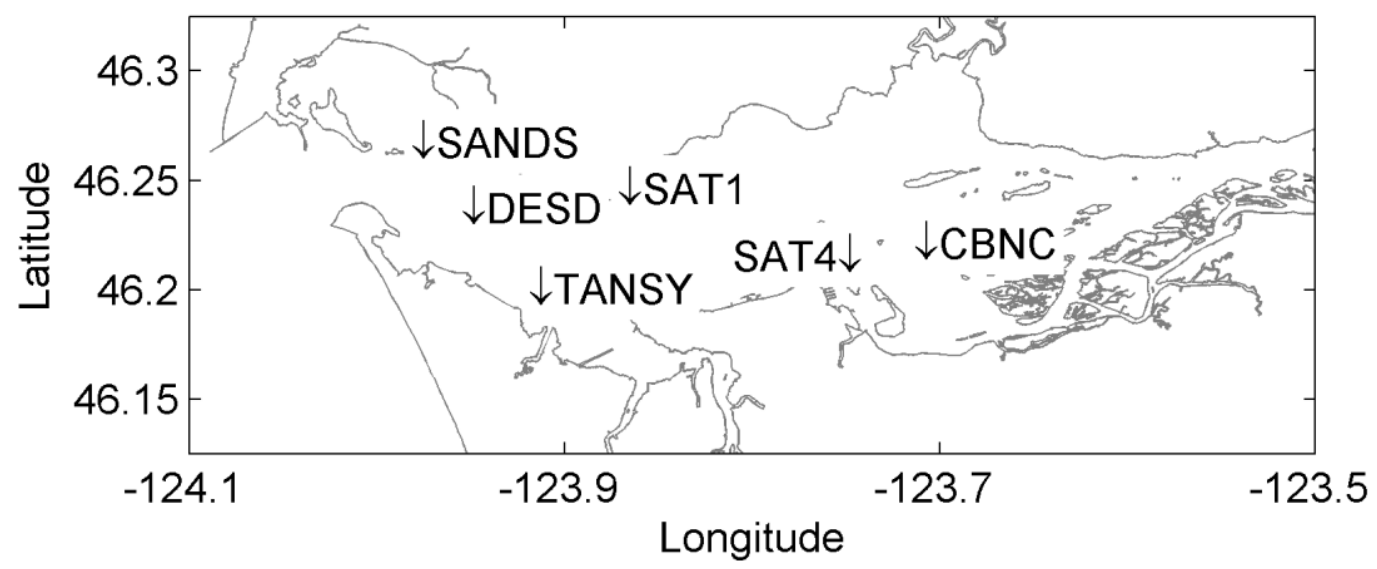

Figure 2.1.3. Buoy sites for stations used to derive salinity transects and stratification estimates. 
Forcing variables used in the analysis include river flow, tidal range, water surface elevation, wind speed, and wind direction. Data are managed by USGS (United States Geological Survey) and NOAA (National Oceanic and Atmospheric Administration) and were recorded at various locations throughout the CRE (Table 2.1.3). River flow and meteorological data were processed as daily averages and all other measurements as hourly averages.

Table 2.1.3. Measurement details of forcing parameters used in the analysis.

\begin{tabular}{|c|c|c|}
\hline Forcing & Measurement Location & Time of record \\
\hline $\begin{array}{l}\text { Wind Speed/Direction } \\
\left(\mathrm{ms}^{-1} / \text { degrees }\right)\end{array}$ & $\begin{array}{c}\text { NOAA Station ASTO3. Astoria, OR } \\
\text { NOAA Station 46029. Columbia River Bar }\end{array}$ & $\begin{array}{l}2005-2013 \\
2000-2013 \\
\end{array}$ \\
\hline $\begin{array}{l}\text { Tidal Range/Elevation } \\
(\mathrm{m})\end{array}$ & NOAA Station 9439040 . Astoria, OR & $2000-2013$ \\
\hline $\begin{array}{l}\text { River Flow } \\
\left(\mathrm{m}^{3} \mathrm{~s}^{-1}\right)\end{array}$ & $\begin{array}{l}\text { USGS 14296900. Columbia River. Quincy, OR } \\
\text { USGS 14243000. Cowlitz River. Castle Rock, WA } \\
\text { USGS 14211720. Willamette River. Portland, OR } \\
\text { USGS 14105700. Columbia River. The Dalles, OR }\end{array}$ & $2000-2013$ \\
\hline
\end{tabular}




\section{SECTION 2: REMOTE SENSING OF TURBIDITY}

Two broad approaches exist for deriving remote estimates of WQVs: semianalytical methods that rely on decomposing the reflectance spectrum of a water body into individual constituents, and empirical methods that seek correlations between remote and in-situ data. The former approach has proved successful in the open ocean, where a number of algorithms have been formulated to derive the concentration of in situ WQVs (Siegel et al. 2005; Maritorena et al. 2002). In coastal waters, however, more in-situ sources of reflectance are found such as suspended particulate matter (SPM), colored dissolved organic matter (CDOM), and different species of chlorophyll. Reflectance intensity of these optically active constituents (OACs) in any given spectral band is geographically variable, which complicates the development of semi-analytical approaches in coastal waters (Siegel et al. 2005).

As an example, consider a water body with comparable concentrations of SPM, CDOM, and chlorophyll-a. The reflectance spectra of each are a function of their distinct absorption and backscatter characteristics (Bricaud et al. 1981; Bricaud et al. 1995; Buiteveld 1994; Snyder et al. 2008), and when combined together form the color of the water body in which they reside (denoted as the total spectrum). MODIS measures at discrete bandwidths within the total spectrum; it does not measure the continuous total spectrum and is unable to explicitly measure those contributions of the individual constituents. Semi-analytical approaches attempt to estimate the observed total spectrum by minimizing the error between discrete MODIS measurements and the inherent total spectrum (theoretically based on the spectral 
properties of OACs). The total spectrum is then inverted to determine the concentration of each constituent.

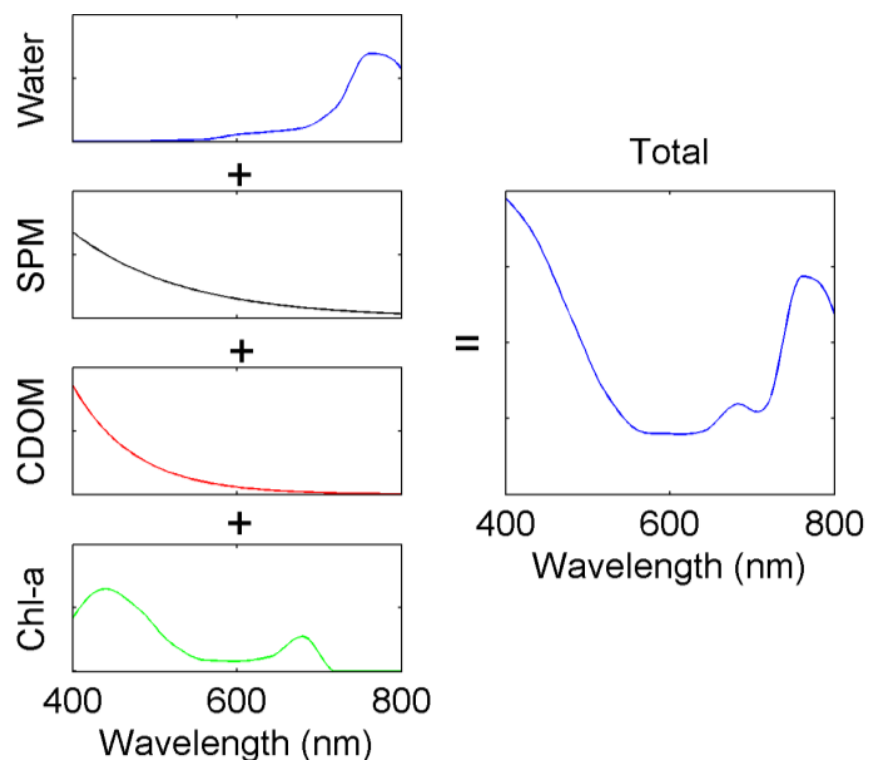

Figure 2.2.1. Conceptual diagram of absorption spectra for various OACs and the resulting total absorption spectrum.

Critical to the inversion procedure is adequate characterization of the spectral properties of each $\mathrm{OAC}$, and any uncertainties therein greatly reduce the accuracy of the approach (Maritorena et al. 2002). Application of semi-analytical methods, therefore, requires extensive knowledge of the OACs' optical properties if any reasonable estimates of in situ concentrations are to be expected. The properties in the CRE are not fully characterized and as a result semi-analytical methods developed for the Oregon coast typically fail in the estuary (Palacios et al. 2009). Therefore, an empirical model was used here to derive remote estimates of surface turbidity. Empirical methods have been successful in other estuarine systems (Doxaran et al. 2009, Hu et al. 2004) and are reliable, provided there are sufficient data to calibrate the model. 


\section{EMPIRICAL MODEL}

A number of different methods have been used in empirical models (Chen et al. 2006; Doxaran et al. 2003, 2006, 2009; Hu et al. 2004). This thesis focuses on one using Bands 1 and 2, as they are of the highest spatial resolution among all MODIS bands $(250 \mathrm{~m})$. Experimentation showed that a linear combination of the two correlated most strongly with in situ data. Band 1 described a majority of the turbidity variance, however, and least squares regression estimates of model parameters were statistically the same as a model with both bands. Therefore a simpler model was favored using only Band 1 (620-670nm).

Five Saturn buoys (Table 2.1.1) were used to develop the model and a total of 170 concurrent measurements of turbidity and cloud-free surface reflectance were recovered during the observation period. Note that the SAT1 measurements are made on a profiling system such that samples the entire water column. In situ measurements were averaged over a 1-hour period centered at the time of each satellite passing. This filter generated a reasonable regression and was selected to smooth fluctuations in the in-situ measurements caused by vertical variations in sensor height and spatial variability (Figure 2.2.2). Filtering also ensured that spatial advection of surface waters through a pixel is accounted for. 


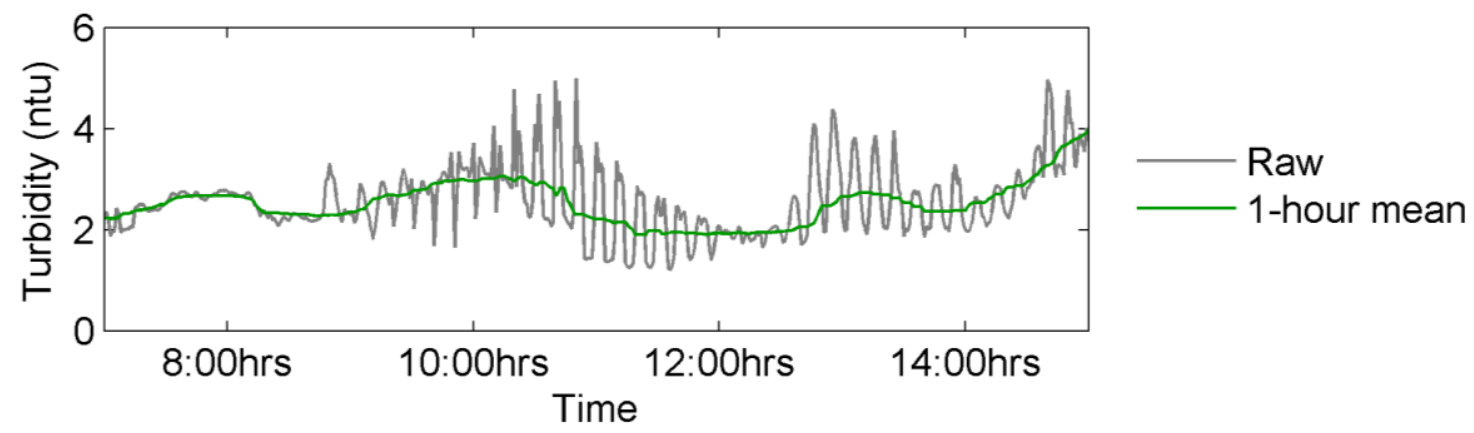

Figure 2.2.2 Averaging of in-situ measurements. The filter reduces fluctuations in turbidity caused by changes in vertical height of the sensor at SAT1 that do not accurately represent the state of the pixel during the time of MODIS measurement. Data here is recorded at SAT1 on February 26, 2010.

Elevated aerosol concentrations were abundant throughout the dataset and can significantly affect the radiance transmitted to and from the surface (Vermote and Vermeulen 1999; Hu et al. 2004). Therefore, regressions were performed under high and low aerosol scenarios to gain insight into their effect on measurements in the CRE. Results show that aerosol presence moderately increases scatter between remote and in situ measurements but it does not significantly affect the coefficient estimates (Table 2.2.1). The regression demonstrates a strong relationship between the MODIS and in situ data for both cases $\left(\mathrm{R}^{2}=0.84\right.$ and 0.96 for the high and low aerosol, respectively). This correlation most likely exists due to the proximity of the MODIS Band 1 spectral range $(620-670 \mathrm{~nm})$ and the detection wavelength of the in situ turbidity sensor $(\sim 695 \mathrm{~nm})$. Although the regression for the low aerosol case produced the best correlation, each regression results in statistically similar coefficient estimates and a p-value of $<(10)^{-25}$. 
Table 2.2.1. Model statistics for OLS between Band1 and in situ turbidity and coefficient estimates. Confidence intervals ( $\alpha=0.05$ ) for coefficients are provided in brackets.

\begin{tabular}{|c|c|c|c|c|c|}
\hline \multicolumn{6}{|c|}{ MODEL STATISTICS } \\
\hline Aerosol & Sample size & $\mathrm{R}^{2}$ & F statistic & P $_{\text {value }}$ & $\begin{array}{c}\text { Error } \\
\text { variance }\end{array}$ \\
\hline Low & 40 & 0.96 & 883 & 0 & $0.89 \mathrm{ntu}$ \\
\hline High & 170 & 0.84 & 853 & 0 & $1.63 \mathrm{ntu}$ \\
\hline \multicolumn{6}{|c|}{ COEFFICIENT ESTIMATES } \\
\hline Aerosol & \multicolumn{3}{|c|}{ Intercept } & \multicolumn{3}{c|}{ Slope } \\
\hline Low & $0.23 \quad[-0.15 ; 0.61]$ & 146.5 & {$[136.5 ; 156.5]$} \\
\hline High & 0.35 & {$[0.08 ; 0.62]$} & {$[124.6 ; 142.6]$} \\
\hline
\end{tabular}
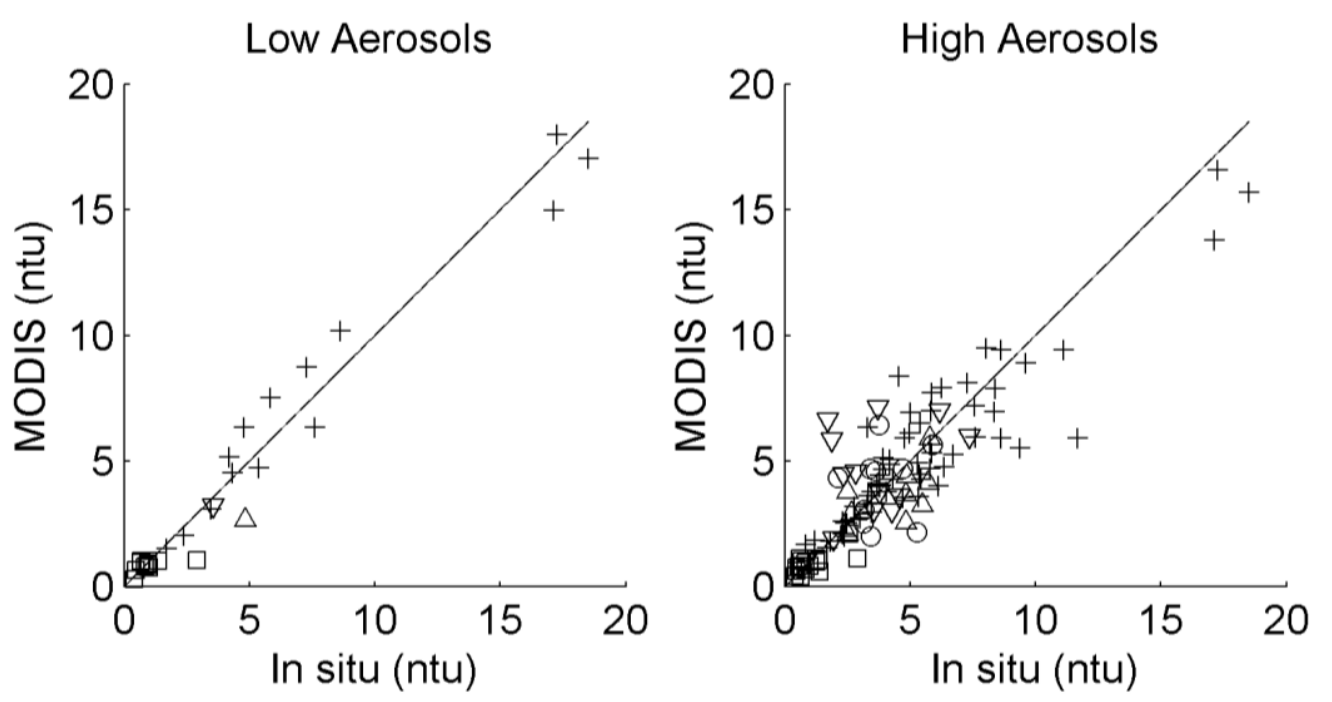

+ SAT1 $\square$ SAT2 $\triangle$ SAT3 $\circ$ SAT4 $\nabla$ SAT5

Figure 2.2.3 Scatter plots of remotely estimated, and in situ turbidity. Results for the low (left) and high (right) aerosol cases are statistically similar.

Many sources of error exist that may affect the relationship between MODIS and buoy data including (but certainly not limited to) atmospheric properties, the existence of other OACs, the disparity between the in situ and remote detection wavelengths, reflectance off the bed in shallow regions, and land contamination for pixels that overlap the shoreline. Furthermore, inherent differences in the nature of 
measurement between the two methods may also lead to errors in the regression. The CRE experiences strong spatial gradients, which could contribute to error between remote and in situ measurements. Buoy observations are a point measurement, whereas MODIS records a 250m-square average measurement and it is possible that a local maximum or minimum of turbidity frequently occurs at the buoy location, in which case a discrepancy would be observed between the two datasets. One measurement, SAT1, measured vertical profiles continuously. Filtering the buoy data served to reduce this effect (Figure 2.2.2) and improve the regression statistics.

Another source of error results from the difference in the measurement depths of the in-situ and satellite observation. At low turbidity levels the water surface can appear optically clear and remote measurements are an integral measure of several meters of surface water. As concentrations increase, the water becomes more opaque and the sampling volume is driven to the surface. Since turbidity is a strong function of depth (increasing towards the bed) any inconsistency in measurement depth would generate variability between the two datasets. Stratification in the water column, which is prevalent in the CRE, augments measurement-depth-related discrepancies and its effect on the calibration remains to be explored.

The contribution of other OACs to surface reflectance observations cannot be discounted, after all it is the presence of multiple OACs that often confound remote estimates of WQVs. One constituent in particular, chlorophyll-a, must be addressed 
since MODIS Band-1 observations coincide with a peak in chlorophyll-a's absorptions spectrum. The model calibrated herein, following the observations of (Fain et al., 2001), assumes the influence of chlorophyll-a to be negligible, and that turbidity is a good proxy for sediment concentration. Since the food chain is predominantly detritus-based and primary production in the CRE is comparatively lower than other estuarine systems (Simenstad et al. 1990), the assumption may be valid. Further investigation is necessary, however, to assert this claim.

Despite all of this, the empirical model developed here appears to provide reliable estimates of in situ turbidity. The model can be used with MODIS data to develop a climatology of turbidity measurements in the CRE, which can then be analyzed in the context of estuarine physics to better understand spatial and seasonal variability. In the following section, an investigation of the MODIS-derived turbidity distributions shows promising results for using satellite data to monitor sedimentary processes in estuaries. 


\section{SECTION 3: THE TURBIDITY DISTRIBUTION}

Here we analyze the behavior of the turbidity field using the MODIS-based estimates of surface turbidity. Measurements display a high degree of temporal and spatial variability. This observation agrees with current knowledge of the CRE where sediment concentrations can vary by 3 to 4 orders in magnitude seasonally and up to ten orders spatially (Fain et al. 2001; Jay et al. 1990). Spatial maps of MODIS data can reveal further insights into the temporal evolution of the turbidity field, and the processes that drive this development, which have been heretofore unmeasured.

Monthly averaged surface turbidity distributions expose the spatial signature of seasonal variance in the turbidity field, which follows closely that of the river flow. Maximum system wide concentrations are observed in January and December during the winter freshet season (Figure 2.3.1). High levels persist throughout the spring freshet but to a lesser degree (perhaps due to the export of fine particulates during the winter months). Once the river flow subsides in late summer, estuarine turbidity concentrations reduce to their minimum values and the process repeats in the oncoming winter. Although global turbidity levels vary seasonally, the spatial distribution is less variable. For example, large gradients in the turbidity field are always observed in the lower-estuary. This consistency, as will be discussed further in the following chapter, is likely due to the combination of local bottom topography and the role of ITAC, which maintains considerable salinity intrusion in the CRE even under large river flows (Jay and Musiak 1994). 

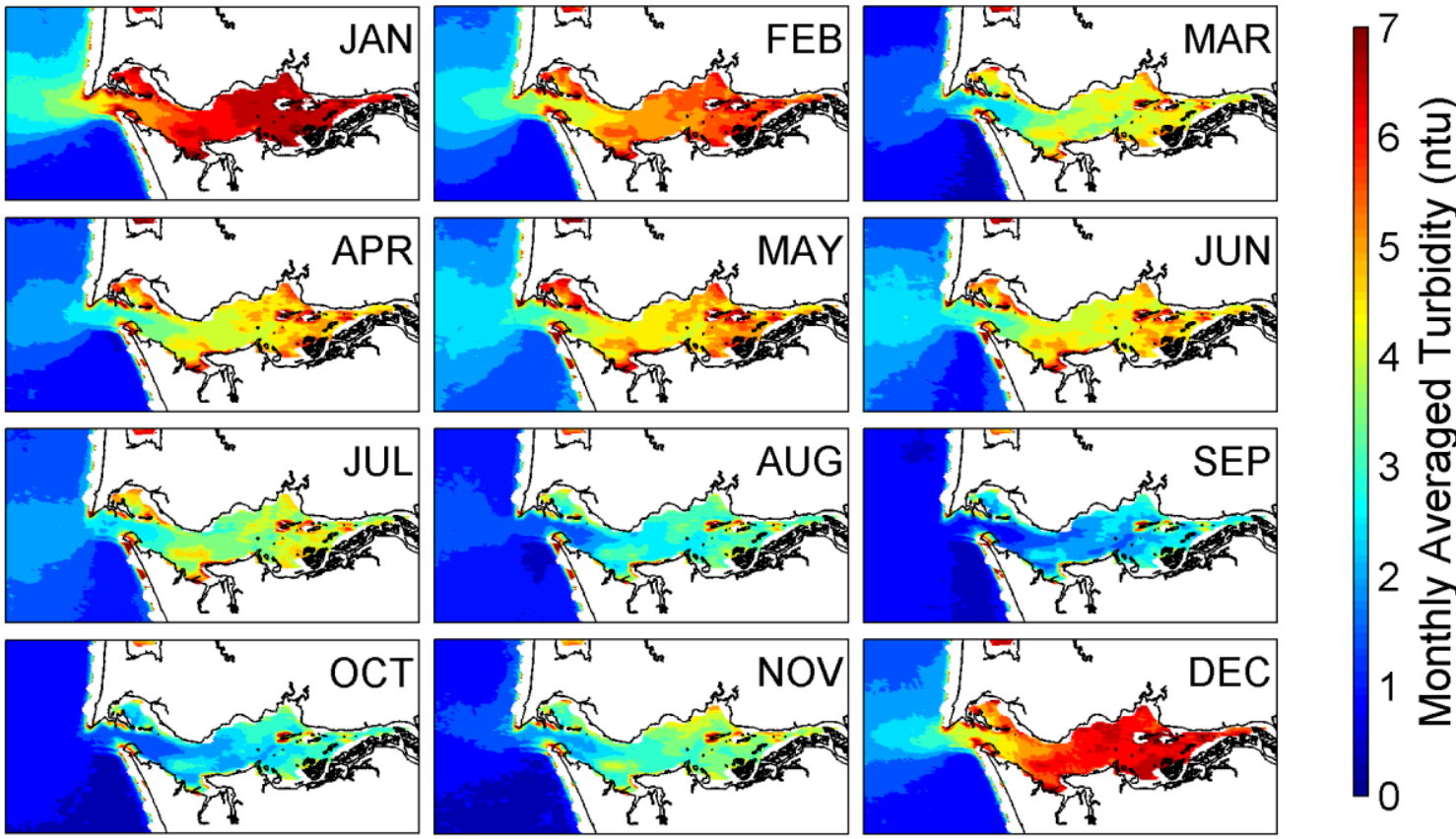

Figure 2.3.1 Monthly averaged turbidity distributions. Elevated concentrations begin during the winter months and persist throughout the spring while high river flows are maintained. Minimum concentrations occur in late summer at periods of low flow.

The Columbia River Plume (CRP) also displays seasonal variability following that of the river flow. During winter months the export of sediment increases, bringing nutrients to the coastal margin (Figure 2.3.1). Concentrations decrease in March and April during a lull in the river flow and after most of the material that could be transported under winter freshet flows has been exported. The spring freshet increases mean monthly turbidity once again as flows exceed those during the winter months. Afterwards the turbidity signal along the Oregon coast declines, reaching an annual minimum in September and October.

Another interesting feature is that the CRP structure observed from the MODIS instrument are consistent with seasonal atmospheric patterns observed in the region. Northerly winds prevail during winter, which generate along-shelf transport directed northward and Ekman transport directed towards the coast that favors downwelling 
conditions (Hickey et al. 2010). The CRP spreads northward but also compresses due to downwelling convergence, increasing retention times of river water and sediment concentrations near the mouth (Figure 2.3.1). In contrast, southward transport and upwelling conditions are favored during summer, which dilates the CRP and acts on the surface as a source of sea water thereby decreasing land-based sediment concentrations.

MODIS-based measurements also capture CRP anatomy, which can be separated into four different water masses: source water, the tidal plume, recirculating plume, and far-field plume (Horner-Devine et al., 2009). Since the concentration of turbid freshwater decreases as river water continues to mix with sea water among successive plume components, the extent of each can be qualitatively estimated by examining the "isoterras" (contours of constant sediment, or turbidity) along the coast. Although the averaging done to create Figure 2.3.1 filters plume expressions at tidal time-scales, it highlights the seasonal variability of the source water, re-circulating plume, and far-field plume, all of which follow wind and river flow cycles mentioned above.

Seasonal cycles in CRE turbidity levels and in sediment/nutrient export to the Oregon coast control primary productivity and are thus vital for ecosystem functioning (Sherwood et al. 1990; Hickey et al. 2010). It is a strategic advantage for regional planning, therefore, to understand what natural phenomena control these cycles. MODIS data, in addition to uncovering the seasonal progression of the turbidity field, have the ability to examine which phenomena drive its variability. As 
mentioned in Chapter 1, tidal and river influences drive sedimentary processes in the CRE. Atmospheric inputs also have an effect though to a smaller degree. By computing the correlation coefficient between MODIS and in-situ data at each location in the CRE $(\alpha=0.05$, sample size $>50)$ a correlation map was created to reveal further information about the spatial structure of these relationships.

Wind forcing has a diverse relationship with turbidity levels. Wind speed measured at Astoria is virtually uncorrelated with surface turbidity and influences only the shallow regions of Youngs Bay (Figure 2.3.2). This station is shielded from local topographic features and at times likely misrepresents conditions elsewhere in the estuary, which may explain the weak response in turbidity levels to this forcing. Wind speed measured in the coastal ocean (Table 2.1.3) has a slightly larger impact that is concentrated along the coast and in the lower-estuary. Wind direction (during speeds greater than $2 \mathrm{~ms}^{-1}$ ) proves to affect turbidity more significantly throughout the system. Measured at Astoria it is greatest in the immediate proximity of the station and along the north shore directly across the river, while measurements at sea show negligible influence in the estuary and increase towards the location of the station. Wind direction is important within the CRE most likely due to the relatively short width of the channel; winds directed across the channel have a smaller fetch than those along the channel and would be less effective at inducing waves that stir sediment from the bed. Surface currents in the coastal ocean primarily result from wind-driven processes (Hickey et al. 2010), the intensity and direction of which 
control the movement of turbid waters originating from the CRE, therefore a relationship between wind properties and turbidity is to be expected.

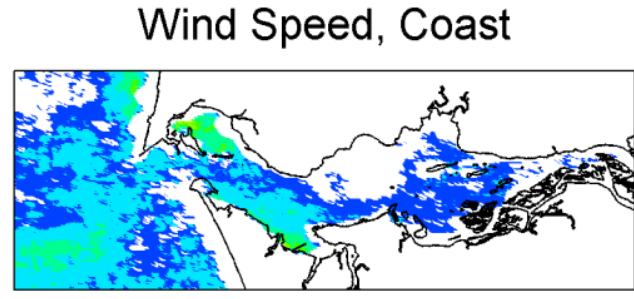

Wind Direction, Coast

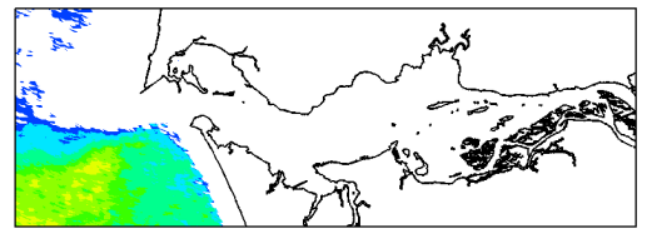

Wind Speed, Astoria

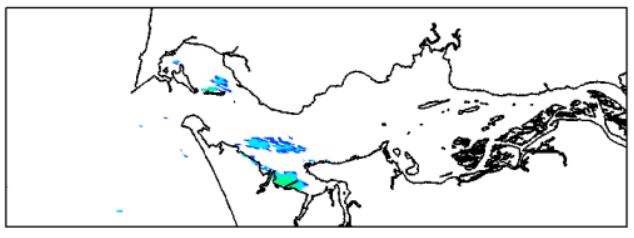

Wind Direction, Astoria

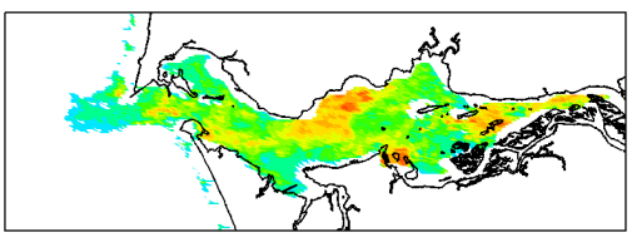

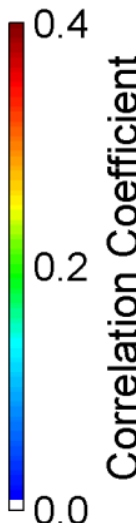

Figure 2.3.2 Correlation map between surface turbidity and wind-related forcing. Wind speed has a minimal effect on turbidity and is confined to shallow regions in the system. Wind direction is of greater importance when measured at either location.

Tidal range, defined here as the difference between maximum and minimum semidiurnal tidal elevations, shows considerable influence throughout the system (Figure 2.3.2, the correlation between MODIS surface turbidity and tidal range 6 hours prior to the satellite passing). As the surface slope that generates tidal currents increases during large tidal ranges (spring tides), vertical mixing also increases, which drives more sediment towards the surface than would occur during small tidal ranges (neap tides). The correlation between turbidity and tidal range peaks in midestuary where tidal variations in stratification and vertical mixing are appreciable. Tidal range also shows a relationship with turbidity in the coastal ocean. More sediment is exported to the CRP during spring tides when vertical mixing is amplified (Fain et al. 2001), and a positive correlation between turbidity and tidal range is observed. 
Tidal Range

Figure 2.3.2. Correlation map between MODIS derived turbidity and tidal range. Tidal range is positively correlated with surface turbidity.

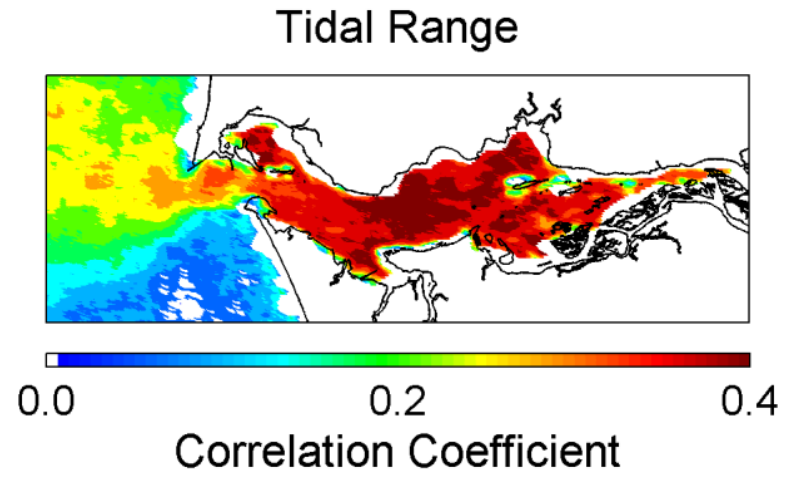

River flow proves to be the strongest process governing variability in surface turbidity in the CRE (Figure 2.3.3, correlation between MODIS surface turbidity and river flow measured at Beaver Army Terminal; The Dalles, 2-day lag; the Willamette River, 1-day lag; and the Cowlitz River). As a river with relatively large discharge that fluctuates by a factor of 5 to 12 annually, and as the source for a majority of the sediment in the system this result is not entirely surprising. What is of greater interest is that the correlation structure for different tributaries to the estuary varies greatly in magnitude and shape. Beaver discharge represents the combination of nearly all fluvial input to the CRE. Its relationship with surface turbidity is considerable and is most correlated with turbidity in the lower-estuary. Columbia River influence, represented by The Dalles discharge, is also maximal in the lower-estuary but its relationship with turbidity is weaker. The Cowlitz River has a stronger correlation than Columbia River flows and exhibits primary influence in the lower and midestuary regions. The correlation with Willamette River discharge and surface turbidity is stronger still and drives variability of the CRE turbidity field to a much larger degree than the other tributaries, particularly in the mid and upper-estuary. 
Beaver

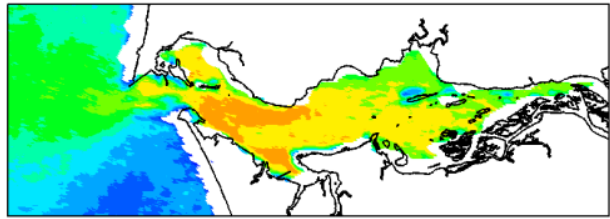

Willamette

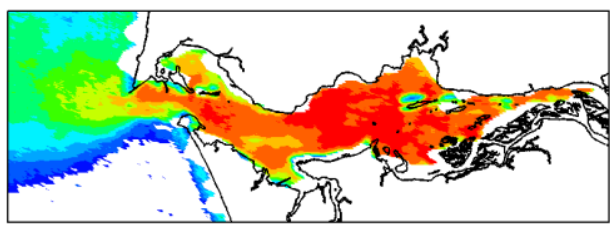

Dalles

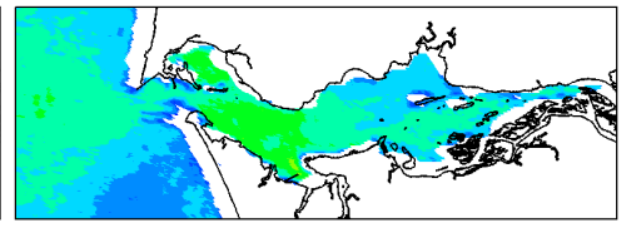

Cowlitz

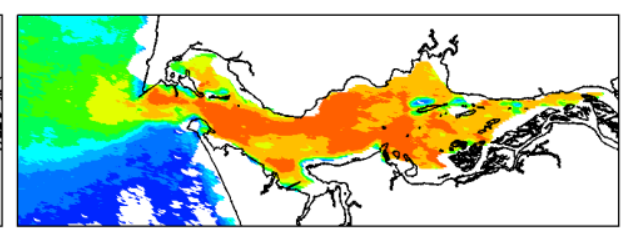

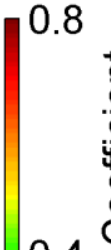

0.4

음

Figure 2.3.3. Correlation map between MODIS derived turbidity and river flow measured at Beaver Army Terminal, The Dalles, Willamette River, and Cowlitz River .

A comparison of the Beaver Army Terminal hydrograph (USGS) and spatiallyaveraged surface turbidity provides further confidence that fluvial inputs control a sizeable portion of variability in the CRE turbidity field. As suggested earlier, seasonal variability of the turbidity follows that of the river flow; elevated turbidity levels are typically observed during periods of large river flow, particularly during the winter and spring freshets (Figure 2.3.4). Signals at frequencies higher than the annual fluvial regime are also noticeable in the turbidity field where most of the change occurs in harmony with river flow fluctuations.

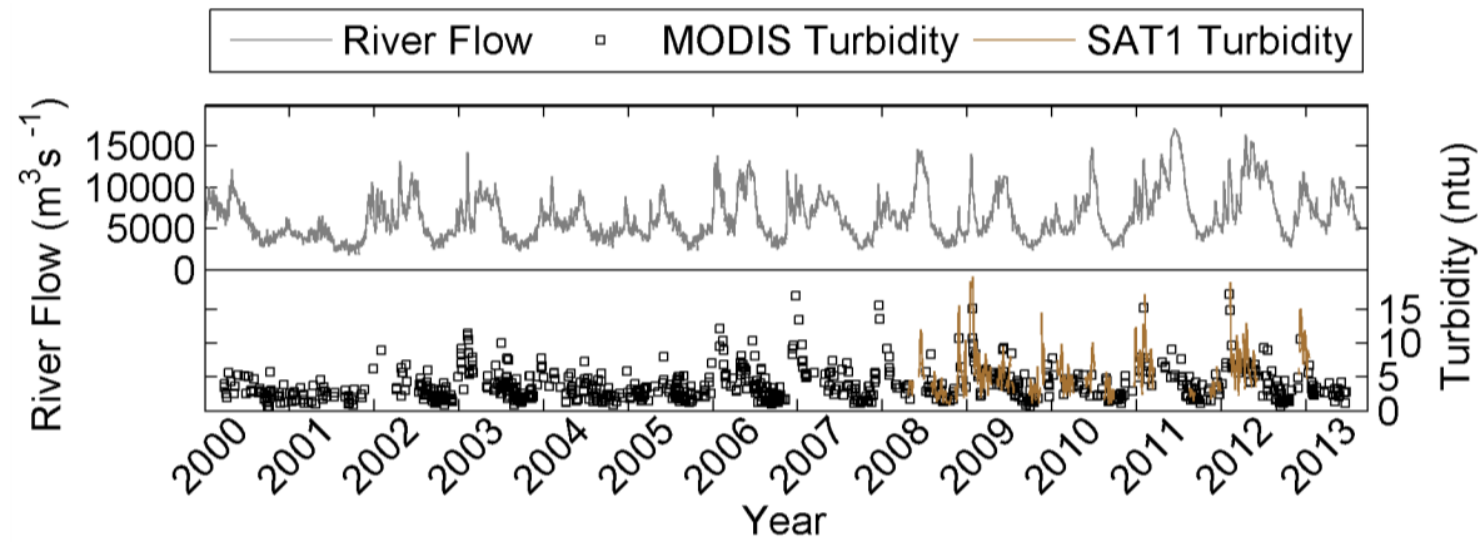

Figure 2.3.3 Hydrograph measured at Beaver and mean turbidity measurements. MODIS estimates are averaged along the North Channel. SAT1 data are daily averaged. 


\section{$\underline{\text { TURBIDITY TRANSECTS }}$}

Analyzing the along channel distribution of turbidity is another approach to explore the variability in the turbidity field-one that allows interpretations of the estuarine circulation and transport from an analytical perspective. To this end, two transects were defined in the satellite data along the North and South Channels of the CRE (Figure 2.3.4). Turbidity was derived from $250 \mathrm{~m}$ resolution surface reflectance using the empirical model and was median-filtered across five adjacent pixels. Transect data were often spatially discontinuous (due to clouds etc.) and only those containing at least $75 \%$ of valid measurements (no cloud flags) were used in the analysis. Between the years 2000 and 2013, a total of 1,243 and 1,202 suitable transects were identified in the South and North Channels, respectively.

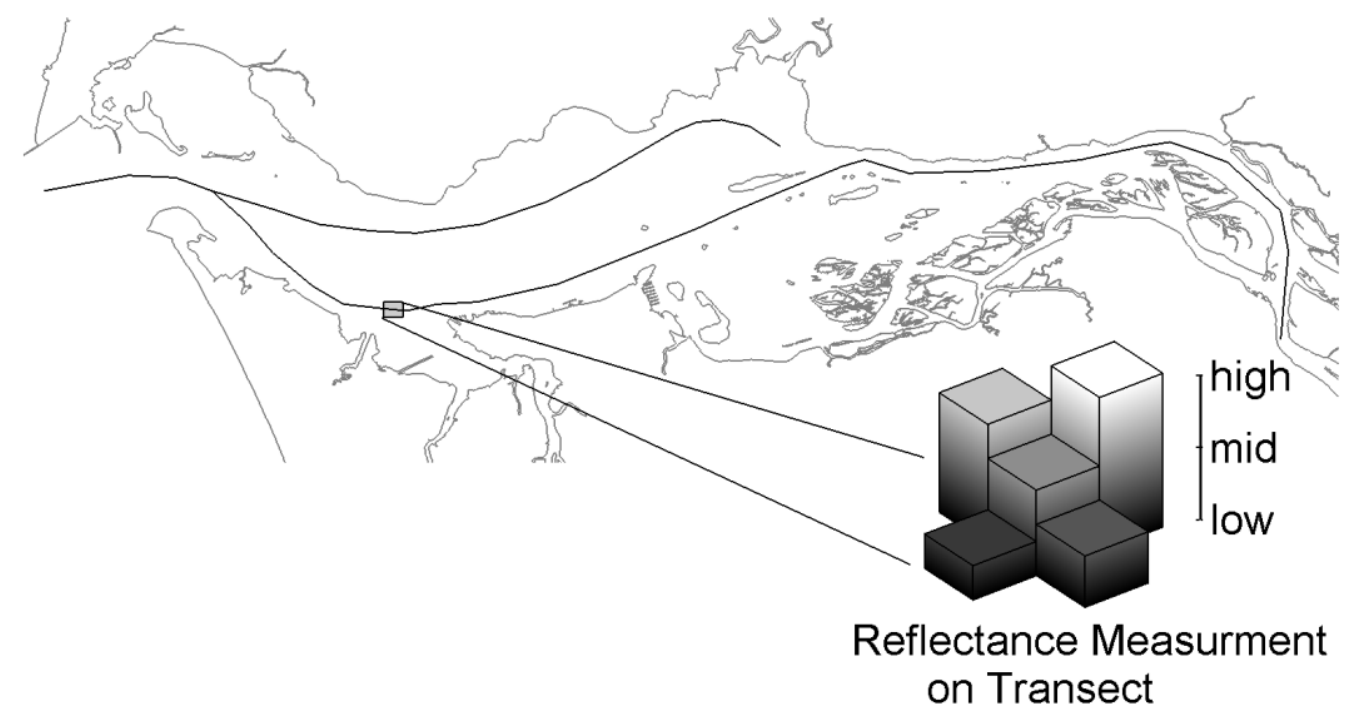

Figure 2.3.4 Transect positions for the North and South Channels. Data were sampled along each transect and median filtered across the five most adjacent pixels. 
Data along both transects were noisy and demonstrated many local maxima and minima so further filtering was conducted to capture the global structure of the turbidity field. Although the behavior of local features may provide insight into the circulation, an investigation thereof is beyond the scope of this study. Instead the focus here is on the feasibility of using MODIS data to better understand properties of the larger, system scale distribution. An optimization approach was used to minimize the mean squared error (MSE) between MODIS data and an analytical model describing the longitudinal distribution of sediment in an estuary. Following Talke et al. (2009), the model describes the along-channel concentration (C) as a function of the salinity $(\mathrm{S})$ and constants that relate to features of the estuarine circulation $\left(\mathrm{k}_{\mathrm{i}}\right)$ :

$$
C(x)=k_{1} \exp \left[k_{2} S(x)+k_{3} x\right]
$$

(Equation 2.3.1)

This is essentially (Equation 14) from Talke et al. (2009) neglecting turbidity currents and assuming the parameters to be bulk values $\left(\mathrm{k}_{1}, \mathrm{k}_{2}, \mathrm{k}_{3}\right)$. The salinity is assumed to take the form of a hyperbolic tangent and is a function of three more constants $\left(\mathrm{k}_{4}, \mathrm{k}_{5}, \mathrm{k}_{6}\right)$ :

$$
S(x)=k_{4}\left[1-\tanh \left(\frac{x-k_{5}}{k_{6}}\right)\right]
$$

The constants $\mathrm{k}_{1-6}$ were constrained to realistic values reported in Talke et al. (2009), and a minimization routine was used to estimate their value. Resulting distributions were successful in illuminating the global features of the turbidity field while preserving the primary signal in the data (Figure 2.3.5). Transects that did not 
agree well with the modeled distribution (MSE $>0.5 n t u$ ) were not included in further analysis. This value was chosen because reasonable agreement was observed for those transects whose MSE was below this threshold. In addition, only those transects with a discernable ETM (having a mean value less than $90 \%$ of the transect maximum) were included in the analysis; this is $\sim 75 \%$ of all transects.
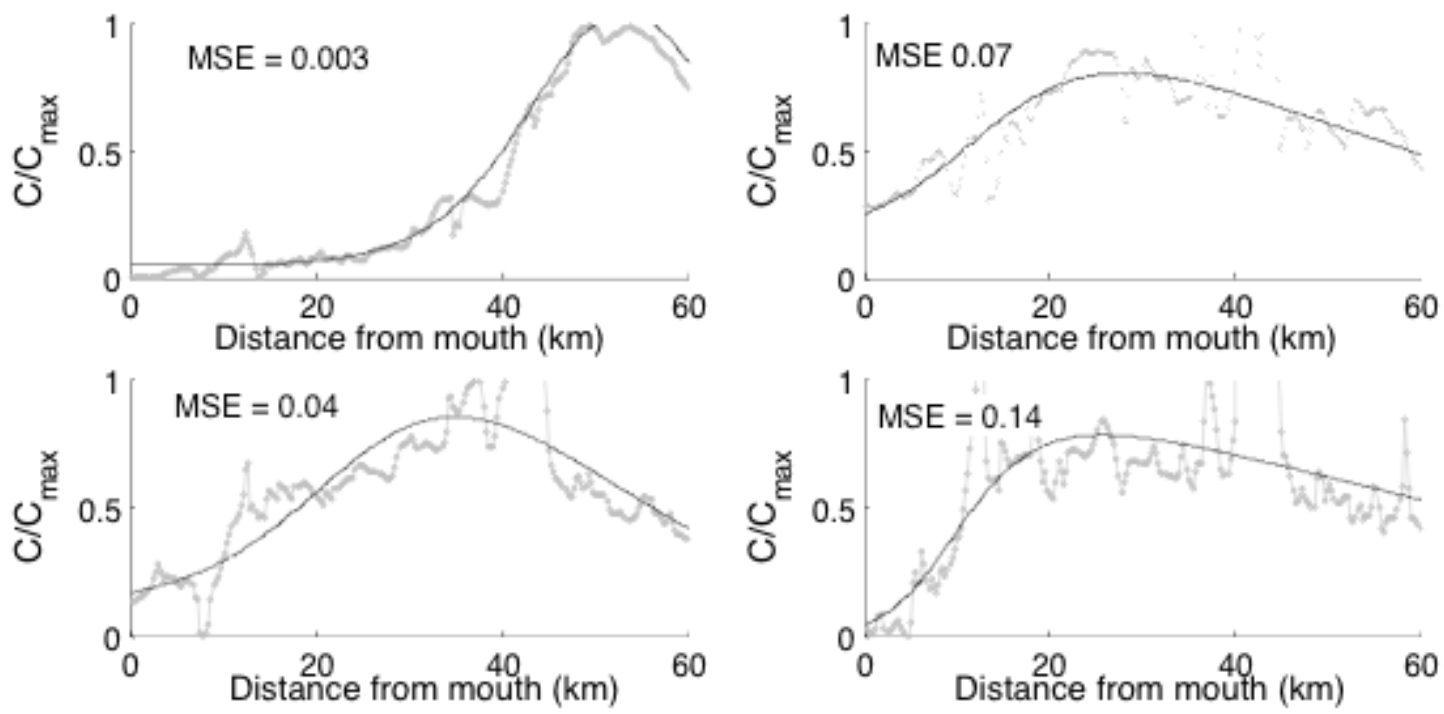

Figure 2.3.5 Data smoothing for measured turbidity transects. Measured data (grey circles) match reasonably with analytical model (black lines).

MODIS-based turbidity transects show that turbidity distributions are typically asymmetrical, with larger gradients observed downstream of the maximum. Binning transects according to greater diurnal tidal range and daily averaged flow rate shows the turbidity distribution and the maximum surface turbidity $\left(\mathrm{C}_{\max }\right)$ to be heavily influenced by the spring/neap cycle as well as fluvial input (Figure 2.3.6, 0.5m window and 1,000 $\mathrm{m}^{3} \mathrm{~s}^{-1}$ window; Figure 2.3.7, $0.1 \mathrm{~m}$ window and $500 \mathrm{~m}^{3} \mathrm{~s}^{-1}$ window). Responses in the two channels, however, show moderately different behavior, which is a result of the distinct estuarine circulation phenomena of each region. 
In both the North and South Channels, the maximum turbidity $\mathrm{C}_{\max }$ increases as tidal range and freshwater discharge become larger. The pattern of $\mathrm{C}_{\max }$ response at either location is different, however. In the South channel, Cmax increases linearly with freshwater discharge, whereas in the North Channel the response is relatively strong at low flows and then plateaus at larger magnitudes. The opposite is true for the tidal range, where $\mathrm{C}_{\max }$ varies in the North Channel more or less linearly and in the South Channel a qualitatively non-linear response is observed.
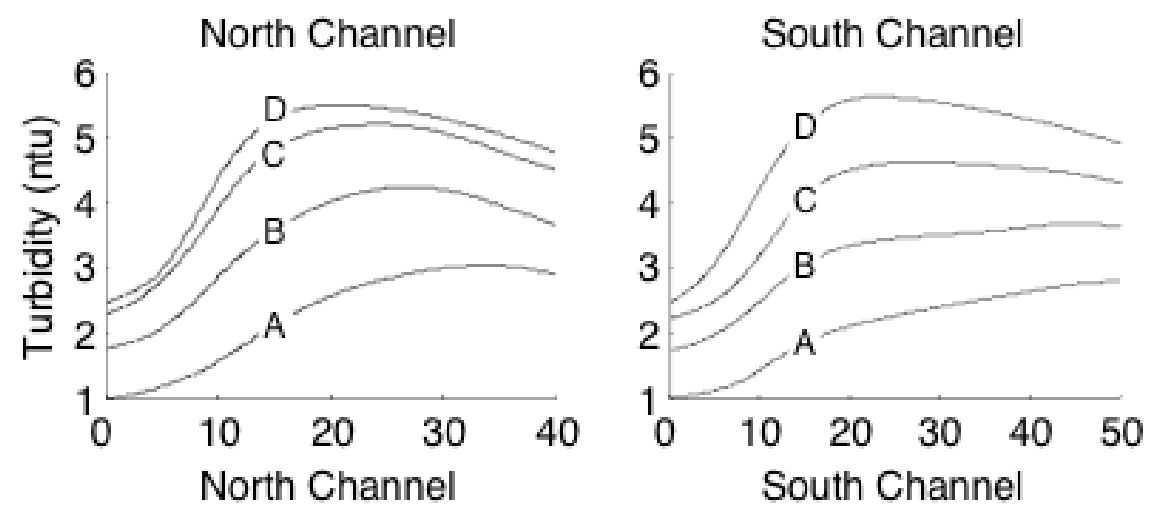

Flow Rate:

$$
A=3000 \mathrm{~m}^{3} / \mathrm{s}
$$

$\mathrm{B}=4500 \mathrm{~m}^{3} / \mathrm{s}$

$\mathrm{C}=7000 \mathrm{~m}^{3} / \mathrm{s}$

$\mathrm{D}=9500 \mathrm{~m}^{3} / \mathrm{s}$
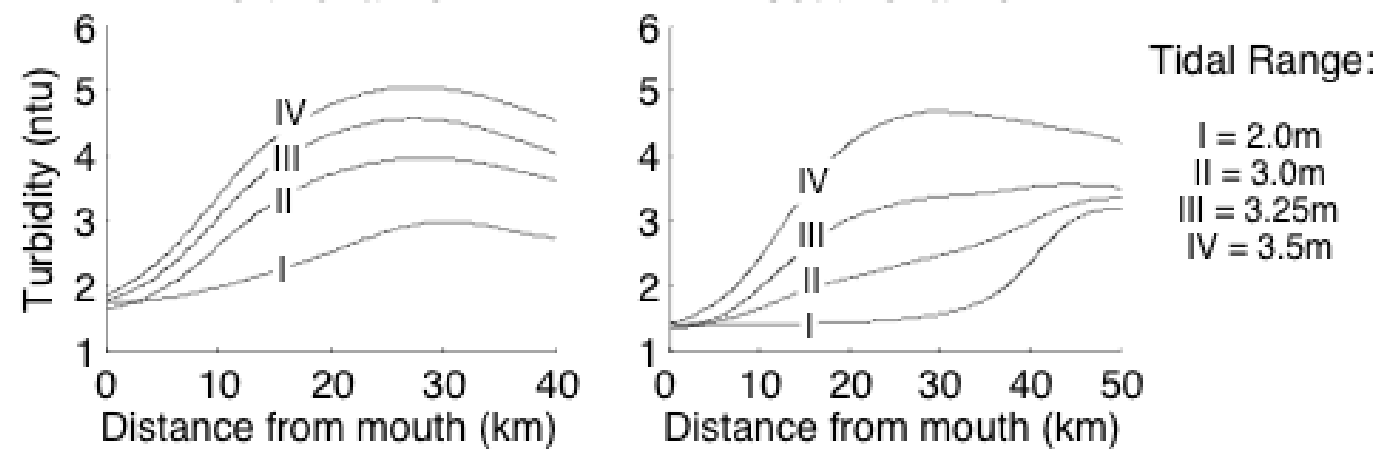

Figure 2.3.6 Longitudinal transects of turbidity in the North (left) and South (right) Channels. Transects are averaged in bins according to greater diurnal tidal ranges (0.5m window) and river flow (1000 $\mathrm{m}^{3} \mathrm{~s}^{-1}$ window). River flow transects are those measured during spring tides. Note: transects are plotted on different horizontal scales. 

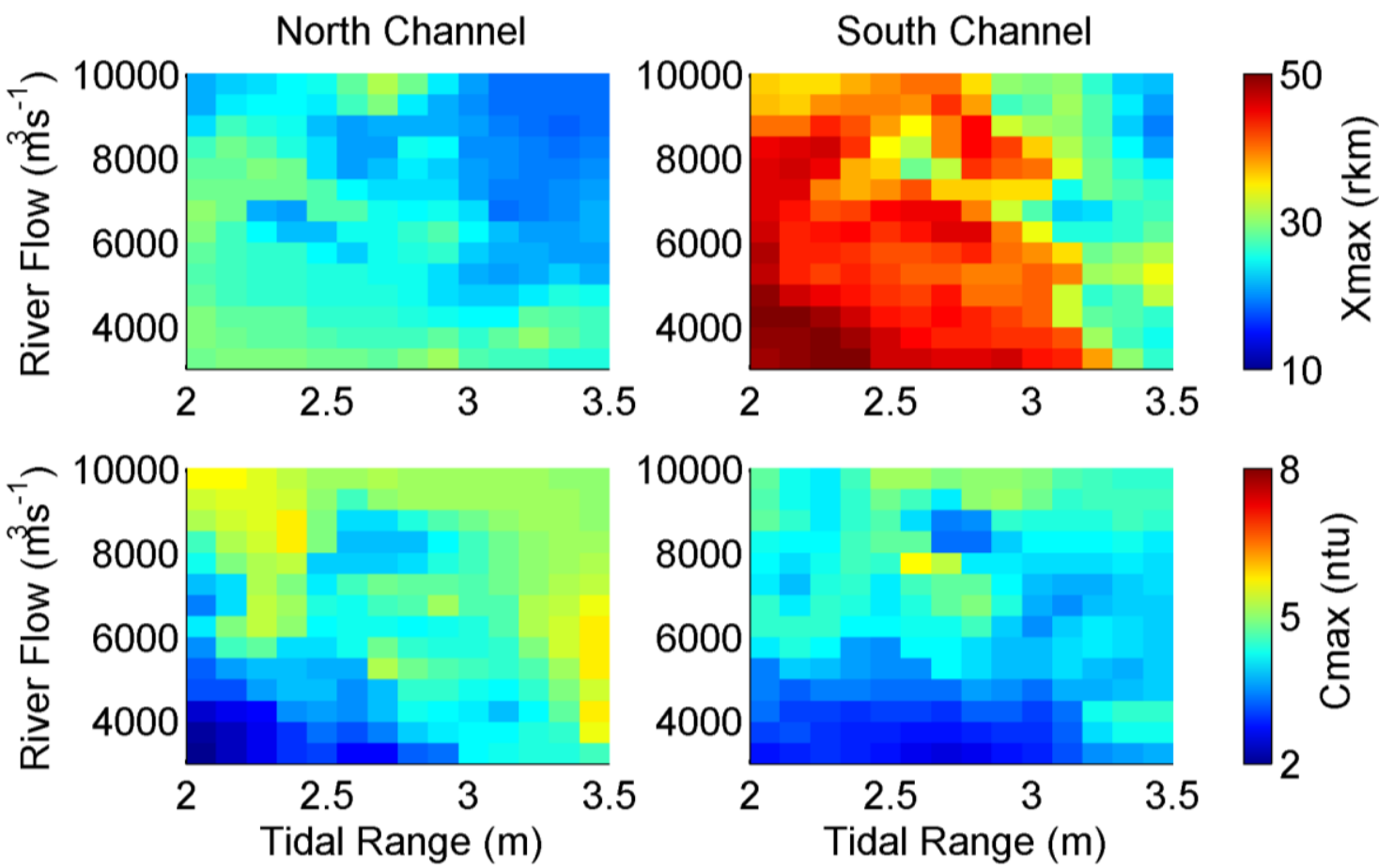

Figure 2.3.7. The location (Xmax) and magnitude (Cmax) of the ETM in the North (left) and South (right) Channel plotted in the forcing parameter space. Increasing river flow and tidal range promote seaward advection and greater intensity of the ETM.

The position of the ETM $\left(\mathrm{X}_{\max }\right)$ is insensitive to changing tidal conditions in the North Channel, and varies very little between neap/spring conditions. Fluvial input drives $\mathrm{X}_{\max }$ seaward in the North Channel, a result of the retreating salinity field and decline in associated landward baroclinic mass fluxes. Note that although $\mathrm{X}_{\max }$ moves along the channel, a region of elevated turbidity gradients is preserved around rkm 10-15. The stationary nature of the North Channel turbidity gradient and the existence of a bottom topographic low at this location suggest a topographically fixed ETM. Given its position at the transition between fresh and salt water, hydrodynamic processes such as internal tidal asymmetry and gravitational circulation are also likely to be important in maintaining this feature. Notice that although stratification (bottom salinity - top salinity) is negatively correlated with tidal range, the water 
column at rkm16 (within the location of large turbidity gradients) is nearly always stratified (Figure 2.3.8). Vertical mixing at this location is thus nearly always inhibited to some degree, resulting in more settling of suspended sediments and decreased surface turbidity.
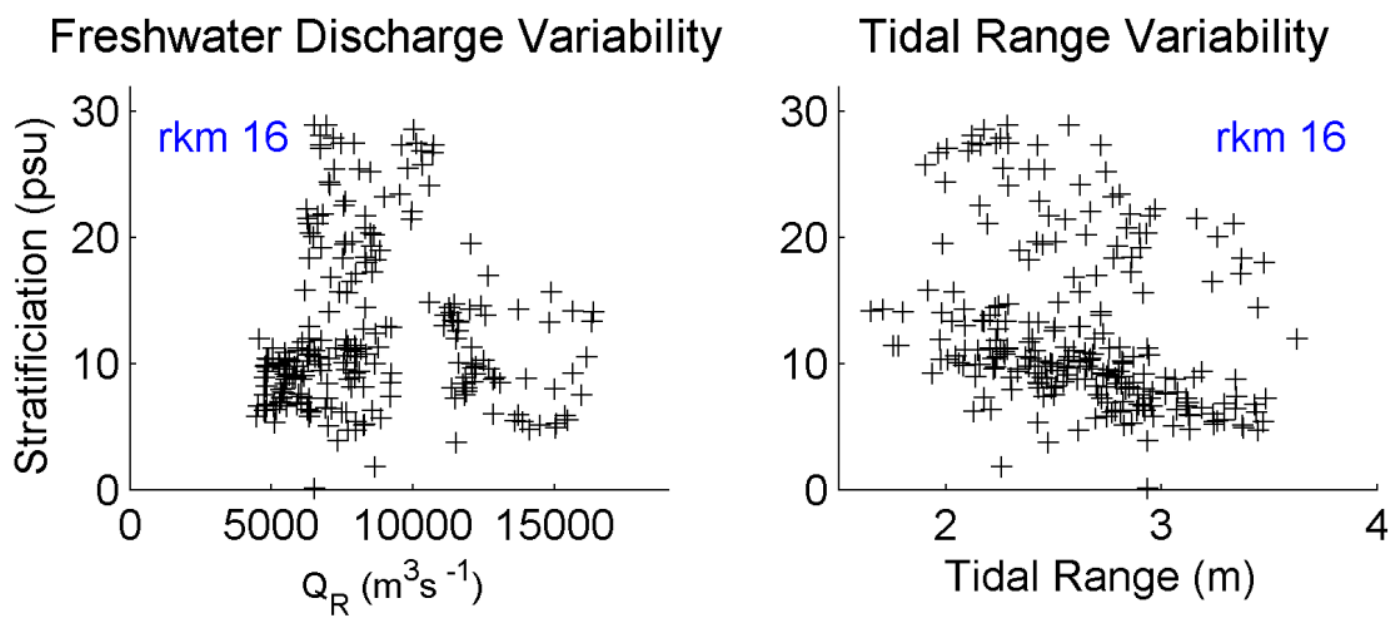

Figure 2.3.8 Daily averaged stratification in the North Channel measured at SAT1 (2008-2012). Its relationship to freshwater discharge (left) is unclear. Increased tidal range (right) serves to decrease stratification.

$\mathrm{X}_{\max }$ in the South Channel exhibits much greater variability than in the North channel, shifting from far upstream during low flows and neap tides to lower/midestuary during high flows and spring tides. We attribute this behavior to the fact that surface concentrations of sediment in the CRE have multiple sources-namely, the sediment load brought in from the river and local resuspension. Fluvial-sourced sediment increases during times of high river flow (Figure 2.3.6; Figure 2.3.7; Figure 2.3.9) but is always diluted as the river widens near rkm 50. Without local resuspension, as would occur during neap tides when decreased bed stress and the accompanying stratification inhibit vertical mixing in the lower \mid-estuary (Chawla et al. 2007; Figure 2.3.10), the fluvial source of sediment represents the 
maximum concentrations observed in the system (Figure 2.3.6; Figure 2.3.7). Similar mechanisms would also explain the seaward progression of $\mathrm{X}_{\max }$ with increasing river flow; notice that the South Channel at rkm 28 is most stratified during low river flows (Figure 2.3.10), and as a result surface turbidity there is lower than at upstream locations. When stratification weakens, local resuspension strengthens and $\mathrm{X}_{\max }$ moves downstream.

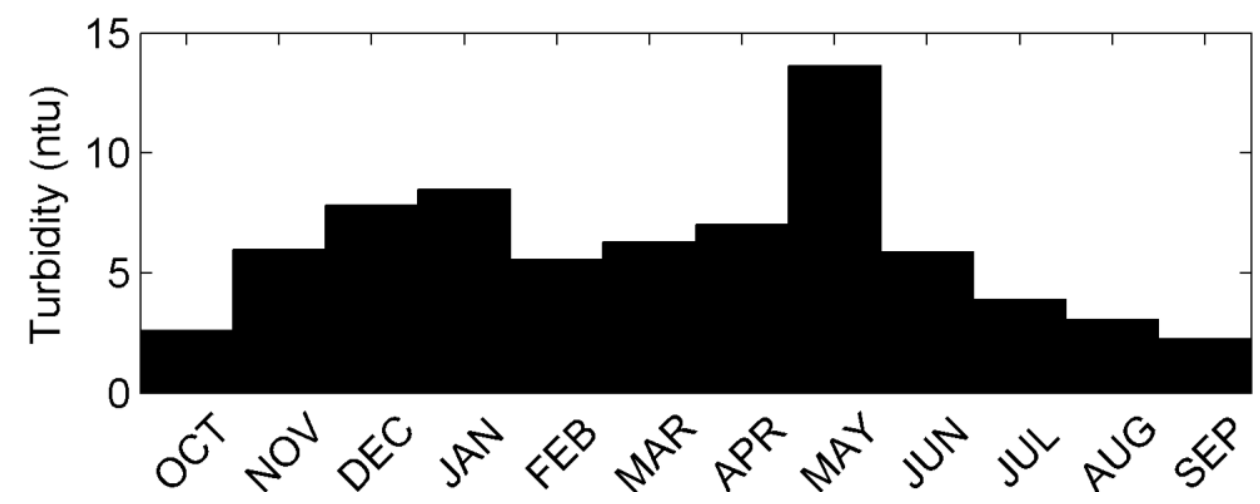

Figure 2.3.9. Monthly averaged turbidity at SAT5 (from 2010 to 2013), representing seasonal fluctuations in the fluvial source of turbidity to the CRE. Sediment loads brought into the system are largest during the spring and winter freshets.

The turbidity distribution has a paired response with the daily averaged salinity intrusion (derived using a least squares fit of hyperbolic tangent curve to CMOP data; table 2.1.2) that is related to river flow (Figure 2.3.11). As freshwater discharge increases, the salinity intrusion (marked by the 2 psu isohaline, $\mathrm{X}_{2}$ ) is pushed seaward, and $\mathrm{X}_{\max }$ follows. During high flows $\mathrm{X}_{\max }$ moves closer to $\mathrm{X}_{2}$ and the salinity field is compressed, and the local turbidity gradient increases. 

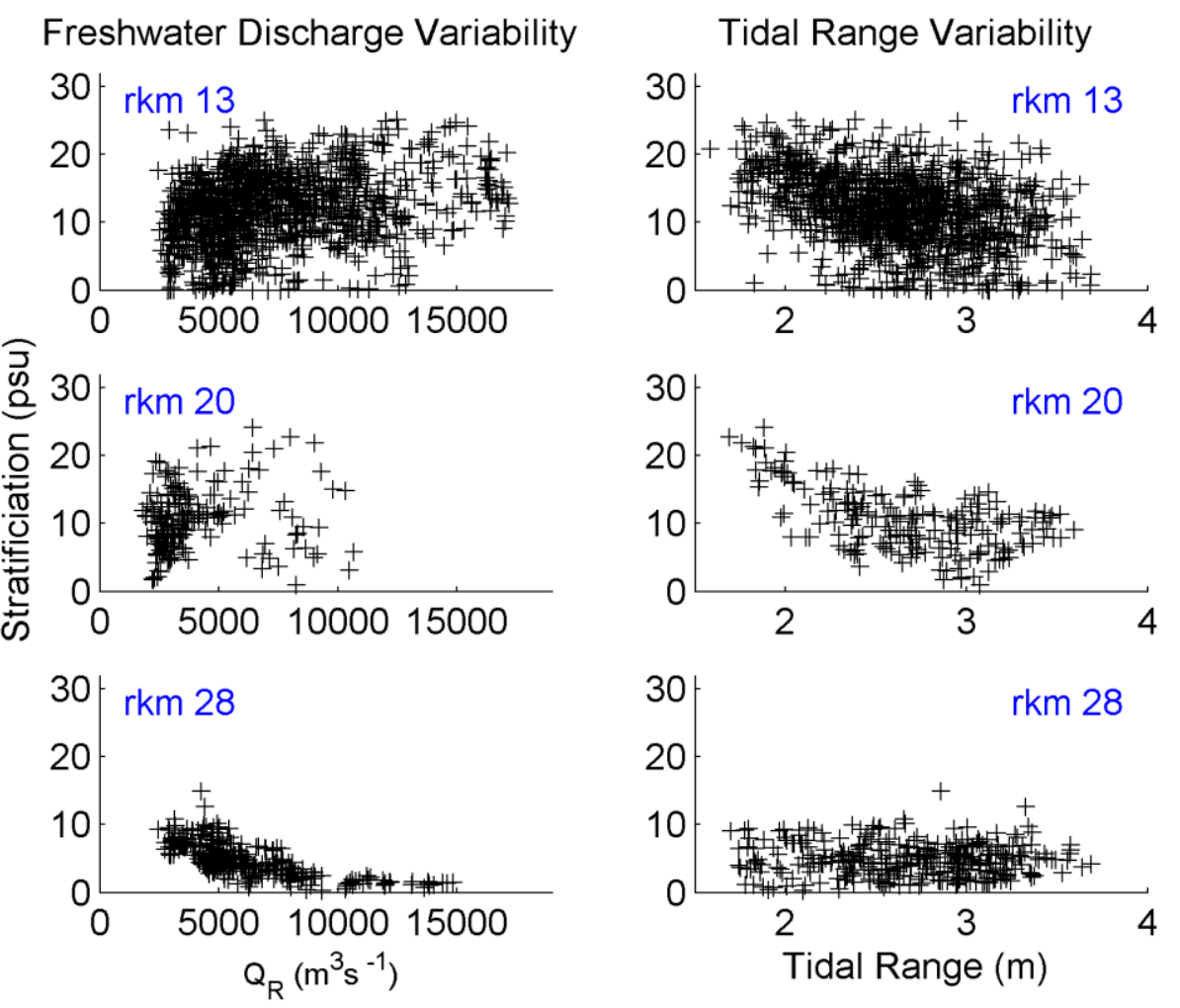

Figure 2.3.10. Daily averaged stratification (bottom - top salinity) behavior in the South Channel of the CRE. Fresh water discharge (left) serves to increase stratification in the lowerestuary but decreases stratification at mid-estuary. Increasing tidal range decreases stratification in the lower reaches of the system.

Talke et al. (2009) demonstrate that the turbidity distribution seaward of $\mathrm{X}_{\max }$ is controlled by the salinity field, and landward it is controlled by fluvial input. Since the relative strength of each is not always balanced asymmetry can develop in the turbidity distribution. The presence of bottom topographic features augment asymmetry (and may even lead to multiple turbidity maxima) by generating divergences in the mean flow and resulting sediment fluxes (Jay and Smith 1990a). These effects are prominent in the turbidity transects, particularly during high river flows when $\mathrm{X}_{\max }$ approaches a topographic depression at near the mouth. 

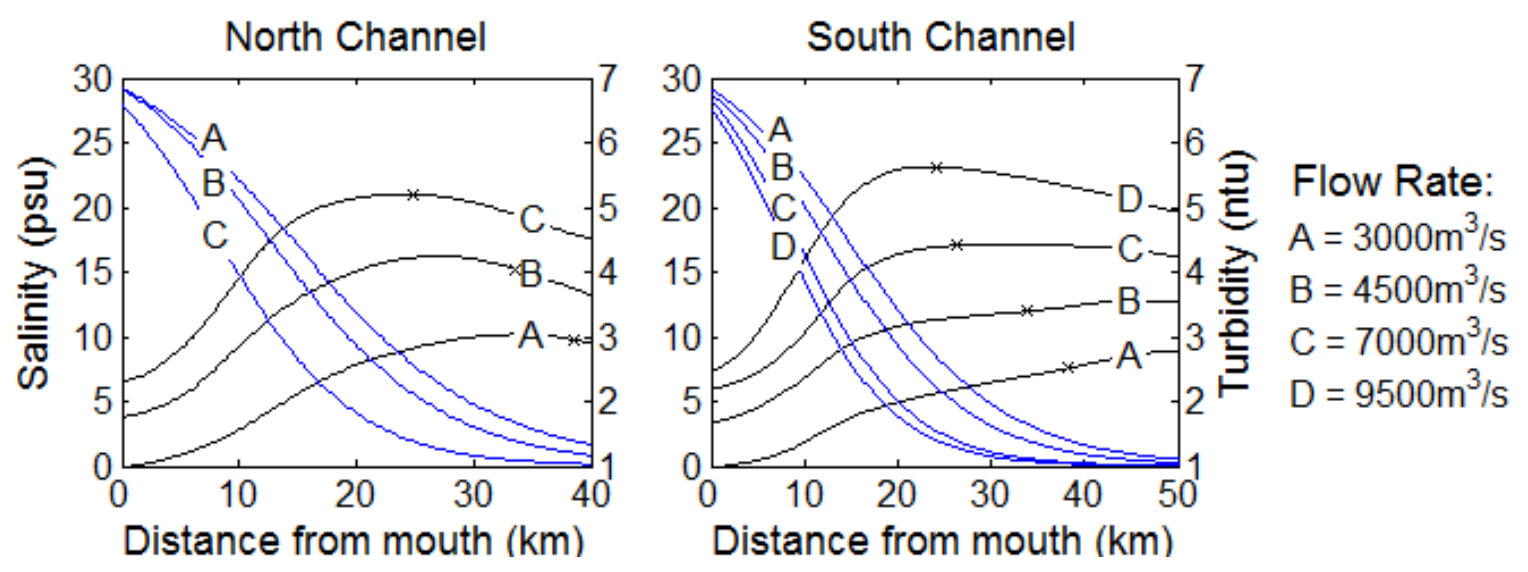

Figure 2.3.11 Turbidity (black) and salinity (blue) transects in the North and South Channels. $X_{2}$ is marked by an ' $x$ ' along the turbidity transects for reference.

The observational study outlined above confirms that satellites are a reliable platform by which to investigate spatial and temporal patterns of the turbidity field in the CRE. Observations agree with current knowledge about the system and suggest that the distribution of turbidity is a strong function of the tides and river flow. Observed turbidity distributions validate a central insight of the Talke et al. modelnamely, since the distribution of sediment downstream of $\mathrm{C}_{\max }$ scales with salinity intrusion and upstream of $\mathrm{C}_{\max }$ with river discharge, an asymmetric (non-Gaussian) sediment profile can develop. Channel bottom topography also appears connected to the shape of the turbidity distribution in the CRE. In the following chapter a theoretical approach is used to investigate the connection between bottom topography, estuarine circulation, and the turbidity distribution. 


\section{Chapter 3: Semi-Analytical Models}

The Navier-Stokes equations describe the hydrodynamics of an estuary. While exact solutions remain to be discovered, a simplified system of partial differential equations describing estuarine flow and mixing can be used to approximate the timeaveraged circulation in an idealized domain. Freshwater discharge and tidal properties define the primary circulation that serves to transport sediment throughout an estuary. Therefore, correctly representing circulation and transport processes requires consideration of various flow modes that result from these stimuli such as gravitational circulation and internal asymmetry circulation (ITAC). The following chapter outlines the formulation of a semi-analytical model describing these features and the sediment transport patterns and distributions that result. First the two dimensional mass and momentum conservation equations are solved for the coupled velocity and salinity fields along the channel. Vertical profiles are determined analytically and are then numerically integrated up the estuary to provide a full description of the laterally averaged flow dynamics. Although a fully analytical solution for the 2-D circulation exists, a numerical approach was used in this study, as it is more adaptable to arbitrary depth configurations. The resulting turbidity field is then calculated for various channel configurations to observe the effect of bottom topography on its distribution. 


\section{SECTION 1: The Tidally AVERAged Velocity FielD}

In this a semi-analytical model is developed from the momentum and massbalance equations following (Jay 2010). Here the main features of the model are outlined and the reader is referred to the appendix for more detail on its derivation and solution. The tidally-averaged velocity field that constitutes the estuarine circulation will be defined as the linear combination of the following residual modes: ITAC, gravitational circulation (exchange flow), and river flow (Figure 3.1.1). A perturbation approach is used to reach a solution for the velocity field, treating each residual mode separately under their own governing equations. The ITAC mode will be first, followed by the other two flow modes. We begin by defining the governing

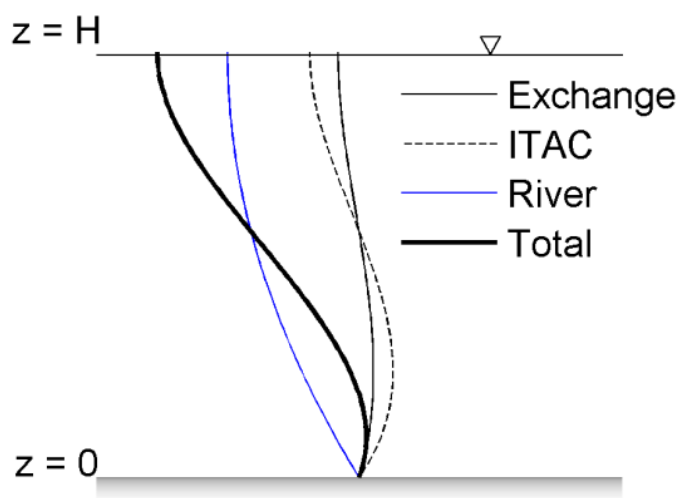
$(-)$

Figure 3.1.1 Residual Flow modes that constitute the model developed herein the following assumptions:

- The estuary is of constant width and assumed to be sufficiently narrow and straight such that lateral currents can be neglected and the flow can be represented in two dimensions.

- The domain is defined having the origin at the mouth of the estuary with $\mathrm{x}$ increasing landward, $\mathrm{z}$ originates at the bed increasing vertically.

- Depth is allowed to vary along the channel, as such numerical integration will be employed to propagate the vertical velocity profiles in the x-direction. 
- As in (Jay 2010) "non-accelerated"(i.e., steady) solutions are sought, omitting the local acceleration (time varying velocity) to simplify the analysis.

- Changes in cross-sectional area are gradual, and the ratio of the tidal amplitude to total depth is small such that residual convective accelerations may be neglected (Ianiello 1979).

- Turbulence is assumed to influence the velocity field primarily through vertical mixing—since shear stresses, which create turbulence, are greatest in this direction—and is parameterized using an eddy viscosity term, $\mathrm{K}$.

These assumptions greatly reduce the momentum and mass conservation equations for an incompressible fluid:

$$
\left.\begin{array}{c}
\rho\left(\frac{\partial \overrightarrow{\boldsymbol{V}}}{\partial t}+\overrightarrow{\boldsymbol{V}} \cdot \nabla \overrightarrow{\boldsymbol{V}}\right)=-\nabla P+\mu \nabla^{2} \overrightarrow{\boldsymbol{V}}+\overrightarrow{\boldsymbol{g}} \\
\nabla \cdot \overrightarrow{\boldsymbol{V}}=0
\end{array}\right\}
$$

(Where $\rho$ is the fluid density; $\vec{V}$ is the velocity vector in the $\mathrm{x}, \mathrm{y}$, and $\mathrm{z}$ directions; $\mathrm{P}$ is the pressure; the fluid viscosity is $\mu$; and $\vec{g}$ is gravity) into formulae that are analytically tractable and describe tidally-averaged fluid motion as the balance between pressure forces (surface slopes or salinity gradients) and turbulent mixing. The along-channel governing equations for the residual circulation are:

$$
\left.\begin{array}{c}
0=-\frac{\partial P}{\partial x}+\frac{\partial}{\partial z}\left(K \frac{\partial U}{\partial z}\right) \\
\frac{\partial U}{\partial x}+\frac{\partial W}{\partial z}=0
\end{array}\right\}
$$


Where $\frac{\partial P}{\partial x}$ is the along-channel pressure gradient, the eddy viscosity is $\mathrm{K}$; and $\mathrm{U}$ and $\mathrm{W}$ are the velocity components in the $\mathrm{x}$ and $\mathrm{z}$ directions, respectively. If we further assume the flow to be hydrostatic, the pressure term may be expressed as the sum of the surface slope and horizontal density gradient:

$$
\left.\frac{\partial P}{\partial x}=g \frac{\partial \zeta}{\partial x}+\frac{g}{\rho_{O}} \int_{z}^{H} \frac{\partial \rho}{\partial x} d z\right\}
$$

Where $\frac{\partial \zeta}{\partial x}$ is the along-channel surface slope; $\rho_{O}$ is the freshwater density; $\frac{\partial \rho}{\partial x}$ is the along-channel density gradient.

The residual velocity field described by (Equation 3.1.2) derives in part from non-linearity in the tidal flow (Jay 2010), and this fact should be considered under a framework of perturbation theory. This approach provides an analytical approximation to non-linear processes by representing the solution as an asymptotic expansion of a small parameter, $\varepsilon$, that appears naturally in the system (Neyfeh 1973). An O(1) process is assumed to dominate the physics of the system, which is then modulated by smaller $\mathrm{O}(\varepsilon)$ processes. The dependent variables are expanded in an infinite series of $\varepsilon$, each element of the series having a set of governing equations. Elements are assumed linearly independent such that they can be added together to approximate the non-linear dynamics of the system. Consider the horizontal velocity as an example:

$$
U=\sum_{i=0}^{\infty} \varepsilon^{i} U_{i}
$$


Where $\mathrm{U}$ is the velocity along the channel and the $\mathrm{i}^{\text {th }}$ summand corresponds to individual elements in the asymptotic series, increasing ad infinitum.

The model is developed under the assumption that the $\mathrm{O}(1)$ velocity field, $\mathrm{U}_{0}$, is the tidal flow and that ITAC is the only non-linear process significantly affecting $\mathrm{U}_{0}$. Mathematically the series takes the following form:

$$
U(x, z, t)=U_{T}(x, z, t)+\varepsilon_{I A} U_{I A}(x, z, t)+O\left(\varepsilon_{I A}^{2}\right)+\cdots \quad \text { (Equation 3.1.5) }
$$

Where $\mathrm{U}_{\mathrm{T}}$ is the tidal motion and $\mathrm{U}_{\mathrm{IA}}$ represents ITAC. The ellipses represent other non-linear processes not considered in the analysis (stokes drift, for example).

Perturbation parameters are estimated through a scaling exercise. The scaling, specified in (Jay 2010) for ITAC is adopted, which defines $\varepsilon_{I A}$ by the ratio of the vertical and horizontal density gradients:

$$
\varepsilon_{I A} \equiv \frac{\Delta \rho_{V}}{\Delta \rho_{H}}
$$

Here only the first element $(j=1)$ of the perturbation series is considered. Errors of the perturbation approximation are therefore assumed to be $\mathrm{O}\left(\varepsilon_{I A}{ }^{2}\right)$. An important restriction to this approach is that perturbations to the tidal flow must be small $(\varepsilon<<$ 1) so that truncation errors in each series are minimized. If perturbation parameters become too large (approaching the scale of tidal circulation) then additional elements must be considered to achieve similar accuracy. In this case, if the water column remains adequately mixed $\left(\varepsilon_{I A} \leq 1 / 3\right)$ errors of $\mathrm{O}\left(\varepsilon_{I A}{ }^{2}\right)$ are negligible.

In addition to the tidal flow and ITAC, this model considers the influences of gravitational circulation and the river flow. The governing equations for these flow 
modes are linear partial differential equations, and as such their solutions may be added together to approximate the full dynamics of the system:

$$
\left.\begin{array}{c}
U(x, z, t)=U_{T}(x, z, t)+ \\
\varepsilon_{I A}\left[\left\langle U_{I A}\right\rangle(f(x), z)+U_{I A_{O}}(x, z, t)\right]+O\left({\varepsilon_{I A}}^{2}\right)+\cdots \\
\left\langle U_{G}\right\rangle(f(x), z)+\left\langle U_{R}\right\rangle(f(x), z)
\end{array}\right\}
$$

Where $U_{G}$ is the gravitational circulation and $U_{R}$ is the velocity of the river. Angled brackets, $\langle\quad\rangle$, indicate residual variables. Note that the ITAC is composed of residual and overtide $\left(U_{I A_{O}}\right)$ parts. The residual flow modes, unlike the tidal flow, are not waves propagating through the estuary, so their along-channel variability, $f(x)$, relates to changes in cross-sectional area, vertical mixing, and tidal range.

Turbulent mixing is parameterized with an eddy viscosity, assumed to be vertically constant, to close the model. Although more sophisticated parameterizations of the eddy viscosity can be used, a vertically constant value was chosen to make the development of the various flow modes more straightforward. The eddy viscosity will be temporally variable with the tidal phase, defined using the ITAC perturbation parameter. Including harmonic eddy viscosity simulates ebb/flood tidal variability that is directly responsible for ITAC-recall that ITAC results from tidally-varying stratification and vertical mixing (see Chapter 1):

$$
K^{*}(t)=K_{O}\left(1+\varepsilon_{I A} e^{i(\omega t+\varphi)}\right)
$$


Where $K_{o}$ is the tidally-averaged eddy viscosity under neutrally stratified conditions; $\omega$ is the tidal frequency; time is $t$; and $\varphi$ is the phase difference between the tidal velocity and the eddy viscosity (assumed to be $180^{\circ}$ so that vertical mixing is largest at the end of flood and weakest at the end of ebb; $\mathrm{t}=0$ is defined at peak flood). $K_{O}$ will be defined using the depth, $\mathrm{H}$, Von Karman constant, $\kappa$, and the shear velocity, $u_{*}$ : $K_{O}=\kappa u_{*} H$. The shear velocity is defined using a drag coefficient, $\mathrm{C}_{\mathrm{d}}$, and the tidal velocity: $u_{*}=\sqrt{C_{d}} \bar{U}_{T}$.

The treatment of stratification and its effect on vertical mixing is important to properly represent along channel variability that is present in estuaries. Here a stratification correction is applied to $K^{*}$ following Jay and Musiak (1996):

$$
K(x, t)=K^{*}\left(1+3 R_{i g}\right)^{-1}
$$

Where $\mathrm{K}$ and $\mathrm{K}^{*}$ are the eddy viscosities under stratified and neutral conditions, respectively. The gradient Richardson number is used to characterize the effect of stratification on turbulent mixing:

$$
R_{i g}=\frac{\frac{g}{\rho_{O}} \frac{\partial \rho}{\partial z}}{\left(\frac{\partial U}{\partial z}\right)^{2}}
$$

A vertically constant eddy viscosity means the stratification correction must also be a constant, so the vertical median $R_{\text {ig }}$ was used. This parameterization is included in the model by first calculating the velocity and salinity fields using a neutral eddy viscosity. $R_{\text {ig }}$ and then $\mathrm{K}$ are determined, and the model is run again 
using the new value. Iteration continues until subsequent eddy viscosities converge, which was assumed when the root mean squared error between subsequent K's was less than $1 \mathrm{E}-10 \mathrm{~m}^{2} \mathrm{~s}^{-1}$, a value much less than typical values of $\mathrm{K}$, and beyond which further iteration exhibited a minimal effect on the model results.

Substituting (Equation 3.1.6) and (Equation 3.1.7) into (Equation 3.1.2a,b) gives rise to the governing equations for the tidal and residual flows (ITAC, gravitational circulation, and river flow). The total estuarine circulation formulates by solving each flow mode separately, and then adding their results. The final specification for a solution of the along-channel velocities is that of the boundary conditions, we use here a no-slip condition at the bed and an unstressed free surface:

$$
\left.U\right|_{z=0}=\left.0 \quad \frac{\partial U}{\partial z}\right|_{z=1}=0
$$

A summary of the model structure demonstrates the distinct origins of each flow mode (Figure 3.1.2). Note that each mode has its own a surface slope; the gravitational circulation is driven furthermore by the residual density field; and ITAC by the vertically uniform tidal frequency density field, and tidal variations in vertical mixing. All of these forcing mechanisms are balanced by the stress divergence (friction) generated by fluid movement of the respective flow mode. 


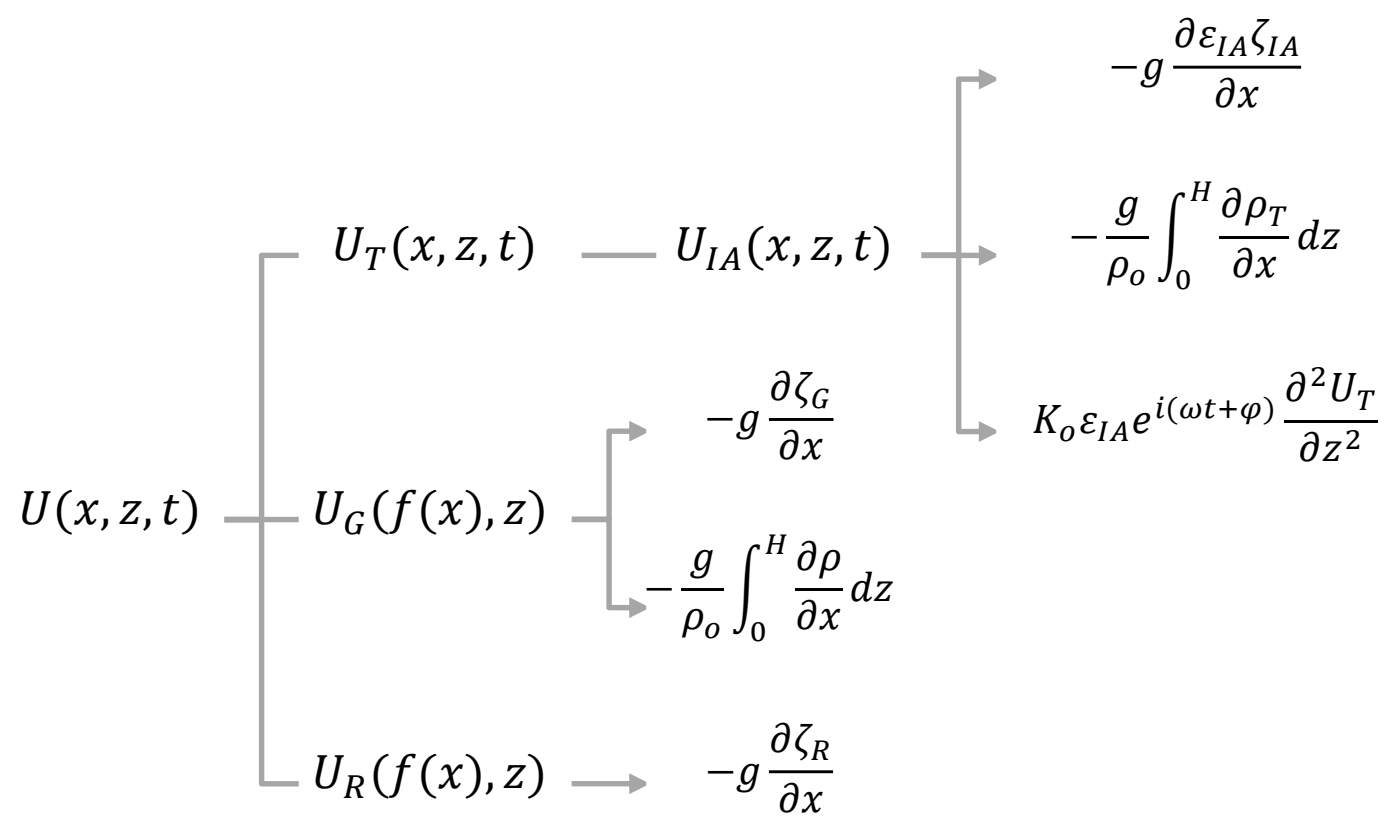

Figure 3.1.2. Model structure for the velocity field. Three components are considered to describe the residual flow: ITAC, Gravitational Circulation, and River Flow. Each component is driven by distinct forcing mechanisms.

Note that much of the velocity field depends on the state of the salinity field. In the following section equations describing the salinity field are developed. Before continuing, however, the vertical velocity structure is separated into the depthaveraged (denoted with an overbar) and depth-varying components (this will facilitate analysis of the salinity and turbidity fields):

$$
U(x, z)=\bar{U}(x)+U^{\prime}(x, z)
$$

The solution for the depth-averaged component is simply the depth-averaged river velocity. The depth-varying portion is the difference between the depthaveraged component and (Equation 3.1.6). 


\section{SECTION 2: THE SALINITY FIELD}

In this section the mathematical representation of the residual salinity field is introduced. Formulation of the governing equations and their solution follows the procedure of (MacCready 2004). Here the main features of the model are outlined and the reader is referred to the appendix for more detail on its derivation and solution.

The vertical profile of salinity is defined using the depth-averaged (overbar) and depth-varying (prime) components:

$$
S(x, z)=\bar{S}(x)+S^{\prime}(x, z)
$$

(Equation 3.2.1)

Mass conservation will be used to describe the salinity field. Following MacCready (2004) the governing equation for the depth-varying portion of the salinity field (the salinity defect) is a balance between shear induced stratification and vertical mixing:

$$
U^{\prime} \frac{\partial \bar{S}}{\partial x}=K \frac{\partial^{2} S^{\prime}}{\partial z^{2}}
$$

The depth-averaged portion of the salinity field is described by the integral salt balance:

$$
0=\bar{U} \bar{S}+\overline{U^{\prime} S^{\prime}}-K_{H} \frac{\partial \bar{S}}{\partial x}
$$

(Equation 3.2.7) states that salt flux in and out of the estuary is driven by the mean advection of salinity by the river flow (first term); the depth-average of the correlation between the velocity and salinity defects (second term); and horizontal dispersion (last term). 
Note that the salinity and velocity defects are functions of the residual, depthaverage salinity gradient. After substitution of these solutions, (Equation 3.2.7) becomes third-order algebraic equation in the depth-averaged salinity gradient and as such can be solved analytically for this variable at that location in the channel. The model is initialized with a seaward boundary condition where the bottom salinity is that of the ocean.

$$
\left.S^{\prime}\right|_{x=0, z=0}+\left.\bar{S}\right|_{x=0}=S_{O C N}
$$

This specification defines the depth average salinity at the seaward boundary as a function of the salinity defect and the gradient at the seaward boundary can then be found using (Equation 3.2.7). Following (MacCready 2004), the integral salt balance is then numerically integrated using an upwind finite differences scheme in order to propagate the solution for the salinity field along the channel:

$$
\left.\bar{S}\right|_{x+\Delta x}=\left.\bar{S}\right|_{x}+\left.\Delta x \frac{\partial \bar{S}}{\partial x}\right|_{x}
$$

Where $\Delta x$ is horizontal the grid spacing. (Equations 3.2.6-7) and (Equation 3.2.9) are iterated until the salinity field and its gradient are specified within the entire domain. With velocity and salinity fields specified, the resulting distribution of turbidity can now be examined. 


\section{SECTION 3: THE TURBIDITY FIELD}

The analysis that follows proceeds similarly as the salinity field and stems largely from the approach of (Talke et al. 2009). First the vertical structure of the turbidity is defined, as before, using depth-averaged and depth-varying components:

$$
C(x, z)=\bar{C}(x)+C^{\prime}(x, z)
$$

(Equation 3.3.1)

The turbidity field is defined similarly to salinity using mass conservation (Equation 3.2.2) including a sediment settling velocity ( $\mathrm{w}_{\mathrm{s}}$ ) in the vertical velocity term. Using scaling arguments (Talke et al. 2009), the vertical distribution of sediment is driven to first order by vertical turbulent mixing and the settling of sediment:

$$
\frac{\partial}{\partial z}\left(C w_{S}\right)+\frac{\partial}{\partial z}\left(K \frac{\partial C}{\partial z}\right)=0
$$

Assuming deposition equals erosion at the bed, zero turbidity flux at the surface, and integrating twice gives the following vertical turbidity profile:

$$
C=C_{b} e^{-P e z}
$$

Where $\mathrm{P}_{\mathrm{e}}$ is the sediment Peclet number, which scales the particle settling velocity to vertical mixing:

$$
P e=\frac{w_{S} H}{K}
$$

Integrating (Equation 3.3.3) from the bed to the surface gives the depthaveraged concentration: 


$$
\bar{C}=\int_{0}^{1} C_{b} e^{-P e z}=C_{b}\left[\frac{e^{-P e}}{-P e}+\frac{1}{P e}\right]
$$

Which can then be subtracted from (Equation 3.3.3) to give the depth-varying component:

$$
C^{\prime}=C_{b}\left[e^{-P e z}+\frac{e^{-P e}}{P e}-\frac{1}{P e}\right]
$$

We are now in a position to describe the global (along channel) structure of the turbidity field, which is driven by a balance between the freshwater discharge, the internal modes, and horizontal dispersion. In general freshwater input serves to push sediment out of the system while tidal processes push it back. Note that the same processes are driving the salinity field but the different vertical structure of each (particularly the tendency of sediment to collect near the bed) results in markedly different transport phenomena. Along with the condition of morhpodynamic equilibrium, which states that the vertically integrated transport of turbidity vanishes at each location in the domain (Talke et al. 2009), these processes can be described mathematically with the integral mass conservation equation. At steady state this is:

$$
0=\bar{U} \bar{C}+\overline{U^{\prime} C^{\prime}}-K_{H} \frac{\partial \bar{C}}{\partial x}
$$

To close the model the sediment concentration is constrained by the average sediment available for suspension in the domain:

$$
C_{*}=\frac{1}{L} \int_{0}^{L} C_{b}(x) d x
$$


Where $\mathrm{L}$ is the length of the channel. After substituting the forms defined above into (Equation 3.3.6) the turbidity can be determined throughout the domain as a function of the salinity field, velocity field, sediment concentration at the bed, and horizontal dispersion. The model is initialized with a boundary condition at the landward end of the system where the bed concentration is some arbitrary value found in the river:

$$
\left.C_{b}\right|_{x=L}=C_{\text {river }}
$$

With a boundary condition specified, the turbidity gradient at the landward boundary can be determined directly using (Equation 3.3.6). Note that (Equation 3.3.6) could be solved analytically to provide for an expression of the along channel sediment concentration provided that the width and depth of the channel are defined by a smooth function (e.g. exponential or geometric). For the purposes of this experiment, however, (Equation 3.3.6) is integrated numerically to allow for arbitrary depth configurations. Using an upwind scheme the sediment concentration at the next grid point downstream is defined using the bed concentration and its gradient at the previous cell:

$$
\left.C_{b}\right|_{x-\Delta x}=\left.C_{b}\right|_{x}-\left.\Delta x \frac{\partial C_{b}}{\partial x}\right|_{x}
$$

Note that here we subtract the gradient because the numerical integration proceeding in the negative x-direction. (Equation 3.3.6) and (Equation 3.3.8) are iterated until the turbidity field and its gradient are specified within the entire domain. 


\section{SECTION 5: RESULTS}

\section{THE COUPLED VELOCITY AND SALINITY FIELDS}

The internal modes demonstrate the classic cubic profile as described in (Hansen and Rattray 1965), except that this velocity profile is composed not only of gravitation circulation but also of ITAC driven by the time variability of vertical mixing (Figure 3.5.1). Although the shape of these two circulation modes is similar, distinct physical processes generate them. The total flow departs from the classical theory, having a greater surface velocity and a landward maximum that is closer to the bed, both a result of considering a parabolic river flow. Despite relatively low velocities near the bed a landward salt flux is still observed because the velocity and salinity defects are both positive-in fact a net residual landward flux of salt is observed at depth in the CRE even though the residual velocity field is primarily directly seaward (Jay and Smith 1990a).
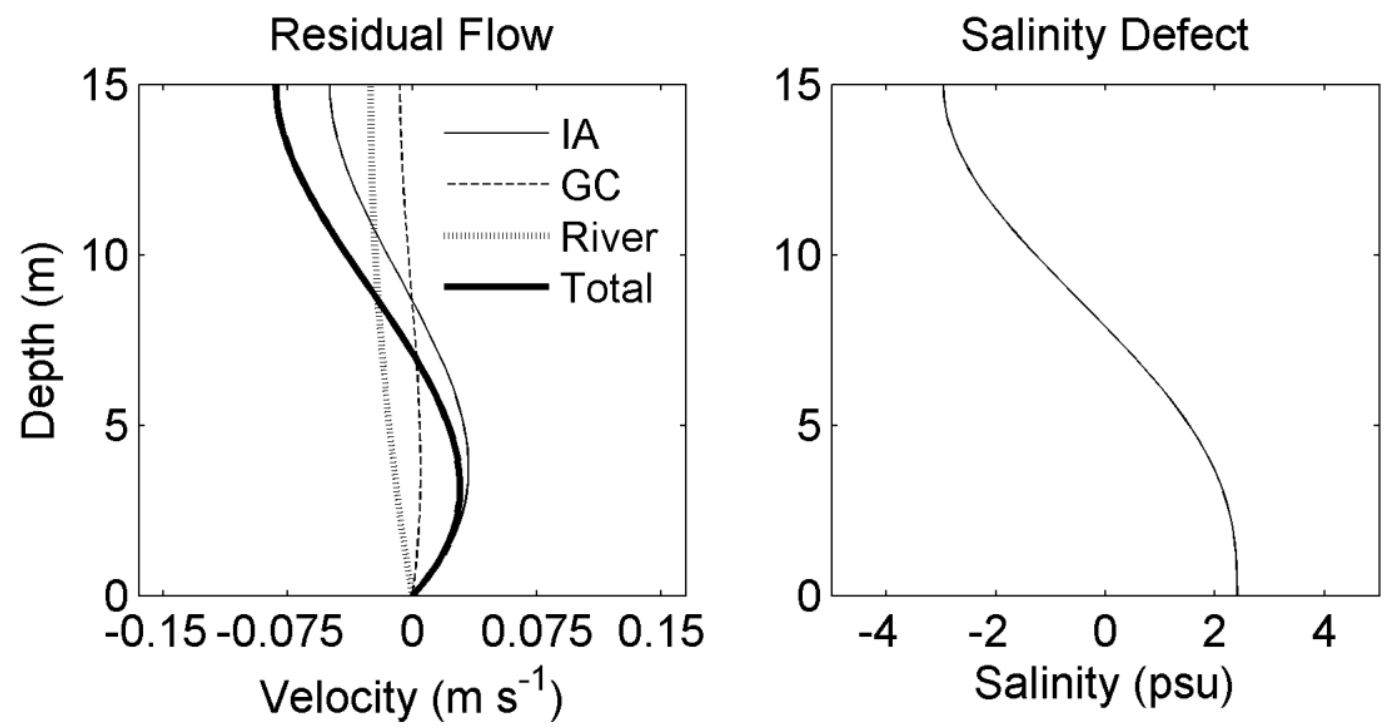

Figure 3.5.1. Example vertical profiles of the three residual circulation modes (left) and the resulting salinity defect (right).Profile taken $20 \mathrm{~km}$ from the mouth for constant depth channel, tidal velocity is $1 \mathrm{~ms}^{-1}, U_{R O}=0.05 \mathrm{~ms}^{-1}, H=15 \mathrm{~m}$. 
The distinct origins of gravitational circulation and ITAC highlight the importance of treating them separately in the formation of the total residual flow, because, as their separate scaling suggests, they react differently to bottom topography and to the state of the density field. Recall that different parts of the density field drive each mode-the tidal-frequency density appears in the equation for ITAC, and the residual density field in the equation for gravitational circulationso their behavior is not identical. Increasing depth serves to increase these residual flow modes, thereby increasing their local influence on the velocity fields and mass fluxes. However a comparison of the baroclinic scaling for each reveals that ITAC is more sensitive to the density field, and as such it will exhibit more variability in the domain, especially around topographic features where the density field is locally modulated:

$$
U_{G O} \pi_{G 2}=\frac{U_{G O} \Delta \rho_{H} g H^{2}}{L_{S} \rho_{O} \kappa u_{*} U_{G O}} \quad U_{O} \pi_{I A 3}=U_{O}\left(\frac{\Delta \rho_{H}{ }^{2} g H^{2}}{\Delta \rho_{V} \omega L_{S}{ }^{2} \rho_{O} \kappa u_{*}}\right)
$$

Under most estuarine conditions the ITAC scales greater than the gravitational circulation, except when horizontal density gradients are weak, , or stratification is considerable (Figure 3.5.2):

$$
\frac{U_{G O} \pi_{G 2}}{U_{O} \pi_{I A 3}}=\frac{\frac{\Delta \rho_{H} g H^{2}}{L_{S} \rho_{O} \kappa u_{*}}}{U_{O}\left(\frac{\Delta \rho_{H}^{2} g H^{2}}{\Delta \rho_{V} \omega L_{S}^{2} \rho_{O} \kappa u_{*}}\right)}=\frac{\Delta \rho_{V} \omega L_{S}}{U_{O} \Delta \rho_{H}}
$$


Figure 3.5.2 Ratio of the gravitational circulation scaling to that of ITAC as a function of vertical and horizontal salinity differences. ITAC dominates the gravitational circulation for most estuarine conditions, except in systems with weak horizontal density gradients and considerable stratification.

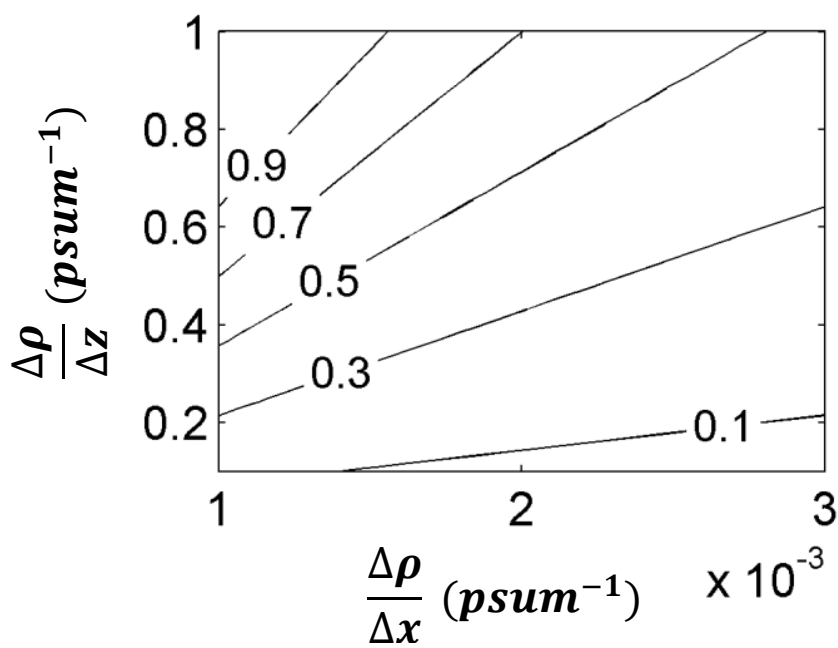

The scaling outlined above and in (Figure 3.5.2) suggests that although gravitational circulation and ITAC exhibit similar behavior their response to estuarine conditions are distinct and as such it is vital to treat them separately in the analytical model, especially if one wishes to investigate the effects of bottom topography on estuarine transport. Note that because ITAC greatly increases the residual circulation, more salt is transported into and sediment is trapped within the estuary; ITAC is critical for the maintenance of the salinity field and turbidity field. 


\section{$\underline{\text { THE TURBIDITY FIELD }}$}

Turbidity transects generated from the semi-analytical models demonstrate typical features observed in previous studies and the satellite data analyzed herein. Primarily they exhibit an asymmetrical Gaussian-like distribution, which is fundamentally a function of depth, freshwater discharge, and the tidal velocity. These characteristics all define vertical mixing and consequently mass transport throughout the system. Bottom topographic features modulate mass transport processes through interactions with the residual flow as described above, and thereby exert significant influence over the turbidity distribution.

To further understand the nature of how each mode of the residual flow-and their response to bottom topography—affects the turbidity distribution four experiments with different channel configurations were conducted. In Case I the channel was assumed flat with a depth of $15 \mathrm{~m}$ (this will be the control experiment), Case II and Case III were identical except for a local change in depth $(5 \mathrm{~m})$ modeled with a Gaussian curve to create a topographic high and low, respectively, at rkm 20. Case IV uses bottom topography that simulates that found in the CRE. In each case the horizontal dispersion $\left(\mathrm{K}_{\mathrm{H}}\right)$ was constant at $200 \mathrm{~m}^{2} \mathrm{~s}^{-1}$, a value consistent with those reported in estuarine systems (Fischer et al. 1979), and one that also generated a reasonable distribution of turbidity. Additional scaling used for the experiments are listed in Table 3.5.1. Simulations were performed under various tidal velocities holding river velocity scale constant at $0.05 \mathrm{~ms}^{-1}$, and similarly for variable river flow with a constant tidal velocity scale of $1.0 \mathrm{~ms}^{-1}$. 
Table 3.5.1 Scaling magnitudes used in model simulations

\begin{tabular}{|c|c|c|c|c|c|c|}
\hline $\mathrm{Ls}_{\mathrm{S}}(\mathrm{km})$ & $\omega\left(\mathrm{s}^{-1}\right)$ & $\mathrm{C}_{\mathrm{d}}$ & $\mathrm{K}_{\mathrm{H}}\left(\mathrm{m}^{2} \mathrm{~s}^{-1}\right)$ & $\mathrm{C}^{*}\left(\mathrm{gm}^{-3}\right)$ & $\mathrm{C}_{\text {river }}\left(\mathrm{gm}^{-3}\right)$ & $\mathrm{w}_{\mathrm{s}}\left(\mathrm{ms}^{-1}\right)^{*}$ \\
\hline 20 & $1.4 \mathrm{E}-4$ & $2.6 \mathrm{E}-3$ & 200 & 10 & 10 & $1 \mathrm{E}-3$ \\
\hline
\end{tabular}

*Surface sediment in the CRE typically has $\mathrm{w}_{\mathrm{s}}$ of $1 \mathrm{E}-3 \mathrm{~ms}^{-1}\left( \pm 5 \mathrm{E}-4 \mathrm{~ms}^{-1}\right)$, (Fain et al. 2001).

As suggested previously the role of local topographic features in maintaining the global turbidity distribution is extremely important. While the control experiment demonstrates features consistent with previous studies, those for Case II and Case III diverge from current theoretical frameworks (Figure 3.5.3). The turbidity distribution in Case II is bottom topographically trapped under nearly all estuarine conditions and $\mathrm{X}_{\max }$ is relatively insensitive to both tidal range and river flow. Distributions for Case III also experience bottom topographic trapping; $\mathrm{X}_{\max }$ appears upstream of the depression for most river and tidal velocities and at large values displaces far downstream to the location of the control experiment.
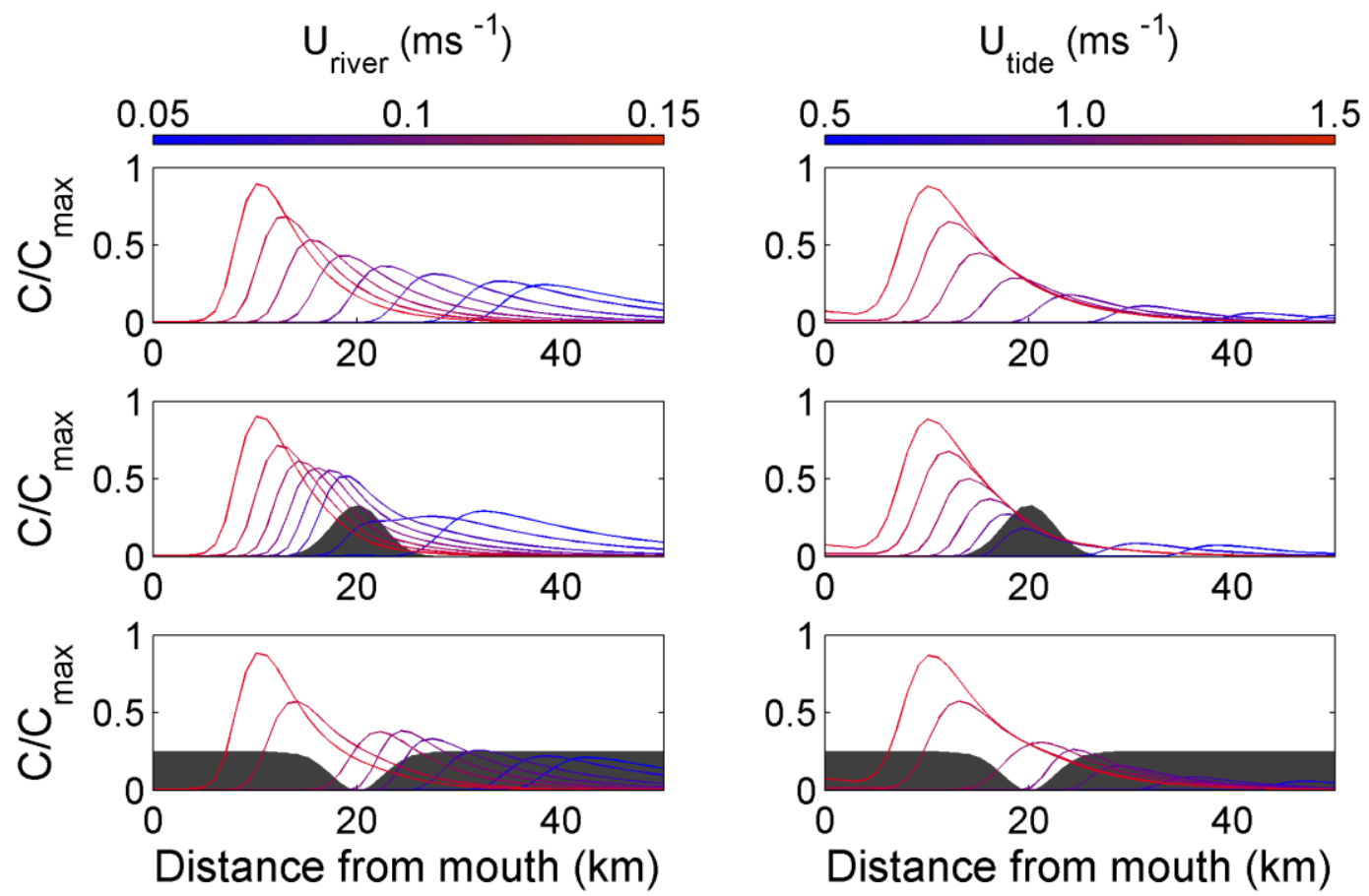

Figure 3.5.3. Surface turbidity transects during various river flow conditions (left) and stages of the neap/spring cycle (right) for domains with constant depth (top), topographic elevation (middle), and topographic depression (bottom). 
Behavior of the turbidity distributions can be interpreted by examining the fluxes of sediment in (Equation 3.3.6) throughout the domain. To reiterate, sediment transport in this model is a result of advection due to the river, the correlation between velocity and sediment defects (primarily a result of the internal modes), and horizontal dispersion. Local interactions of residual flow modes with bottom topography modify these fluxes resulting in the distinct turbidity distributions for each case.

Topographic highs inhibit saltwater from advancing into the system, both as a result of strengthened saline flux caused by increased river velocity over the bump as well as a reduction in landward fluxes from ITAC and gravitational circulation due to the decreased depth. They also serve to intensify baroclinic pressure gradients on their downstream slope, again due to associated increases in the river velocity. Sediment fluxes react accordingly with greater advective fluxes near the bump, an increase in internal mode fluxes downstream, and larger dispersion throughout due to elevated turbidity gradients (Figure 3.5.4). The turbidity field reflects this response with noticeable displacement downstream and a local compression in its distribution on either side of $\mathrm{X}_{\mathrm{max}}$.

Interpreting the effects of a topographic low can be made in a similar manner. In this case, salinity intrusion is promoted due to a divergence in the river flow and an increase of landward mass fluxes, both a result of the increased depth. Elevated internal mode fluxes persist in the turbidity field near the feature and $\mathrm{X}_{\max }$ is displaced landward. 

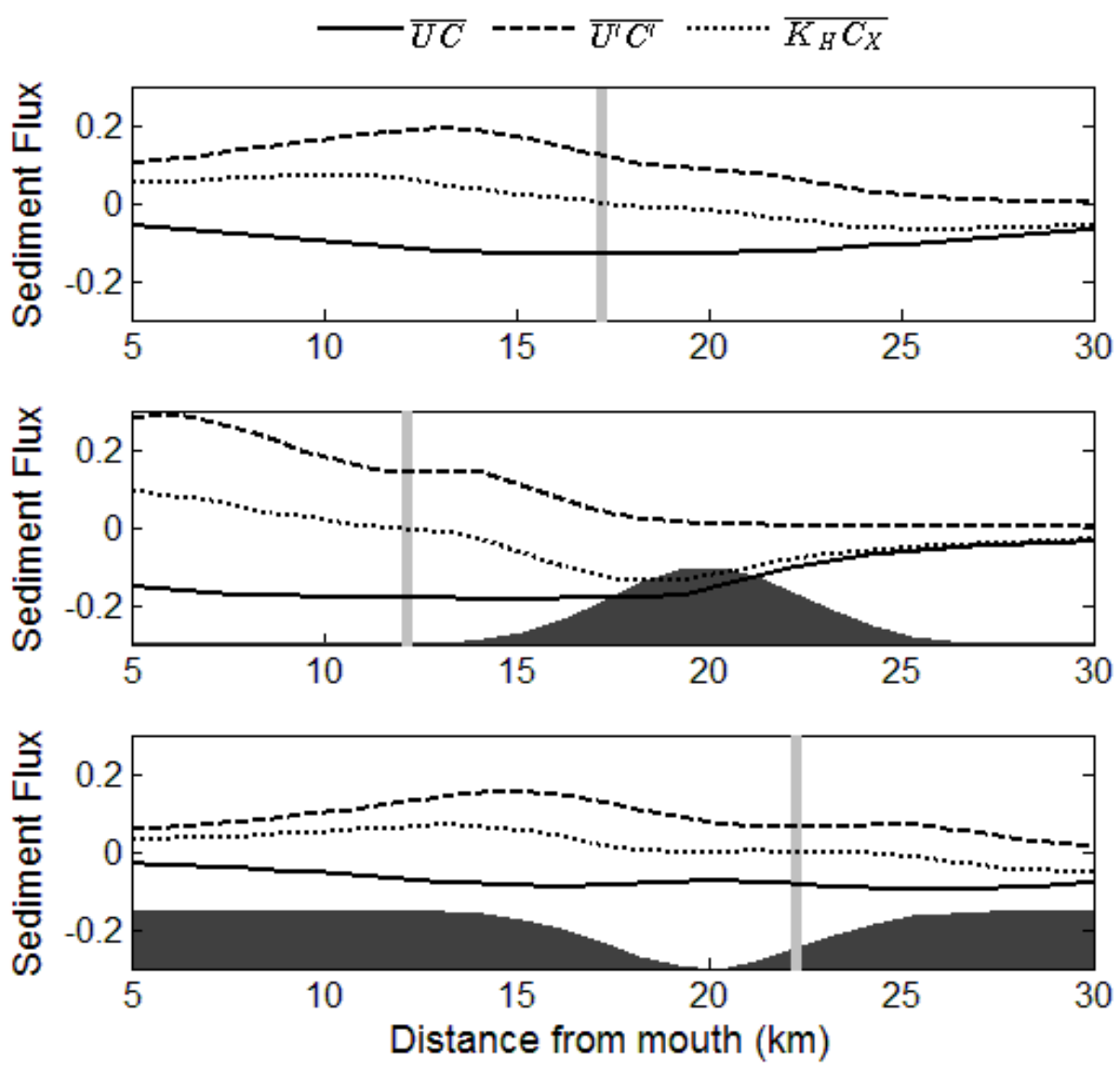

Figure 3.5.4 Sediment fluxes $\left[\mathrm{gm}^{-2} \mathrm{~s}^{-1}\right]$ and $X_{\max }$ location (grey line) for the three cases during $U_{\text {river }}=-0.075 \mathrm{~ms}^{-1}$ and $U_{\text {tide }}=1 \mathrm{~ms}^{-1}$ (see Figure 3.5.4). Disparities between advective and internal mode fluxes lead to the interesting differences observed in the turbidity distribution.

Studying the fluxes of sediment in each experiment clarifies the important role that the salinity field plays in creating the distinct turbidity distributions near bottom topographic features. In fact, much of the variability observed between the three cases is due to disparities in baroclinic pressure gradients. Once the river influence has increased enough such that the salinity field no longer resides near the topographic feature, turbidity distributions approach the state of the control run. Therefore distributed features that exist throughout the domain, rather than at one point, should have a greater influence on the turbidity field, as is observed in Case IV (Figure 3.5.5). 

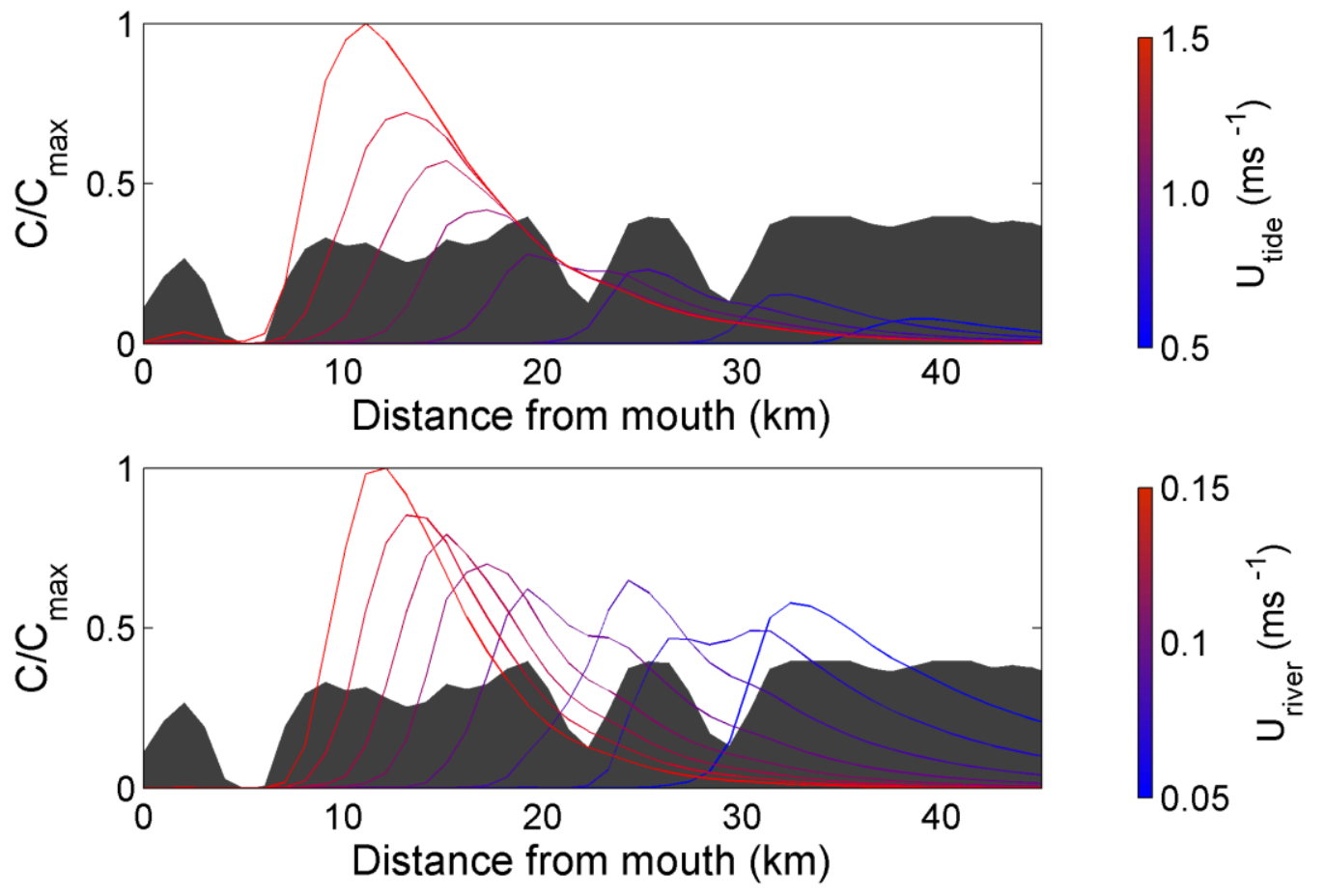

Figure 3.5.5. Surface turbidity transects during various stages of the spring/neap cycle (top) and river flow conditions (bottom). More complicated bottom topography mimicking that found in the CRE produces distributions that approach those of the observed transects.

Through interactions with the estuarine circulation as discussed above, the irregular bottom topography of the CRE, as simulated in Case IV, creates many interesting local features in the turbidity field as well as controls the global nature of its distribution. Multiple turbidity maxima even exist within a limited parameter space (Figure 3.5.6), providing a possible explanation for some of the 'noise' observed in the satellite turbidity transects. The distributions also agree qualitatively with those obtained in Chapter 2 qualitatively, in that $X_{\max }$ moves seaward due to increasing tidal velocities and river flow, but does not exceed $\sim$ rkm 10 . 
Figure 3.5.6. Turbidity maxima occurrences as a function of river flow and tidal velocity. Topographic lows cause a local divergence in sediment fluxes, which results in multiple maxima. The bottom topography of the CRE has multiple lows resulting in multiple maxima.

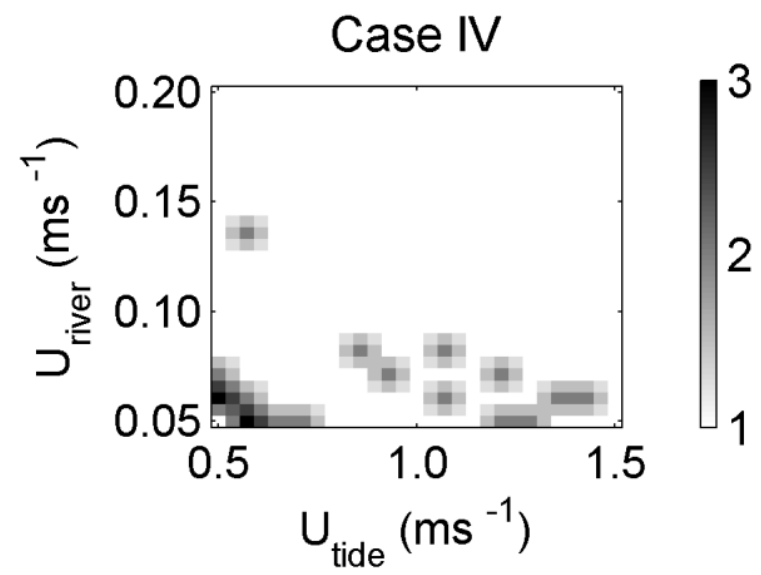

Note while the model qualitatively explains features observed in the data (tidal and river flow dependence; bottom topographic trapping; etc.) modeled distributions do not follow strictly the same pattern. An important distinction between the remotely derived transects and the analytical model is that satellite measurements depict a random, rather than tidal, average of the turbidity field. Simplifying assumptions employed in creating the model also lead to discrepancies. For example, here the sediment concentration at the landward boundary, Criver, the sediment settling velocity, $\mathrm{w}_{\mathrm{s}}$, and the average bed concentration, $\mathrm{C}^{*}$, were constant. In reality, increasing river flow would serve to transport more material into the system, and seasonal and tidal variability in the velocity field would lead to differential deposition and erosion altering the composition of bed and source material. In addition, the assumption of a vertically constant eddy viscosity, the neglect of lateral circulation, convective accelerations, wind, stokes drift, and many other processes that can affect the turbidity field ultimately weaken the predictive capability of the model. Nevertheless the model does provide valuable insight into 
how the turbidity field responds to bottom topography and serves as a reasonable starting point for future investigations.

Beyond altering the shape of and creating multiple maxima in the turbidity field, what other affects does bottom topography have on its distribution? As discussed above, these features can serve to amplify or dampen landward mass fluxes implying that they have an influence on sediment export from the estuary to the ocean, which is exactly what the model suggests. The existence of multiple topographic depressions that successively enforce internal flow modes in the CRE serves to guarantee the existence of ETM in the system under a greater range of estuarine conditions (Figure 3.5.7). For example, if we assume that $\mathrm{X}_{\max }$ values less than $5 \mathrm{~km}$ imply flushing of the turbidity maxima then during spring tide the ETM remains within the system up to $0.2 \mathrm{~ms}^{-1}$ in the CRE simulations and only $0.14 \mathrm{~ms}^{-1} \mathrm{in}$ the other three cases.
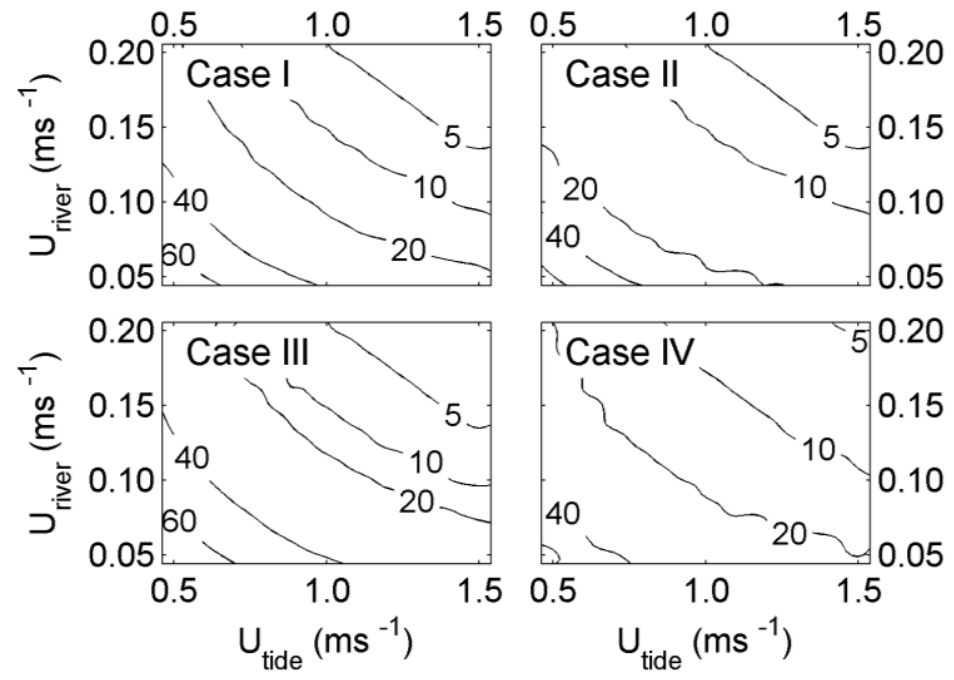

Figure 3.5.7. Location of turbidity maximum (measured as the distance in kilometers from the estuary mouth) as a function of river flow and tidal velocity for each experiment. Topographic highs reduce sensitivity to each forcing variable, the lows drive turbidity maxima upstream as a result of increased landward flux. 
Exercises such as those described herein begin to illuminate the dynamic nature of the turbidity field and although an exhaustive investigation was not carried out, the importance of bottom topography in maintaining distinctive features of the sediment distribution and transport is clear. As suggested in previous studies, convergence/divergence in the residual circulation has direct consequences on transport and subsequently the distribution of suspended material. The theoretical approach outlined in this chapter brings to light some of the physical mechanisms that drive the spatial and temporal variability observed in satellite-based measurements of the turbidity field. A synthesis of these two approaches has certainly proven useful in studying estuarine circulation related phenomena in the CRE. Applications, however, are not merely limited to this system but may be transferred to other estuaries to gain insight into their own spatial and temporal variability, particularly those that have been historically under sampled in which satellite data could form the longest lasting record of transport processes. 


\section{CHAPTER 4: DisCUSSION/CONCLUSION}

In this study satellite-based surface reflectance measurements and in situ data were used to gain insight into estuarine circulation and transport processes in the Columbia River Estuary (CRE). Satellite data was useful in this regard because measurements span a considerable timeframe ( $\sim 13$ years), and were thereby able to formulate a climatology of turbidity in the system. In addition, the synoptic nature of satellite observations permitted examination of the entire structure of the turbidity field and how it responds to different estuarine conditions. A semi-analytical 2-D model of the circulation and resulting turbidity distribution was developed in order to investigate this response further. Together, the observational and theoretical approaches were used to answer the following questions:

1. Can we calibrate satellite-based surface reflectance measurements to in-situ turbidity measurements in the CRE, and use the results to monitor turbidity?

2. What spatial and temporal signals exist in the turbidity field and how do they relate to different estuarine conditions?

3. How does bottom topography affect the along-channel distribution of turbidity, and what physical mechanisms are responsible?

A least squares regression between in situ measurements of turbidity and remote surface reflectance demonstrated that MODIS can estimate with useful accuracy the surface turbidity at multiple locations in the system. Using these 
estimates, river flow revealed to be the dominant processes driving sediment transport followed by tidal velocity differences associated with the neap/spring cycle. Wind was of negligible influence except in the shallow peripheral bays where wind waves can be a dominant process in the transport of material, as has been suggested to be the case in the CRE. Seasonal variability of these forcing variables prompts the notion that turbidity in the estuary also has a temporal signal, which is confirmed with monthly averaged estimates throughout the system. Maximum values were observed during the winter months when supply is greater and persists during the spring freshet while high river flows are maintained; annual minimums were observed during late summer. Although magnitudes of turbidity fluctuated greatly during the year, general features of its spatial distribution were more consistent.

Remotely estimated turbidity transects along the two main channels were examined to detail how the structure of the turbidity field changes under various estuarine conditions. These transects promoted a more fundamental interpretation of the processes that control the turbidity field because previous studies of ETM could be used to develop a theoretical framework by which to explain its various features. Transects resembled an asymmetric Gaussian-like distribution whose shape was a function of the flow and tidal regime. The behavior was distinct in each channel. Although distributions in the North Channel responded to river and tidal conditions, the ETM location itself was rather rigid. That in the South Channel was more variable with steep turbidity gradients often in the lower-estuary. The unique behavior of these distributions, along with the complex nature of bottom topography in the CRE, 
implies a link between the two-namely because topographic depressions, which are prevalent along both channels, locally enforce the internal circulation modes that cause landward fluxes of sediment.

The model developed herein supports the hypothesis that bottom topographic features trap turbidity and control the shape of the turbidity field. Here the residual circulation composed of gravitational circulation, ITAC, and river flow exhibited variations in sediment fluxes near topographic features, which caused corresponding disparities in the turbidity field when compared to a system without bottom topographic features. Topographic elevations restricted movement of the ETM location and compressed the distribution of turbidity; depressions restricted movement to a lesser degree but were capable of generating multiple turbidity maxima.

While the bottom topography helped produce and maintain the features observed in the turbidity distribution, it is extremely important not to discount the vital role of ITAC in controlling the turbidity field in energetic systems like the CRE. Aided by the many topographic depressions in the CRE, ITAC serves to trap most of the sediment even under the largest of river flows (Jay and Musiak 1994). A number of previous studies examining estuarine circulation have chosen to neglect the role of ITAC, using gravitational circulation to account for both internal modes. Despite reaching reasonable results, in some cases these models undermine the physics that drive the very processes they were developed to study and are nothing more than a fitting exercise, using mixing parameterizations as tunable variables. Inclusion of 
ITAC herein helps guarantee a more realistic response of the turbidity field to tidal and fluvial processes and to bottom topographic features. A more realistic representation of the eddy viscosity, including non-linear tidal asymmetry and 3D processes, including multiple sediment size classes, and other factors are required for a fully realistic representation of the physics. Nonetheless, the first order agreement between the simple model and satellite results is encouraging.

The results of this study are not confined to the CRE. Many of the transport processes seen in the system are shared with other estuaries, and therefore interpretations based on the river and tidal regimes, bottom topography, and their effect on sediment fluxes that define the transport and turbidity field applies universally. As such, the lessons learned here serve to advance the fundamental understanding of estuarine transport.

A coupled approach using satellite measurements and theoretical models presents an unprecedented opportunity to further understand the various mechanisms that control ecosystem processes in estuaries. Here, the focus was on the transport features associated with suspended sediment using a simple analytical model but other avenues exist. Numerical modeling of the three-dimensional circulation would prove to shed further light on the subject because here we assumed a 2-D domain and the CRE and the nature of its transport certainly are not. Nonetheless, a fully 3D model cannot as easily discern the influence of individual forcing mechanisms such as ITAC and river flow, as explored here. Furthermore, analyses beyond the distribution of turbidity can be explored by examining other 
water quality parameters such as temperature and chlorophyll-a, which would provide further insight into circulation behavior and more importantly a direct assessment of ecosystem health and function. These examples summarize merely a few possibilities but one thing is clear: satellite data have remarkable potential to change the way we measure, monitor, and understand how estuaries behave. Perhaps, when used in conjunction with theoretical and other measurement-based approaches, they will also serve to help protect important habitat functions and aid with regional management of such ecosystems. 


\section{REFERENCES}

Bricaud, Annick. André Morel, Louis Prieur. (1981). Absorption by dissolved organic matter of the sea (yellow substance) in the UV and visible domains. Limonl. Oceaonogr., 26 p. 43-53.

Bricaud, Annick. Marcel Babin, André Morel, Herve Claustre. (1995). Variability in the chlorophyll-specific absorption coefficients of natural phytoplankton: Analysis and parameterization. Journal of Geophysical Research, 100(C7) p. 13,321-13,332.

Buiteveld, H. (1994). The optical properties of pure water. SPIE 2258 p. 174-183.

Chawla, Arun. David A. Jay, Antonio M. Baptista, Michael Wilkin. Charles Seaton. (2007). Seasonal variability and estuary-shelf interactions in circulation dynamics of a river-dominated estuary. Estuaries and Coasts, 31(2) p. 269-288. doi:

10.1007/s12237-007-9022-7.

Zhiqiang, Chen. Chuamin Hu, Frank Muller-Karger. (2006). Monitoring turbidity in Tampa Bay using MODIS/Aqua 250-m imagery. Remote Sensing of Environment, 109 p. 207-220.

Doxaran, David. Jean-Marie Friodefond, Patrice Castaing. (2003). Remote-sensing reflectance of turbid sediment-dominated waters. Reduction of sediment type variations and changing illumination conditions effects by the use of reflectance ratios. Applied Optics, 42 p. 2623-2634.

Doxaran, David. Patrice Castaing, S.J. Lavender. (2006). Monitoring the maximum turbidity zone and detecting fine-scale turbidity features in the Gironde estuary using high spatial resolution satellite sensor (SPOT HRV, Landsat ETM+) data. International Journal of Remote Sensing, 27 p. 2303-2321.

Doxaran, David. Jean-Marie Friodefond, Patric Castaing, Marcel Babin. (2009). Dynamics of the turbidity maximum zone in a macrotidal estuary (the Gironde, France): Observations from field and MODIS satellite data. Estuarine, Coastal and Shelf Science, 81 p. 321-332. doi:10.1016/j.ecss.2008.11.013.

Fain, Annika M. V., David A. Jay, Doug J. Wilson, Phil M. Orton, Antonio M. Baptista. (2001). Seasonal and tidal monthly patterns of particulate matter dynamics in the Columbia River Estuary. Estuaries. 24 p. 770-786.

Fischer, Hugo B. E. John List, Robert C. Y. Koh, Jörg Imberger, Norman H. Brooks. (1979). Mixing in inland and coastal waters. Academic Press.

Geyer, W. Rockwell. (1993). The importance of suppression of turbulence by stratification on the estuarine turbidity maximum. Estuaries, 16 p. 113-125. 
Hansen, D. V. and M. Rattray, Jr. (1965) Gravitational circulation in straits and estuaries. J. Mar. Res. 23 p. 104-122.

Hickey, B. M., et al. (2010), River Influences on Shelf Ecosystems: Introduction and synthesis. J. Geophys. Res., 115. C00B17, doi: 10.1029/2009JC5452

Horner-Devine, Alexander R. David A. Jay, Phillip M. Orton, Emily Y. Spahn. (2009). A conceptual model of the strongly tidal Columbia River plume. Journal of Marine Systems, 78 p. 460-475. doi: 10.1016/j.jmarsys.2008.11.025

$\mathrm{Hu}$, Chuanmin. Zhiqiang Chen, Tonya D. Clayton, Peter Swarzenski, John C. Brock, Frank E. Juller Karger. (2004). Assessment of estuarine water-quality indicators using MODIS medium-resolution bands: Initial results from Tampa Bay, FL. Remote Sensing of Environment, 93 p. 423-441. doi: 10.1016/j.res.2004.08.007.

Hughes, F. W. and M. Rattray Jr. (1980) Salt flux and mixing in the Columbia River Estuary. Estuarine and Coastal Marine Science, 10 p. 479-493.

Ianniello, John P. (1979). Tidally Induced Residual Currents in Estuaries of Variable Breadth and Depth. Journal of Physical Oceanography, 9 p. 962-974.

Jay, David A. (1991). Green's Law Revisited: Tidal long-wave propagation in channels with strong topography. Journal of Geophysical Research, 96 p. 20,58520,598 .

Jay, David A. (2010). Estuarine Variability. Contemporary Issues in Estuarine Physics. 1 p. 62-99.

Jay, David A. Benjamin S.Giese, Christopher R. Sherwood. (1990) Energetics and sedimentary processes in the Columbia River Estuary. Progress in Oceanography, 25 p. 157-174.

Jay, David A., J. Dungan Smith. (1990a). Circulation, density distribution and neapspring transitions in the Columbia River Estuary. Progress in Oceanography, 25 p. 81-112.

Jay, David A., J. Dungan Smith. (1990b). Residual circulation in shallow estuaries 1. Highly stratified, narrow estuaries. Journal of Geohpysical Research, 95 p. 711-731.

Jay, David A., J. Dungan Smith. (1990c). Residual circulation in shallow estuaries 2. Weakly stratified and partially mixed, narrow estuaries. Journal of Geohpysical Research, 95 p. 733-748. 
Jay, David A., Jeffery D. Musiak. (1994). Particle Trapping in estuarine tidal flows. Journal of Geophysical Research, 99 p. 20,445-20,461.

Jay, David A., Jeffery D. Musiak. (1996). ITAC in channel flows: Origins and consequences. Coastal and Estuarine Studies, 50 p. 211-249.

Jay, David A., Philip M. Orton. Thomas Chishom. Douglas J. Wilson. Annika M. V. Fain. (2007). Partical trapping in stratified estuaries: consequences of mass conservation. Estuaries and Coasts, 30 p.1095-1105.

MacCready, Parker. (2007). Estuarine Adjustment. Journal of Physical Oceanography, 37 p. 2133-2145. doi: 10.1175/JP03082.1

Maritorena, Stéphane. David A. Siegel, Alan R. Peterson. (2002). Optimization of semianalytical ocean color model for global-scale applications. Applied Optics.

Naik, Pradeep K. David A. Jay. (2005). Estimation of Columbia River virgin flow: 1879 to 1928. Hydrol. Process., 19 1807â€“1824. doi: 10.1002/hyp.5636.

Naik, Pradeep K. David A. Jay. (2010). Human and climate impacts on Columbia River hydrology and salmonids. River Research and Applications, 27 p.1270-1276. doi: $10.1002 /$ rra.1422.

Naik, Pradeep K. David A. Jay. (2011). Distinguishing human and climate influences on the Columbia River: Changes in mean flow and sediment transport. Journal of Hydrology, 404 p. 259-277. doi: 10.1016/j.jhydrol.2001.04.035.

Neyfeh, Ali (1973). Perturbation Methods. Pure and Applied Mathematics, WileyInterscience Publication.

Palacios, L. Sherry. Tawnya D. Peterson, Raphael M. Kudela. (2009). Development of synthetic salinity from remote sensing for the Columbia River Plume. Journal of Geophysical Research, 114C00B05. doi:10.1029/2008JC004895.

Schippers, Robert (2007). 'The Impact of Variations in Turbulent Mixing on the Formation of Tidally Averaged Estuarine Flow'. Master's Thesis, University of Utrecht.

Sherwood, Christopher R. David A. Jay, R. Bradford Harvey, Peter Hamilton, Charles A. Simenstad. (1990). Historical changes in the Columbia River Estuary. Progress in Oceanography, 25 p. 299-352.

Siegel, D. A. S. Maritorena., N. B. Nelson, M. J. Behrenfeld, C. R. McClain. (2005). Colored dissolved organic matter and its influence on the satellite-based 
characterization of the ocean biosphere. Geophysical Research Letters, 32 L20605. doi:10.1029/2005GL024310.

Simenstad, Charles A. Lawrence F. Small, C. David McIntire. (1990). Consumption processes and food web structure in the Columbia River Estuary. Progress in Oceanography, 25 p. 271-297.

Simenstad, Charles A. Lawrence F. Small, C. David McIntire, David A. Jay, Christopher Sherwood. (1990). Columbia River Estuary studies: An introduction to the estuary, a brief history, and prior studies. Progress in Oceanography, 25 p. 1-13.

Simpson J. H., J. Brown, J. Matthews, G. Allen. (1990). Tidal straining, density currents, and stirring in the control of estuarine stratification. Estuaries, 13 p. 125132.

Snyder, William A. Robert A. Arnone, Curtiss O. Davis, Wesley Goode, Richard W. Gould, Sherwin Ladner, Gia Lamela, William J. Rhea, Robert Stavn, Michael Sydor, Allen Weidemann. (2008). Optical scattering and backscattering by organic and inorganic particulates in U.S. coastal waters. Applied Optics, 47(5) p. 666677.

Talke, S.A, H.E. De Swart \& H.M.Schuttelaars, (2009). Feedback between residual circulation and sediment distribution in highly turbid estuaries: an analytical model. Continental Shelf Research, 29(1) p. 119-135. doi:10.1016/j.csr.2007.09.002

Templeton, J. William. David A. Jay. (2012). Lower Columbia River sand supply and removal: estimates of two sand budget components. J. Waterway, Port, Costal, Ocean Eng., 139(5) p. 383-392.

Vermote E. F. and A. Vermeulen. (1999). MODIS algorithm technical background document, atmospheric correction algorithm: spectral reflectances (MOD09). NASA.

Vermote E. F., S. Y. Kotchenova, and J. P. Ray. (2011) MODIS surface reflectance user's guide, version 1.3. NASA 


\section{APPENDIX: MODEL DEVELOPMENT}

\section{SECTION 1: VELOCITY FIELD}

In this section details regarding the derivation of the solution for the velocity

field are outlined. From Chapter 3 Section 1, substituting (Equation 3.1.6) and (Equation 3.1.7) into (Equation 3.1.2a,b) gives rise to the governing equations for the tidal and residual flows. The tidal mode is considered first, followed by higher order processes. Although the model considers only the residual circulation, the tidal flow is addressed because it resurfaces in the equations describing ITAC.

Focusing on the perturbation expansion gives movement due to the tides:

$$
\begin{gathered}
0=-\frac{\partial}{\partial x}\left\{P_{T}+\varepsilon_{I A} P_{I A}+O\left(\varepsilon_{I A}^{2}\right)+\cdots\right\} \\
+K_{O}\left(1+\varepsilon_{I A} e^{i(\omega t+\varphi)}\right) \frac{\partial^{2}}{\partial z^{2}}\left\{U_{T}+\varepsilon_{I A} U_{I A}+O\left(\varepsilon_{I A}^{2}\right)+\cdots\right\} \\
0=\frac{\partial}{\partial x}\left\{U_{T}+\varepsilon_{I A} U_{I A}+O\left(\varepsilon_{I A}^{2}\right)+\cdots\right\} \\
+\frac{\partial}{\partial z}\left\{W_{T}+\varepsilon_{I A} W_{I A}+O\left(\varepsilon_{I A}^{2}\right)+\cdots\right\}
\end{gathered}
$$

(Equation A.1.1a,b)

Organizing (Equation A.1.1a,b) into like orders of $\varepsilon_{I A}$ gives rise to the governing equations for the leading order $\mathrm{O}(1)$ tidal flow and the $\mathrm{O}\left(\varepsilon_{I A}\right)$ ITAC. The momentum balance for the $O(1)$ velocity field is between the tidal frequency pressure gradients and turbulent mixing. Assuming the surface slope to dominate the alongchannel pressure gradient (see Equation 3.1.3) the following results: 


$$
\left.\begin{array}{c}
0=-g \frac{\partial \zeta_{T}}{\partial x}+K_{O}\left(\frac{\partial^{2} U_{T}}{\partial z^{2}}\right) \\
\frac{\partial U_{T}}{\partial x}+\frac{\partial W_{T}}{\partial z}=0 \\
\frac{\partial}{\partial x} \int_{0}^{H} U_{T} d z+\frac{\partial \zeta_{T}}{\partial t}=0
\end{array}\right\}
$$

(Equation A.1.2a,b,c)

(Equation A.1.2b) is used to determine the vertical velocity. (Equation A.1.2c) results from vertically integrating (Equation A.1.2b), and is used to determine the tidal surface elevation. For simplicity the effects of channel topography and river flow on tidal wave propagation will be neglected in the solution for the tidal velocity field.

Considering only terms of $\mathrm{O}\left(\varepsilon_{I A}\right)$ in (Equation A.1.2a,b) gives a system of equations for the currents associated with ITAC. The pressure field consists of a surface slope, which assures that ITAC is an internal mode, and the vertically uniform, tidal frequency along-channel density gradient: 


$$
\begin{gathered}
0=-g \frac{\partial \varepsilon_{I A} \zeta_{I A}}{\partial x}-\frac{g}{\rho_{O}} \int_{z}^{H} \frac{\partial \rho_{T}}{\partial x} d z \\
+K_{O}\left(\frac{\partial^{2} \varepsilon_{I A} U_{I A}}{\partial z^{2}}\right)+K_{O} \varepsilon_{I A} e^{i(\omega t+\varphi)}\left(\frac{\partial^{2} U_{T}}{\partial z^{2}}\right) \\
\frac{\partial \varepsilon_{I A} U_{I A}}{\partial x}+\frac{\partial \varepsilon_{I A} W_{I A}}{\partial z}=0 \\
\int_{0}^{H} \varepsilon_{I A} U_{I A} d z=0
\end{gathered}
$$

(Equation A.1.3a,b,c)

Note that although (Equation A.1.3) isolates the $\mathrm{O}\left(\varepsilon_{I A}\right)$ terms, the $\mathrm{O}(1)$ density field appears. Some work is required to see why. Dividing (Equation A.1.3a) by the eddy viscosity, (Equation 3.1.7), and using the binomial theorem to bring it into the numerator gives:

$$
\left.\begin{array}{c}
0=\left[-g \frac{\partial \varepsilon_{I A} \zeta_{I A}}{\partial x}-\frac{g}{\rho_{O}} \int_{z}^{H} \frac{\partial \rho_{T}}{\partial x} d z\right. \\
\left.+K_{O}\left(\frac{\partial^{2} \varepsilon_{I A} U_{I A}}{\partial z^{2}}\right)+K_{O} \varepsilon_{I A} e^{i(\omega t+\varphi)}\left(\frac{\partial^{2} U_{T}}{\partial z^{2}}\right)\right] \\
\times\left[\frac{1}{K_{O}}\left(1-\varepsilon_{I A} e^{i(\omega t+\varphi)}+\varepsilon_{I A}^{2} e^{2 i(\omega t+\varphi)}-\cdots\right)\right]
\end{array}\right\}
$$

Simplifying and keeping only terms of $\mathrm{O}\left(\varepsilon_{I A}\right)$ gives, for the residual ITAC: 


$$
\left.\begin{array}{l}
0=-g \frac{\partial \varepsilon_{I A} \zeta_{I A}}{\partial x}+\left\langle\varepsilon_{I A} e^{i(\omega t+\varphi)} \frac{g}{\rho_{O}} \int_{z}^{H} \frac{\partial \rho_{T}}{\partial x} d z\right\rangle \\
+K_{O}\left(\frac{\partial^{2} \varepsilon_{I A} U_{I A}}{\partial z^{2}}\right)+\left\langle K_{O} \varepsilon_{I A} e^{i(\omega t+\varphi)}\left(\frac{\partial^{2} U_{T}}{\partial z^{2}}\right)\right\rangle
\end{array}\right\}
$$

(Equation A.1.5)

Equation (A.1.5) says the residual currents due to ITAC result from tidallyaveraged correlations between tidally-varying mixing and vertical shear (last term on the right hand side) and tidally-varying mixing and density field (second term on the right hand side). Where the tidally-varying density field is given by mass conservation:

$$
\frac{\partial \rho_{T}}{\partial t}+\bar{U}_{T} \frac{\partial \bar{\rho}}{\partial x}=0
$$

Since further elements of the perturbation expansion are not considered the other residual flow modes will now be considered. The momentum equation for the gravitational circulation is a balance between the surface slope, residual horizontal density gradient, and turbulent mixing. Integral continuity, as with the ITAC, sets the net transport equal to zero:

$$
\left.\begin{array}{c}
0=-g \frac{\partial \zeta_{G}}{\partial x}-\frac{g}{\rho_{O}} \int_{z}^{H} \frac{\partial \rho}{\partial x} d z+K_{O}\left(\frac{\partial^{2} U_{G}}{\partial z^{2}}\right) \\
\frac{\partial U_{G}}{\partial x}+\frac{\partial W_{G}}{\partial z}=0 \\
\int_{0}^{H} U_{G} d z=0
\end{array}\right\}
$$


The river flow is modeled as the balance between the freshwater surface slope and turbulent mixing:

$$
\left.\begin{array}{c}
0=-g \frac{\partial \zeta_{R}}{\partial x}+K_{O}\left(\frac{\partial^{2} U_{R}}{\partial z^{2}}\right) \\
\frac{\partial U_{R}}{\partial x}+\frac{\partial W_{R}}{\partial z}=0 \\
\int_{0}^{H} U_{R} d z=q_{R}
\end{array}\right\}
$$

Where continuity requires that the specific discharge, $q_{R}$, must equal the integrated velocity profile.

It is useful to scale and non-dimensionalize the governing equations so that the parameter dependence of the solution is clear (Jay 2010). How does water depth (or bottom topography) specifically affect the velocity profile of any one flow mode, for example? Following (Jay 2010) the scaling below is used for the tidal flow (nondimensional variables denoted with a caret):

$$
\begin{gathered}
x=L_{X} \hat{x}=\frac{(g H)^{1 / 2}}{\omega} \hat{x} \quad z=H \hat{z} \quad t=\frac{\hat{t}}{\omega} \\
U_{T}=U_{O} \widehat{U}_{T} \quad \zeta_{T}=\zeta_{O} \hat{\zeta}_{T} \quad W_{T}=\frac{U_{O} H}{L_{X}} \widehat{W}_{T} \quad K_{O}=\kappa u_{*} H \widehat{K}_{O}
\end{gathered}
$$


Where $\mathrm{H}$ is the depth, $\omega$, is the tidal frequency, and $U_{0}$ and $\zeta_{0}$ are the tidal velocity and amplitude, respectively. Ko describes the vertical variability of the eddy viscosity and is equal to one in this case. Scaling for ITAC is similar to that of the tidal flow, with the following additions:

$$
U_{I A}=\varepsilon_{I A} U_{O} \widehat{U}_{I A} \quad \zeta_{I A}=\varepsilon_{I A} \zeta_{O} \hat{\zeta}_{I A} \quad \frac{\partial \rho_{T}}{\partial x}=\frac{\Delta \rho_{H}}{L_{S}} \frac{\partial \hat{\rho}_{T}}{\partial \hat{x}}
$$

Where $\Delta \rho_{H}$ is the horizontal density difference along the salinity intrusion length, $L_{S}$. Gravitational circulation and river flow are, again, similar, but with different scaling for the velocity:

$$
U_{G}=U_{G O} \widehat{U}_{G}=\left(\frac{g H \Delta \rho_{V}}{\rho_{O}}\right)^{1 / 2} \widehat{U}_{G} \quad U_{R}=U_{R O} \widehat{U}_{R}
$$

Where $\mathrm{U}_{\mathrm{RO}}$ is the river velocity magnitude. Substitution into the governing equations and non-dimensionalizing leads to the following momentum equations for the tidal flow (carets have been dropped for convenience):

$$
0=-\pi_{T 1} \frac{\partial \zeta_{T}}{\partial x}+K_{O}\left(\frac{\partial^{2} U_{T}}{\partial z^{2}}\right)
$$

ITAC:

$$
\left.\begin{array}{rl}
0 & =-\pi_{I A 1} \frac{\partial \varepsilon_{I A} \zeta_{I A}}{\partial x}+\left\langle\pi_{I A 2} e^{i(t+\varphi)} \int_{z}^{1} \frac{\partial \rho_{T}}{\partial x} d z\right\rangle \\
& +K_{O}\left(\frac{\partial^{2} \varepsilon_{I A} U_{I A}}{\partial z^{2}}\right)+\left\langle K_{O} e^{i(t+\varphi)}\left(\frac{\partial^{2} U_{T}}{\partial z^{2}}\right)\right\rangle
\end{array}\right\}
$$


Gravitational circulation:

$$
0=-\pi_{G 1} \frac{\partial \zeta_{G}}{\partial x}-\pi_{G 2} \int_{z}^{1} \frac{\partial \rho}{\partial x} d z+K_{O}\left(\frac{\partial^{2} U_{G}}{\partial z^{2}}\right)
$$

And river flow:

$$
0=-\pi_{R 1} \frac{\partial \zeta_{R}}{\partial x}+K_{O}\left(\frac{\partial^{2} U_{R}}{\partial z^{2}}\right)
$$

Also worth outlining is the dimensionless integral continuity for the tidal flow, which defines the structure of the incoming tidal wave:

$$
\frac{\partial}{\partial x} \int_{0}^{1} U_{T} d z+\pi_{T 1 B} \frac{\partial \zeta_{T}}{\partial t}=0
$$

Where non-dimensional numbers are defined as follows:

$$
\begin{gathered}
\pi_{T 1}=\frac{(g H)^{1 / 2} \zeta_{O} \omega}{\kappa u_{*} U_{O}} \quad \pi_{T 1 B}=\frac{(g H)^{1 / 2} \zeta_{O}}{U_{O} H} \\
\pi_{I A 1}=\frac{(g H)^{1 / 2} \zeta_{O} \omega}{\kappa u_{*} U_{O}} \quad \pi_{I A 2}=\frac{\Delta \rho_{H} g H^{2}}{L_{S} \rho_{O} \kappa u_{*} U_{O}} \\
\pi_{G 1}=\frac{g \zeta_{O} H}{L_{S} \kappa u_{*} U_{G O}} \quad \pi_{G 2}=\frac{\Delta \rho_{H} g H^{2}}{L_{S} \rho_{O} \kappa u_{*} U_{G O}} \\
\pi_{R 1}=\frac{g \zeta_{O} H}{L_{S} \kappa u_{*} U_{R O}}
\end{gathered}
$$


The $\pi_{1}$ and $\pi_{2}$ terms for ITAC and gravitational circulation scale, respectively, the strength of barotropic and baroclinic pressure gradients to that of the stress divergence. Even without solving (Equations A.1.10-12) valuable information regarding the estuarine circulation can be obtained by examining these dimensionless quantities. For example, the sensitivity of the baroclinic forcing to channel depth is captured by $\pi_{G 2}$ and $\pi_{I A 2}$, and one could expect ITAC and gravitational circulation mass fluxes to be greater in deeper regions of the system. A more detailed analysis into the behavior of different flow modes is included in Section 5, but now a solution of (Equations A.1.10-12) is laid out to give an expression for the residual flow.

The solution for the ITAC mode will be derived first followed by the other two residual modes. To begin, however, the tidal flow $\left(\mathrm{U}_{\mathrm{T}}\right)$ must be defined from (Equation 3.1.2a,c). Separating variables and assuming harmonic temporal variation of $\mathrm{U}_{\mathrm{T}}$ and $\zeta_{T}$ gives for the momentum balance:

$$
K_{O} \operatorname{Re}\left\{i M^{\prime}(x) F^{\prime \prime}(z) e^{i t}\right\}=\pi_{T 1} \operatorname{Re}\left\{M^{\prime}(x) e^{i t}\right\}
$$

Where: $\quad \zeta_{T}=\operatorname{Re}\left\{M(x) e^{i t}\right\} \quad U_{T}=\operatorname{Re}\left\{i M^{\prime}(x) P(z) e^{i t}\right\}$

Solving for the vertical structure of the tidal flow, $\mathrm{F}(\mathrm{z})$, using the boundary conditions mentioned above gives a parabolic velocity profile (real part assumed):

$$
P(z)=\frac{i \pi_{T 1}}{K_{O}}\left(z-\frac{1}{2} z^{2}\right)
$$


The horizontal structure of the tidal flow, $\mathrm{M}(\mathrm{x})$, is determined from (Equation A.1.2c). Substituting the forms for the tidal velocity and surface elevation:

$$
i M^{\prime \prime}(x) \int_{0}^{1} P(z) d z e^{i t}+\pi_{T 1 B} i M(x) e^{i t}=0
$$

The characteristic polynomial for this ordinary differential equation has complex roots, which gives (for the incident tidal wave):

$$
M(x)=A_{I} e^{i q x}
$$

Where $A_{I}$ is the wave amplitude and $q$ is the complex wave number:

$$
q=\sqrt{\frac{\pi_{T 1 B}}{\int_{0}^{1} P(z) d z}}
$$

The tidal flow horizontal velocity is then:

$$
U_{T}=R e\left\{i\left(i q A_{I} e^{i q x}\right)\left(\frac{i \pi_{T 1 B}}{K_{O}}\right)\left(z-\frac{1}{2} z^{2}\right) e^{i t}\right\}
$$

Another term that must be defined before solving for the ITAC mode is the tidal frequency density gradient. This can be done by examining the mass conservation for $\rho_{T}$ (Equation A.1.6), non-dimensionally:

$$
\frac{\partial \rho_{T}}{\partial t}+\left(\frac{U_{O}}{w L s}\right) \bar{U}_{T} \frac{\partial \bar{\rho}}{\partial x}=0
$$


From the harmonic form for $\mathrm{U}_{\mathrm{T}}$ we have:

$$
\rho_{T}=-\left(\frac{U_{O}}{w L s}\right) \operatorname{Re}\left\{M^{\prime}(x) \int_{0}^{1} P(z) d z e^{i t}\right\} \frac{\partial \bar{\rho}}{\partial x}
$$

The tidal-frequency density gradient is then:

$$
\frac{\partial \rho_{T}}{\partial x}=-\left(\frac{U_{O}}{w L s}\right) \operatorname{Re}\left\{M^{\prime \prime}(x) \int_{0}^{1} P(z) d z e^{i t}\right\} \frac{\partial \bar{\rho}}{\partial x}
$$

In deriving (Equation A.1.22), $\frac{\partial^{2} \bar{\rho}}{\partial x^{2}}$ has been assumed to be negligible.

(Equation A.1.10) is solved, again, using separation of variables. Our product solutions take the form:

$$
\zeta_{I A}=\operatorname{Re}\left\{M(x) S_{I A}\right\} \quad U_{I A}=\operatorname{Re}\left\{i M^{\prime}(x) F(z)\right\}
$$

$$
\left.\begin{array}{c}
0=-\pi_{I A 1} \operatorname{Re}\left\{M^{\prime}(x) S_{I A}\right\} \\
-\pi_{I A 3}\left\langle\operatorname{Re}\left\{e^{i \varphi} e^{i t}\right\} \operatorname{Re}\left\{M^{\prime \prime}(x) \int_{0}^{1} \int_{0}^{1} P(z) d z d z e^{i t}\right\} \frac{\partial \bar{\rho}}{\partial x}\right\rangle \\
+\operatorname{Re}\left\{i M^{\prime}(x) F^{\prime \prime}(z)\right\}+\frac{1}{\varepsilon_{I A}}\left\langle\operatorname{Re}\left\{e^{i \varphi} e^{i t}\right\} \operatorname{Re}\left\{i M^{\prime}(x) P^{\prime \prime}(z) e^{i t}\right\}\right\rangle
\end{array}\right\}
$$

Where $S_{I A}$ is a function defining the surface slope and $\pi_{I A 3}=\frac{U_{O} \pi_{I A 2}}{\omega L_{S} \varepsilon_{I A}}$. Multiplying through the harmonic terms: 


$$
\begin{gathered}
0=-\pi_{I A 1} \operatorname{Re}\left\{M^{\prime}(x) S_{I A}\right\} \\
-\frac{\pi_{I A 3}}{2}\left\langle\operatorname{Re}\left\{e^{i \varphi} M^{\prime \prime}(x) \int_{0}^{1} \int_{0}^{1} P(z) d z d z e^{2 i t}+e^{-i \varphi} M^{\prime \prime}(x) \int_{0}^{1} \int_{0}^{1} P(z) d z d z\right\} \frac{\partial \bar{\rho}}{\partial x}\right\rangle \\
+\operatorname{Re}\left\{i M^{\prime}(x) F^{\prime \prime}(z)\right\}+\frac{1}{2 \varepsilon_{I A}}\left\langle\operatorname{Re}\left\{e^{i \varphi} i M^{\prime}(x) P^{\prime \prime}(z) e^{2 i t}+e^{-i \varphi} i M^{\prime}(x) P^{\prime \prime}(z)\right\}\right\rangle
\end{gathered}
$$

And eliminating terms that are not at residual frequency gives:

$$
\left.\begin{array}{c}
0=-\pi_{I A 1} \operatorname{Re}\left\{M^{\prime}(x) S_{I A}\right\} \\
-\frac{\pi_{I A 3}}{2}\left\langle\operatorname{Re}\left\{e^{-i \varphi} M^{\prime \prime}(x) \int_{0}^{1} \int_{0}^{1} P(z) d z d z\right\} \frac{\partial \bar{\rho}}{\partial x}\right\rangle \\
+\operatorname{Re}\left\{i M^{\prime}(x) F^{\prime \prime}(z)\right\}+\frac{1}{2 \varepsilon_{I A}}\left\langle\operatorname{Re}\left\{e^{-i \varphi} i M^{\prime}(x) P^{\prime \prime}(z)\right\}\right\rangle
\end{array}\right\}
$$

Finally, integrating twice results in the vertical structure for the ITAC circulation mode (real part assumed):

$$
\left.\begin{array}{c}
F(z)=i \pi_{I A 1} S_{I A}\left(z-\frac{1}{2} z^{2}\right) \\
-\frac{\pi_{I A 3} e^{-i \varphi} q}{2} \frac{\partial \bar{\rho}}{\partial x} \overline{P(z)}\left(\frac{1}{2} z-\frac{1}{2} z^{2}+\frac{1}{6} z^{3}\right) \\
-\frac{e^{-i \varphi}}{2 \varepsilon_{I A}} \frac{i \pi_{T 1}}{K_{O}}\left(z-\frac{1}{2} z^{2}\right)
\end{array}\right\}
$$

Where $\mathrm{S}_{\mathrm{IA}}$, determined from integral continuity, is: 


$$
S_{I A}=\frac{3 \overline{P(z)} e^{-i \varphi}}{2 i \pi_{I A 1}}\left(\frac{\pi_{I A 3} q}{8} \frac{\partial \bar{\rho}}{\partial x}+\frac{1}{\varepsilon_{I A}}\right)
$$

The full form for the ITAC mode becomes:

$$
\left.\begin{array}{c}
U_{I A}=i\left[i q A_{I} e^{i q x}\right] \times \\
{\left[\frac{3 \overline{P(z)} e^{-i \varphi}}{2}\left(\frac{\pi_{I A 3} q}{8} \frac{\partial \bar{\rho}}{\partial x}+\frac{1}{\varepsilon_{I A}}\right)\left(z-\frac{1}{2} z^{2}\right)\right.} \\
-\frac{\pi_{I A 3} e^{-i \varphi} q}{2} \frac{\partial \bar{\rho}}{\partial x} \overline{P(z)}\left(\frac{1}{2} z-\frac{1}{2} z^{2}+\frac{1}{6} z^{3}\right) \\
\left.-\frac{e^{-i \varphi}}{2 \varepsilon_{I A}} \frac{i \pi_{T 1}}{K_{O}}\left(z-\frac{1}{2} z^{2}\right)\right]
\end{array}\right\}
$$

(Equation A.1.27)

There are two distinct parts of (Equation A.1.27), one that is a function of the density gradient and one that is not. Separating these will facilitate the analysis of the salinity field:

$$
\left.\begin{array}{c}
U_{I A}=i\left[i q A_{I} e^{i q x}\right] \times \\
{\left[I_{I A}\left(z-\frac{1}{2} z^{2}\right) \frac{\partial \bar{\rho}}{\partial x}\right.} \\
-I I_{I A}\left(\frac{1}{2} z-\frac{1}{2} z^{2}+\frac{1}{6} z^{3}\right) \frac{\partial \bar{\rho}}{\partial x} \\
\left.+I I I_{I A}\left(z-\frac{1}{2} z^{2}\right)\right]
\end{array}\right\}
$$

Where: 


$$
\begin{gathered}
I_{I A}=\frac{3}{8} I I_{I A} \\
I I_{I A}=\frac{\pi_{I A 3} \overline{P(z)} e^{-i \varphi} q}{2} \\
I I I_{I A}=\frac{3 \overline{P(z)} e^{-i \varphi}}{2 \varepsilon_{I A}}-\frac{e^{-i \varphi}}{2 \varepsilon_{I A}} \frac{i \pi_{T 1}}{K_{O}}
\end{gathered}
$$

The solutions for gravitational circulation and river flow are more easily achieved. Simply integrating (Equation A.1.11-12) twice in the vertical, and using the integral continuity constraint gives for the gravitational circulation:

$$
U_{G}=\frac{\pi_{G 2}}{K_{O}} \frac{\partial \bar{\rho}}{\partial x}\left(\frac{3}{8}\left(z-\frac{1}{2} z^{2}\right)+\left(\frac{1}{2} z-\frac{1}{2} z^{2}+\frac{1}{6} z^{3}\right)\right)
$$

And for the river flow:

$$
U_{R}=-3 \frac{\bar{U}}{U_{R O}}\left(z-\frac{1}{2} z^{2}\right)
$$

The constraint is imposed that the river flow transport must be constant along the channel: $q_{R}=\bar{U} H \hat{q}_{R}=$ constant.

Substituting (Equation A.1.28-30) into (Equation 3.1.6) gives the full form of the residual velocity field. 


\section{SECTION 2: SALINITY FIELD}

In this section details regarding the derivation of the solution for the salinity field are outlined. From Chapter 3 Section 2, we begin by describing the vertical profile of salinity, which is defined using the depth-averaged (overbar) and depthvarying (prime) components:

$$
S(x, z)=\bar{S}(x)+S^{\prime}(x, z)
$$

The salinity field is defined using mass conservation; locally (at any cross-section in the domain) this is:

$$
\frac{\partial S}{\partial t}+\frac{1}{A} \frac{\partial}{\partial x}(A U S)+\frac{\partial}{\partial z}(W S)=\frac{1}{A} \frac{\partial}{\partial x}\left(A K_{H} \frac{\partial S}{\partial x}\right)+\frac{\partial}{\partial z}\left(K \frac{\partial S}{\partial z}\right)
$$

Where $\mathrm{A}$ is the cross-sectional area of the channel and $\mathrm{K}_{\mathrm{H}}$ is the along-channel eddy viscosity. $\mathrm{K}_{\mathrm{H}}$ parameterizes all salt flux mechanisms not explicitly derived from the flow modes considered above. $\mathrm{K}$ is the vertical mass eddy viscosity, assumed equal to that of momentum. The salinity field is assumed tidally invariant so that the first term is equal to zero (i.e. the salinity field returns to its initial state following the tidal). In addition, since the horizontal velocity scale is greater than the vertical velocity scale, vertical fluxes of salt (last term on the left hand side) are neglected:

$$
\frac{1}{A} \frac{\partial}{\partial x}(A U S)=\frac{1}{A} \frac{\partial}{\partial x}\left(A K_{H} \frac{\partial S}{\partial x}\right)+\frac{\partial}{\partial z}\left(K \frac{\partial S}{\partial z}\right)
$$


Integrating from the bed to the surface with zero salt flux at both boundaries gives a form for the depth-averaged salinity:

$$
\frac{1}{A} \frac{\partial}{\partial x}\left(A \bar{U} \bar{S}+A \overline{U^{\prime} S^{\prime}}\right)=\frac{1}{A} \frac{\partial}{\partial x}\left(A K_{H} \frac{\partial \bar{S}}{\partial x}\right)
$$

Subtracting (Equation A.2.4) from (Equation A.2.3) results in the depth-varying component of the salinity field:

$$
\begin{aligned}
& \frac{1}{A} \frac{\partial}{\partial x}\left(A U S-A \bar{U} \bar{S}-A \overline{U^{\prime} S^{\prime}}\right) \\
& \left.=\frac{\partial}{\partial z}\left(K \frac{\partial S^{\prime}}{\partial z}\right)-\frac{1}{A} \frac{\partial}{\partial x}\left(A K_{H} \frac{\partial S^{\prime}}{\partial x}\right)\right\}
\end{aligned}
$$

(Equation A.2.5) may be simplified, but not before a little bit of work. Separating $U$ and $S$ in depth-varying and depth-averaged components and evaluating the derivative on the left hand side gives:

$$
\left.\begin{array}{l}
\frac{1}{A} \frac{\partial A}{\partial x}\left[\bar{U} S^{\prime}+U^{\prime} \bar{S}+U^{\prime} S^{\prime}-\overline{U^{\prime} S^{\prime}}\right]+ \\
S^{\prime} \frac{\partial \bar{U}}{\partial x}+\bar{U} \frac{\partial S^{\prime}}{\partial x}+\bar{S} \frac{\partial U^{\prime}}{\partial x}+U^{\prime} \frac{\partial \bar{S}}{\partial x}+ \\
S^{\prime} \frac{\partial U^{\prime}}{\partial x}+U^{\prime} \frac{\partial S^{\prime}}{\partial x}-\overline{S^{\prime} \frac{\partial U^{\prime}}{\partial x}}-\overline{U^{\prime} \frac{\partial S^{\prime}}{\partial x}} \\
=\frac{\partial}{\partial z}\left(K \frac{\partial S^{\prime}}{\partial z}\right)-\frac{1}{A} \frac{\partial}{\partial x}\left(A K_{H} \frac{\partial S^{\prime}}{\partial x}\right)
\end{array}\right\}
$$


Since convective accelerations were omitted from the model for the velocity, these terms drop out of (Equation A.2.6). In addition, terms involving along-channel gradients of the cross-sectional area are divided by the area itself and as such are small relative to the remaining terms. We make the further assumptions that alongchannel gradients in the depth-averaged salinity are greater than those in the depthvarying salinity field, and that vertical gradients in the depth-varying salinity are greater than those in the horizontal (Hansen and Rattray 1965). A balance between shear induced stratification and vertical mixing remains:

$$
U^{\prime} \frac{\partial \bar{S}}{\partial x}=K \frac{\partial^{2} S^{\prime}}{\partial z^{2}}
$$

Although the assumptions employed to reach (Equation A.2.7) greatly simplify the physics governing the salt balance, they provide a useful starting point to analyze the salinity field. Scaling and non-dimensionalizing (Equation A.2.7) gives:

$$
\frac{\pi_{S 1}}{K_{O}} \frac{\partial \bar{S}}{\partial x}\left[\varepsilon_{I A} U_{O} \widehat{U}_{I A}+U_{G O} \widehat{U}_{G}+U_{R O} \widehat{U}_{R}-U_{R O} \widehat{\bar{U}}\right]=\frac{\partial^{2} S^{\prime}}{\partial z^{2}}
$$

Where: $\pi_{S 1}=\frac{\mathrm{H} \Delta \rho_{H}}{\mathrm{\kappa u}_{*} \Delta \rho_{V} L_{S}}$

The depth-varying portion of the salinity field (the salinity defect) is determined by integrating (Equation A.2.7) twice in the vertical. Assuming the depth average of the salinity defect is zero and that zero salt flux occurs at the bed and at the surface gives the following: 


$$
\left.\begin{array}{c}
S^{\prime}=\frac{\pi_{S 1}}{K_{O}} \frac{\partial \bar{S}}{\partial x}\left\{\beta \frac { \partial \overline { S } } { \partial x } \left[\alpha_{1}\left(\frac{1}{6} z^{3}-\frac{1}{24} z^{4}-\frac{1}{30}\right)\right.\right. \\
\left.+\alpha_{2}\left(\frac{1}{12} z^{3}-\frac{1}{24} z^{4}+\frac{1}{120} z^{5}-\frac{1}{72}\right)\right] \\
\left.+\alpha_{3}\left(\frac{1}{6} z^{3}-\frac{1}{24} z^{4}-\frac{1}{30}\right)-U_{R O} \bar{U}\left(\frac{1}{2} z^{2}-\frac{1}{6}\right)\right\}
\end{array}\right\}
$$

Where $\beta=0.77 \mathrm{psu} / \mathrm{kgm}^{-3}$ is an isohaline contraction coefficient converting the density gradient in the velocity equation to one of salinity. In addition:

$$
\begin{gathered}
\alpha_{1}=\varepsilon_{I A} U_{O} \operatorname{Re}\left\{i\left[i q A_{I} e^{i q x}\right] I_{I A}\right\}+U_{G O} \frac{3}{8} \pi_{G 2} \\
\alpha_{2}=-\varepsilon_{I A} U_{O} \operatorname{Re}\left\{i\left[i q A_{I} e^{i q x}\right] I I_{I A}\right\}-U_{G O} \pi_{G 2} \\
\alpha_{3}=\varepsilon_{I A} U_{O} \operatorname{Re}\left\{i\left[i q A_{I} e^{i q x}\right] I I I_{I A}\right\}-U_{R O}
\end{gathered}
$$

With the vertical structure of the salinity field specified, a formulation for the depth-averaged portion — and thereby the total salinity profile—can be determined. Integrating (Equation A.2.4) from any location $\mathrm{x}$ to an arbitrary point upstream of the region of salinity intrusion gives the integral salt balance:

$$
0=\bar{U} \bar{S}+\overline{U^{\prime} S^{\prime}}-K_{H} \frac{\partial \bar{S}}{\partial x}
$$


(Equation A.2.9) states that salt flux in and out of the estuary is driven by the mean advection of salinity by the river flow (first term); the depth-average of the correlation between the velocity and salinity defects (second term); and horizontal dispersion (last term). Scaling and non-dimensionalizing:

$$
\begin{gathered}
0=\overline{\widehat{U} \hat{S}}+\frac{\Delta \rho_{V}}{U_{R O} S_{O C N}} \overline{\left[\varepsilon_{I A} U_{O} \widehat{U}_{I A}+U_{G O} \widehat{U}_{G}+U_{R O} \widehat{U}_{R}-U_{R O} \widehat{\widehat{U}}\right] \hat{S}^{\prime}} \\
-\frac{K_{H s c a l e} \Delta \rho_{H}}{U_{R O} S_{O C N} L_{S}} \widehat{K}_{H} \frac{\partial \overline{\hat{S}}}{\partial x}
\end{gathered}
$$

And substituting the velocity and salinity defects gives (dropping carets and depthaveraged assumed):

$$
\left.\begin{array}{c}
0=\bar{U} \bar{S}+\frac{\Delta \rho_{V}}{U_{R O} S_{O C N}}\left[\beta \frac{\partial S}{\partial x}\left(\alpha_{1} F_{1}+\alpha_{2} F_{2}\right)+\alpha_{3} F_{1}-U_{R O} \bar{U}\right] \\
\times \frac{\pi_{S 1}}{K_{O}} \frac{\partial \bar{S}}{\partial x}\left[\beta \frac{\partial S}{\partial x}\left(\alpha_{1}\left(F_{3}-\frac{1}{30}\right)+\alpha_{2}\left(F_{4}-\frac{1}{72}\right)\right)\right. \\
\left.+\alpha_{3}\left(F_{3}-\frac{1}{30}\right)-U_{R O} \bar{U}\left(\frac{1}{2} z^{2}-\frac{1}{6}\right)\right] \\
-\frac{K_{H S c a l e} \Delta \rho_{H}}{U_{R O} S_{O C N} L_{S}} K_{H} \frac{\partial \bar{S}}{\partial x}
\end{array}\right\}
$$

(Equation A.2.10)

Where Socn is the salinity at the seaward boundary and:

$$
\begin{array}{cc}
F_{1}=\left(z-\frac{1}{2} z^{2}\right) & F_{2}=\left(\frac{1}{2} z-\frac{1}{2} z^{2}+\frac{1}{6} z^{3}\right) \\
F_{3}=\left(\frac{1}{6} z^{3}-\frac{1}{24} z^{4}\right) & F_{4}=\left(\frac{1}{12} z^{3}-\frac{1}{24} z^{4}+\frac{1}{120} z^{5}\right)
\end{array}
$$


(Equation A.2.10) represents a third-order algebraic equation in the depthaveraged salinity gradient and as such can be solved analytically for this variable at each location in the channel, provided the remaining variables are known. The model is initialized with a seaward boundary condition where the bottom salinity is that of the ocean. Non-dimensionally:

$$
\left.S^{\prime}\right|_{x=0, z=0}+\left.\bar{S}\right|_{x=0}=1
$$

This specification defines the depth average salinity at the seaward boundary using (Equation A.2.8).

$$
\left.\bar{S}\right|_{x=0}=1-\frac{\pi_{S 1}}{K_{O}} \frac{\partial \bar{S}}{\partial x}\left[\beta \frac{\partial S}{\partial x}\left(-\frac{\alpha_{1}}{30}-\frac{\alpha_{2}}{72}\right)-\frac{\alpha_{3}}{30}+\frac{U_{R O} \bar{U}}{6}\right]
$$

The gradient at the seaward boundary is then found using (Equation A.2.10). Following (MacCready 2004), the integral salt balance is then numerically integrated using an upwind finite differences scheme in order to propagate the solution for the salinity field along the channel:

$$
\left.\bar{S}\right|_{x+\Delta x}=\left.\bar{S}\right|_{x}+\left.\Delta x \frac{\partial \bar{S}}{\partial x}\right|_{x}
$$

Where $\Delta x$ is horizontal the grid spacing. (Equation A.2.8), (Equation A.2.10), and (Equation A.2.13) are iterated until the salinity field and its gradient are specified within the entire domain. With velocity and salinity fields specified, the resulting distribution of turbidity can now be examined. 